\title{
THERE AND BACK AGAIN: SPATIAL AND TEMPORAL VARIATION IN THE RECRUITMENT DYNAMICS OF AN
}

\section{AMPHIDROMOUS FISH}

by

Conor Stewart Bruce Neilson

A thesis submitted to Victoria University of Wellington in partial fulfilment of the requirements for the degree of Master of Science in Ecology and Biodiversity

Victoria University of Wellington 
"One planet, one experiment"

- Edward O. Wilson 


\section{ABSTRACT}

A primary goal of ecology is to identify the factors underlying recruitment variability, and how they may shape population dynamics. Recruitment is driven by the input of new individuals into a population. However, these individuals often show high diversity in phenotypic traits and life histories, and the consequences of this variation are poorly understood. Phenotypic variation is widespread among the early life stages of fish, and this variation may be influenced by events occurring across multiple life stages. While many studies have investigated phenotypic variation and its effect on population dynamics, comparatively few studies use an integrated approach that evaluates patterns and processes across multiple life history stages. Here $I$ focus on a native amphidromous fish, Galaxias maculatus, and I explore patterns and consequences of phenotypic variation during larval stages, migratory stages, and post-settlement stages of this fish.

I explore variability in phenotypes and early life history traits of G. maculatus through both space and time. I use metrics derived from body size and otolith-based demographic reconstructions to quantify potentially important early life history traits. I found that cohorts of juvenile fish sampled later in the year were comprised of individuals that were older, smaller, and grew more slowly relative to fish sampled earlier in the year. I also found that two sampled sites (the Hutt River and the Wainuiomata River) showed different temporal trends, despite their close geographical proximity.

I then investigated whether phenotype was related to mortality. I used otolith-based traits to characterise larval 'quality' for individual fish. I then calculated the average larval quality for discrete cohorts of fish, and used catch-curve analysis to estimate mortality rates for these cohorts. I investigated the overall relationship between quality and mortality, and compared the trend between two sites. My results indicate that phenotype and mortality were not significantly correlated. However, this inference may be limited by low statistical power; the non-significant trends suggest that the relationship might be negative (i.e., larvae of higher quality tend to have lower rates of mortality). This trend is typical of systems where population expansion is limited by food rather than predators. 
I then investigated whether phenotypic traits in the juvenile cohorts were correlated with traits in adult cohorts. I resampled the focal populations $\sim 6$ months after sampling the juvenile stages (i.e., targeting fish from sampled cohorts that had survived to adulthood), and I used data from otoliths to reconstruct life history traits (hatch dates and growth histories). I compared adult life history traits to the traits of discrete juvenile cohorts.

My results suggest that fish that survived to adulthood had comparatively slower growth rates (reconstructed for a period of larval/juvenile growth) relative to the sampled juvenile cohorts (where growth rate was estimated for the same period in their life history). I also found that the distributions of hatch dates varied between sites. Fish that survived to adulthood at one site hatched later in the breeding season, while adult stages from the other site had hatch dates that were distributed across the entire breeding season. Both hatch date and growth rate are likely linked to fitness, and their interaction may have influenced patterns of survival to adulthood. These results provide evidence for carry-over effects of larval phenotype on juvenile success

Collectively my thesis emphasises the importance of phenotype and life history variability in studies of recruitment. It also highlights the importance of spatial scale, and how biological patterns may differ between geographically close systems. Some of the general inferences from my study may extend to other migratory Galaxiid species, and perhaps more generally, to many species with extensive larval dispersal. Finally, my work highlights potentially important interactions between phenotypes, life histories, and mortality, which can ultimately shape recruitment, and the dynamics of populations. 


\section{ACKNOWLEDGEMENTS}

I always suspected that the acknowledgements section would end up being the longest section of this thesis. In truth, there has been a phenomenal amount of people who have contributed to this in some way, and it wouldn't feel right if I didn't thank you all.

First and foremost, I want to thank my supervisor, Jeff Shima. Jeff, thank you for everything you've done for me over the past two years. You have helped me to grow and develop as a scientist, and your input has always been appreciated. Thank you especially for reigning in the first thesis plan I submitted to you. That would have kept me working until 2020! My gratitude also goes out to the members of the Shima Lab. Thanks for listening to me rabbit on about whitebait, and for providing support and advice.

To the VUCEL community, I've really enjoyed being a part of this group of people. Cheers for the BBQs, the morning teas, and the general get-togethers. You've all made my Master's a fantastic experience. John, Dan, and Snout, thank you for all the technical assistance. Everyone would be lost without you three!

This thesis wouldn't have been possible without the small army of volunteers I had come and assist with whitebaiting. In no particular order, thank you to Kayla, Tory, Savita, Heyes, Andrew, Chris, Vinnie, Jessie, Ali, Mel, Eden, Emily, Anna, Jordan, James, and Max. I also want to thank John, Danny, Tom, Kelly, and Jim for donating samples and general advice on whitebaiting.

Chris, Jess, and Vinnie, thanks for being my partners in crime during this journey. It's been great to collaborate, share data, and tackle Galaxiid ecology as a team. Cheers for listening to my ridiculous experimental ideas, and stopping me using models that no normal human would run. Vinnie, thank you in particular for your incredible amount of help in the field. You made me keep going when I was ready to give up, and kept on pushing when everything kept going wrong.

To all of my friends, and particularly my flatmates, thank you for understanding why I neglected you. Your support has meant the world to me. Thanks also needs to be said to Alex, for getting me out of a tight spot, Ben, for some much needed advice, Lisa Woods, who knows more about statistics than anyone I've met, and Phoebe, for answering seemingly endless questions about everything. 
Chris, this concludes five years of us studying together. Thank you for always being there as a source of advice, ideas, and generally helping me to feel better when everything goes wrong. I'm going to miss working alongside you.

There are three people in particular I need to mention. Snout, thank you so much for your guidance. This thesis never would have got here without you. Your knowledge of logistics, fieldwork, otoliths, and everything in between has been invaluable to me, and I cannot thank you enough for all your patience. Also, your cooking skills are second to none!

Secondly, I owe a huge debt of gratitude to Mark Kaemingk. Mark, you have been like a second supervisor to me. You introduced me to whitebait, and you have totally changed the way I think about science. This thesis has been shaped by you in so many ways, and it has been a true pleasure having you as a mentor and friend.

And to my partner Elyse. Thank you for all your love and support. You may have no interest in fish population ecology, but you understood my passion, and always encouraged and supported me.

Lastly, I want to say a massive thank you to my parents, Ian and Vicki. You have always supported me in whatever path I chose to pursue, and for that I am thankful. 


\section{TABLE OF CONTENTS}

CHAPTER 1 - INTRODUCTION ………….................................................................... 15

1.1 DRIVERS OF RECRUITMENT ............................................................................................................. 16

1.2 STUDY SPECIES..................................................................................................................................20

1.3 THESIS RESEARCH.........................................................................................................................................21

\section{CHAPTER 2 - PHENOTYPIC VARIATION OF RECRUITING GALAXIAS MACULATUS} OVER SMALL SPATIAL AND TEMPORAL SCALES ……..................................................... 23

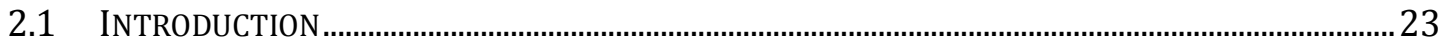

2.2 METHODS....................................................................................................................................26

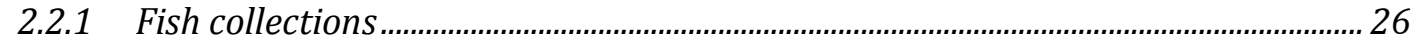

2.2.2 Evaluating developmental characteristics ....................................................................... 27

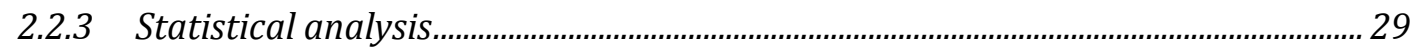

2.3 ReSULTS ................................................................................................................................................. 29

2.3.1 Spatio-temporal variation in standard length.................................................................. 30

2.3.2 Spatiotemporal variation in average growth rate....................................................... 35

2.3.3 Spatio-temporal variation in ages......................................................................................... 39

2.4 DISCUSSION ..........................................................................................................................4

2.4.1 Summary of results ........................................................................................................... 43

2.4.2 Spatial differences in developmental histories................................................................. 43

CHAPTER 3 - IMPLICATIONS OF VARIABLE LARVAL QUALITY ON JUVENILE MORTALITY IN GALAXIAS MACULATUS ............................................................................ 47

3.1 INTRODUCTION .................................................................................................................................4

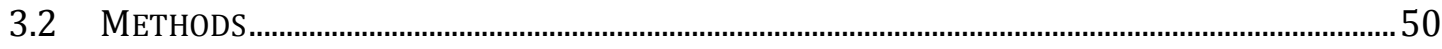

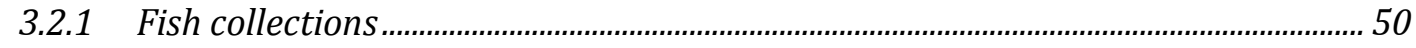

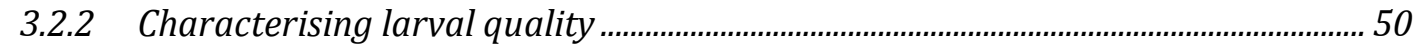

3.2.3 Estimating mortality rates ............................................................................................. 51

3.2.4 Evaluating the relationship between mortality and quality ...................................... 51

3.3 RESULTS ................................................................................................................................................52

3.3.1 Relationship between mortality and larval quality ...................................................... 52

3.4 Discussion ................................................................................................................................53 
CHAPTER 4 - ADULT GALAXIAS MACULATUS RECRUITMENT IS SHAPED BY

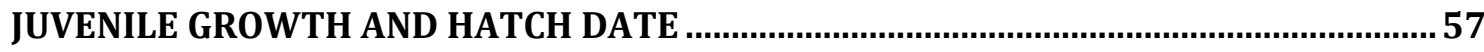

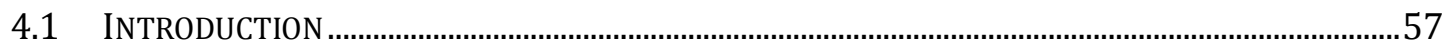

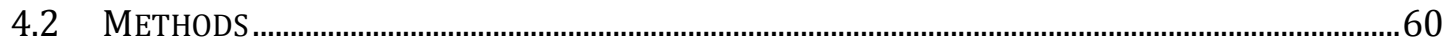

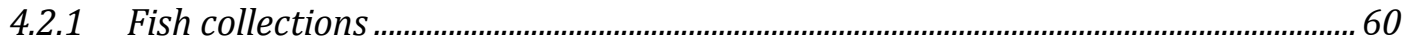

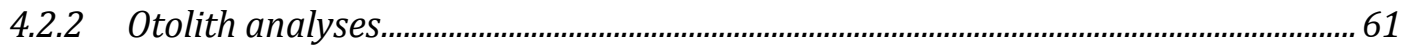

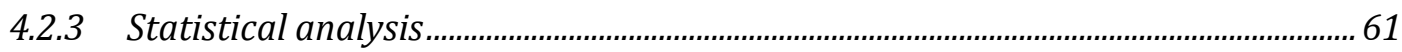

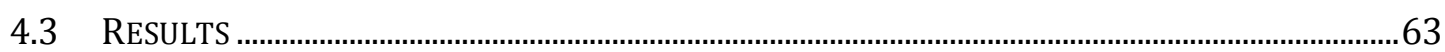

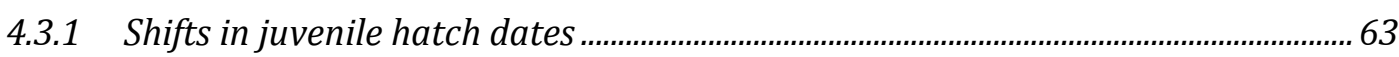

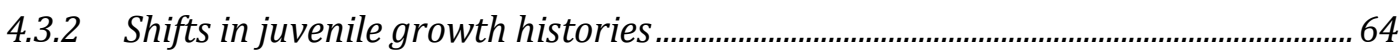

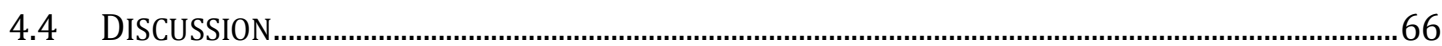

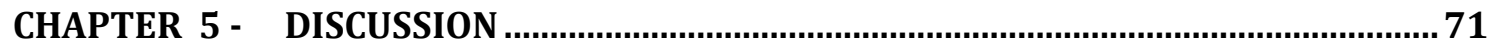

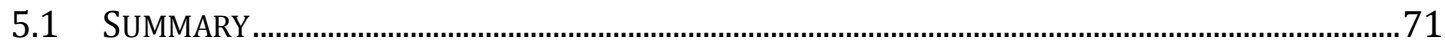

5.2 LANDSCAPE FEATURES AND DISPERSAL POTENTIAL...........................................................................72

5.3 VARIATION IN RECRUITMENT OVER SPATIAL SCALES .......................................................................73

5.4 EFFECTS OF RIVER MOUTH CLOSURE..........................................................................................

$5.5 \quad$ FUTURE DIRECTIONS ....................................................................................................................76

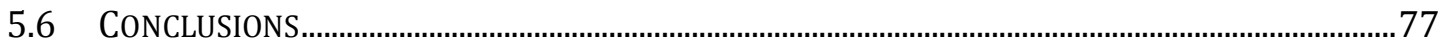

REFERENCES 


\section{LIST OF TABLES}

TABle 2-1 SPATIO-TEMPORAL VARIATION IN LENGTH, GROWTH RATE, AND AGE OF JUVENILE G. MACULATUS. “SITE:MONTH” REPRESENTS THE INTERACTION TERM, AND “(SITE:MONTH)/DAY” REPRESENTS THE DAY TERM, NESTED WITHIN THE MONTH AND SITE INTERACTION TERM. 30

TABLE 2-2 PAIRWISE COMPARISONS OF STANDARD LENGTH BETWEEN DAYS NESTED WITHIN MONTHS AND SITES. NO FISHING WAS CONDUCTED IN THE WAINUIOMATA DURING NOVEMBER DUE TO RIVER MOUTH CLOSURE. NO FISH WERE SUCCESSFULLY CAUGHT ON THE $1^{\text {ST }}$ DAY IN AUgust IN THE WAINUIOMATA OR THE $4^{\mathrm{TH}}$ DAY IN NOVEMBER IN THE HUTT (AS INDICATED BY "NA"). ASTERISKS INDICATE A SIGNIFICANT DIFFERENCE IN LENGTH BETWEEN DAY PAIRS. 34

TABLE 2-3 PAIRWISE COMPARISONS OF AVERAGE OTOLITH GROWTH RATE BETWEEN DAYS NESTED WITHIN MONTHS AND SITES. NO FISHING WAS CONDUCTED IN THE WAINUIOMATA DURING NOVEMBER DUE TO RIVER MOUTH CLOSURE. NO FISH WERE SUCCESSFULlY CAUGHT ON THE $1^{\text {ST }}$ DAY IN AUGUST IN THE WAINUIOMATA OR THE $4{ }^{\mathrm{TH}}$ DAY IN NOVEMBER IN THE HUTT (AS INDICATED BY 'NA”). ASTERISKS INDICATE A SIGNIFICANT DIFFERENCE IN LENGTH BETWEEN DAY PAIRS. 38

TABLE 2-4 PAIRWISE COMPARISONS OF AVERAGE GROWTH RATE BETWEEN DAYS NESTED WITHIN MONTHS AND SITES. NO FISHING WAS CONDUCTED IN THE WAINUIOMATA DURING NOVEMBER DUE TO RIVER MOUTH CLOSURE. NO FISH WERE SUCCESSFULLY CAUGHT ON THE $1^{\text {ST }}$ DAY IN AUgUST IN THE WAINUIOMATA OR THE $4^{\text {TH }}$ DAY IN NOVEMBER IN THE HutT. ASTERISKS INDICATE A SIGNIFICANT DIFFERENCE IN LENGTH BETWEEN A PAIR OF DAYS. 42 


\section{LIST OF FIGURES}

FIGURE 2-1 SAMPLING LOCATIONS FOR JUVENILE G. MACULATUS. GREEN = HUTT RIVER. RED $=$ WAINUIOMATA RIVER. RIVER MOUTHS ARE APPROXIMATELY 20 KM APART. DATA FOR THE MAPS COMES FROM THE 'MAPS' (BECKER ET AL. 2016) AND 'MAPDATA' (BECKER ET AL. 2016) R PACKAGES. 28

FigURE 2-2 SPATIAL VARIATION IN STANDARD LENGTH OF JUVENILE G. MACULATUS COLLECTED FROM TWO SITES (HUTT RIVER AND WAINUIOMATA RIVER). GIVEN ARE L-S MEANS (I.E. CORRECTED FOR OTHER SOURCES OF VARIATION IN THE STATISTICAL MODEL, SEE TABLE 2-1) \pm 95\% CI. DisSIMILAR LOWERCASE LETTERS INDICATE A SIGNIFICANT DIFFERENCE BASED UPON POST HOC TESTS. 31

FIGURE 2-3 TEMPORAL VARIATION IN STANDARD LENGTH OF JUVENILE G. MACULATUS COLLECTED FROM TWO SITES. GIVEN ARE LS MEANS $\pm 95 \%$ CI. DisSIMILAR LOWERCASE LETTERS INDICATE A SIGNIFICANT DIFFERENCE BASED UPON POST HOC TESTS. 32

FIGURE 2-4 DAILY (WITHIN MONTH) TEMPORAL VARIATION IN STANDARD LENGTH BETWEen (A) HutT River, AND (B) WAINUIOMATA RIVER. GiVEN ARE LS MEANS \pm 95\% CI. DIFFERENT COLOURS REPRESENT THE DIFFERENT SAMPLING DAYS. BLUE=DAY 1, ORANGE=DAY 2, GREEN=DAY 3, RED=DAY 4. MISSING SYMBOLS INDICATE DAYS WERE NO FISH WERE SAMPLED. CONFIDENCE INTERVALS ARE OBSCURED BY SIZE OF SYMBOLS FOR SEVERAL OBSERVATIONS. DISSIMILAR LOWERCASE LETTERS INDICATE A SIGNIFICANT DIFFERENCE BASED UPON POST HOC TESTS; SEPARATE ANALYSES WERE CONDUCTED FOR EACH SITE AND MONTH. SAMPLING DID NOT OCCUR IN THE WAINUIOMATA RIVER DURING NOVEMBER DUE TO RIVER MOUTH CLOSURE. 33

FIGURE 2-5 SPATIAL AND TEMPORAL VARIATION IN OTOLITH GROWTH RATE OF JUVENILE G. MACULATUS COLLECTED FROM TWO SITES (CIRCLES/UPPERCASE LETTERS: HUTT RIVER, TRIANGLES/LOWERCASE LETTERS: WAINUIOMATA RIVER). GIVEN ARE LSMEANS (I.E. CORRECTED FOR OTHER SOURCES OF VARIATION IN THE STATISTICAL MODEL (TABLE 2-1) \pm 95\% CI. DisSimiLAR LETTERS INDICATE A SIGNIFICANT DIFFERENCE WITHIN SITES, ACROSS TIME (E.G., NO DIFFERENCE ACROSS MONTHS 
WITHIN THE WAINUIOMATA RIVER). SAMPLING DID NOT OCCUR IN THE WAINUIOMATA RIVER DURING NOVEMBER DUE TO RIVER MOUTH CLOSURE. 36

FIGURE 2-6 DAILY (WITHIN MONTH) TEMPORAL VARIATION IN AVERAGE GROWTH RATE BETWEen (A) HutT River, AND (B) WAINUIOMATA RiVER. Given ARE LS MEANS \pm 95\% CI. DIFFERENT COLOURS REPRESENT THE DIFFERENT SAMPLING DAYS. BLUE=DAY 1, ORANGE=DAY 2, GREEN=DAY 3, RED=DAY 4. MisSING SYMBOLS INDICATE DAYS WERE NO FISH WERE SAMPLED. CONFIDENCE INTERVALS ARE OBSCURED BY SIZE OF SYMBOLS FOR SEVERAL OBSERVATIONS. DISSIMILAR LOWERCASE LETTERS INDICATE A SIGNIFICANT DIFFERENCE BASED UPON POST HOC TESTS; SEPARATE ANALYSES WERE CONDUCTED FOR EACH SITE AND MONTH. SAMPLING DID NOT OCCUR IN THE WAINUIOMATA RIVER DURING NOVEMBER DUE TO RIVER MOUTH CLOSURE.

Figure 2-7 SPATIAL AND TEMPORAL VARIATION IN AGES OF JUVENILE G. MACULATUS COLLECTED FROM TWO SITES (CIRCLES/UPPERCASE LETTERS: HUTT RIVER, TRIANGLES/LOWERCASE LETTERS: WAINUIOMATA RIVER). GIVEN ARE LS-MEANS (I.E. CORRECTED FOR OTHER SOURCES OF VARIATION IN THE STATISTICAL MODEL (TABLE $2-1) \pm 95 \%$ CI. DisSIMILAR LETTERS INDICATE A SIGNIFICANT DIFFERENCE WITHIN SITES, ACROSS TIME (E.G., NO DIFFERENCE ACROSS MONTHS WITHIN THE WAINUIOMATA RIVER). SAMPLING DID NOT OCCUR IN THE WAINUIOMATA RIVER DURING NOVEMBER DUE TO RIVER MOUTH CLOSURE. 40

FiguRE 2-8 DAILY (WITHIN MONTH) TEMPORAL VARIATION IN AGE BETWEEN (A) HUTT River, AND (B) WAinUiomata River. DiFFERENT COLOURS REPRESENT THE DIFFERENT SAMPLING DAYS. BLUE=DAY 1, ORANGE=DAY 2, GREEN=DAY 3, RED=DAY 4. MISSING SYMBOLS INDICATE DAYS WERE NO FISH WERE SAMPLED. ERROR BARS REPRESENT 95\% CONFIDENCE INTERVALS. CONFIDENCE INTERVALS ARE OBSCURED BY SIZE OF SYMBOLS FOR SEVERAL OBSERVATIONS. DISSIMILAR LOWERCASE LETTERS INDICATE A SIGNIFICANT DIFFERENCE BASED UPON POST HOC TESTS; SEPARATE ANALYSES WERE CONDUCTED FOR EACH SITE AND MONTH. SAMPLING DID NOT OCCUR IN THE WAINUIOMATA RIVER DURING NOVEMBER DUE TO RIVER MOUTH CLOSURE. 41

FIGURE 3-1 RELATIONSHIP BETWEEN INSTANTANEOUS MORTALITY RATE (Z SCORE) AND AVERAGE LARVAL QUALITY (PC1) FOR EACH DAILY COHORT OF G. MACULATUS FROM TWO SITES: CIRCLE/SOLID LINE $=$ HUTT RIVER, TRIANGLE/DASHED LINE $=$ 
WAINUIOMATA RIVER. SHADED LINES REPRESENT THE 95\% CONFIDENCE INTERVAL AROUND THE REGRESSION LINES. 53

FIGURE 4-1 COMPARISONS OF HATCH DATE DISTRIBUTIONS (ESTIMATED FROM OTOLITHBASED RECONSTRUCTIONS) FOR SAMPLED ADULTS (PINK) AND JUVENILES (BLUE) OF G. maculatus. Panel (A): Hutt River. Panel (B): Wainuiomata River. VERTICAL LINE INDICATES MEAN HATCH DATE FOR EACH GROUP. ASTERISK INDICATES DISSIMILAR DISTRIBUTIONS AND MEAN VALUES BASED ON THE ANDERSON-DARLING TEST AND ONE-WAY ANOVA. 64

FIGURE 4-2 ESTIMATES OF OTOLITH GROWTH FOR EACH JUVENILE COHORT FROM (A) THE Hutt River, AND (B) THE Wainuiomata River $\pm 95 \%$ CI. Model Calculates JUVENILE GROWTH ESTIMATES RELATIVE TO THE ADULT GROWTH ESTIMATES. THEREFORE ANY ESTIMATE THAT IS APPROXIMATELY ZERO REPRESENTS A JUVENILE OTOLITH GROWTH THAT IS EQUAL TO THE ADULT OTOLITH GROWTH. VALUES ABOVE ZERO REFLECT FASTER JUVENILE GROWTH COMPARED TO ADULT SURVIVOR GROWTH. ASTERISKS REPRESENT OTOLITH GROWTH ESTIMATES SIGNIFICANTLY DIFFERENT FROM ZERO. NO FISHING WAS CONDUCTED IN THE WAINUIOMATA RIVER IN NOVEMBER DUE TO RIVER MOUTH CLOSURE. 65 



\section{Chapter 1 - INTRODUCTION}

Understanding the patterns, causes, and consequences of recruitment variability in marine systems is one of the primary goals among marine ecologists (Hjort 1914, Fogarty et al. 1991, Pepin 1991, Caley et al. 1996, Sutherland et al. 2013, Johnson et al. 2014). Many marine organisms have stage-structured life cycles with distinct larval and adult stages (Thorson 1950). Mortality rates are extremely high during the larval stage (McGurk 1986, Rumrill 1990, Gosselin and Qian 1997), and even small variations in these rates can drive large fluctuations in the abundance of individuals surviving to adulthood (Houde and Hoyt 1987). While many early studies have focused on how larval abundance may regulate recruitment through density-dependent processes (Hjort 1914, Roughgarden et al. 1988, Jones 1990, Murdoch 1994, Caley et al. 1996), there has been a growing appreciation for how the phenotypic composition of a population may affect population dynamics (Gaillard et al. 2000, Schoener 2011). Marine species with planktonic larval stages have the potential to undertake long distance dispersal (Thorson 1950), and encountering novel environments during this dispersal may cause phenotypic plasticity in individuals (Agrawal 2001). However, understanding how phenotype distributions can explicitly drive changes in population dynamics remains a difficult task (Saccheri and Hanski 2006). Thorough understandings of phenotype distributions in both larval and adult populations, and the fitness benefits of these phenotypes, are essential for understanding population dynamics (Johnson et al. 2014). 


\subsection{Drivers of recruitment}

Recruitment dynamics are fundamentally driven by the supply of larvae, both in quantity and quality, which in turn depends on dispersal (Roughgarden et al. 1988, Fogarty et al. 1991, Caley et al. 1996, Cowen and Sponaugle 2009). The processes affecting dispersal can be broadly categorised into physical processes and biological traits (Largier 2003, Pineda et al. 2007). Coastal environments can experience strong interactions between topography, water columns, tidal forces, and wind (Largier 2003), variations in which may either promote long distance dispersal or high rates of retention. Landscape features like eddies (Sponaugle et al. 2005), heterogeneous bottom topography (Largier 2003), and frontal convergences (Graham and Largier 1997) will likely restrict access to offshore currents and limit dispersal. Furthermore, larvae can disperse through active or passive means. Many invertebrates and plants are likely to be passive dispersers, whereas fish may more commonly have actively swimming larvae (Cowen 2002, Leis 2006). Regardless of mechanism, dispersal will determine which environments individuals will encounter (Cowen and Sponaugle 2009, Pfaff et al. 2015), and these environments may then affect the survival and phenotype of individuals (Jonsson 1985, Kerr and Secor 2009). Phenotypic traits are known to vary extensively among individuals (Cushing 1975, Jenkins and King 2006, Shima and Swearer 2009), and these traits may be sensitive to surrounding conditions (Houde and Zastrow 1993).

Genetics will play a considerable role in the quality of individuals, as will pre-hatch factors such as parental condition (McCormick 2006), and reproductive timing (Cargnelli and Gross 1996). However, many marine species display substantial phenotypic plasticity in response to environmental factors. Current paradigms suggest that dispersal pathways may change stochastically in time and space (Siegel et al. 2003, Woodson and McManus 2007), so therefore these pathways will determine what environments will be encountered (Cowen and Sponaugle 2009). Phenotype can 
determine the quality of an individual, and therefore its rearing environment can have substantial impacts on success (Pepin 1991, Shima and Swearer 2009). While many phenotypic traits can be environmentally influenced, growth and size are among the most responsive and most studied (Anderson 1988, Litvak and Leggett 1992, Meekan et al. 2003, Sponaugle and Pinkard 2004, Phillips 2005, Sponaugle et al. 2006, Fiksen et al. 2007). Growth is often correlated with condition, and therefore growth has been used as a proxy to infer fish quality (Bolger and Connolly 1989, Rätz and Lloret 2003, Shima and Swearer 2009). Early work supported the 'bigger is better' hypothesis, suggesting that larger, faster growing individuals are less susceptible to size-selective mortality (Oliver et al. 1979, Post and Prankevicius 1987, Miller et al. 1988, Tsukamoto et al. 1989, Cargnelli and Gross 1996). The growth-mortality framework of Anderson (1988) provided three conceptual mechanisms for the relationship between growth and mortality. First, if mortality is a function of size, then larger individuals of equal age will experience lower rates of mortality (Leggett and Deblois 1994). Second, if mortality is inversely related to size, then faster growing individuals will have lower mortality rates as they spend less time at vulnerable sizes (Ware 1975). Third, if mortality is dependent on ontogeny, and juveniles have lower mortality rates than larvae, then individuals that develop the fastest and transition from larvae to juvenile earliest will experience the lowest mortality (Chambers and Leggett 1987). However, subsequent studies have found either a lack of, or contradictory support for faster growth being beneficial for survival (Amara et al. 1994, Good et al. 2001, Munch et al. 2003, Holmes and McCormick 2006). Predators were also proposed to be the mechanism regulating the growth-mortality hypothesis through size selective mortality (Bailey and Houde 1989), and predation is thought to be the dominant regulating mechanism especially in freshwater systems (Werner et al. 1977, Tonn and Paszkowski 1986, Savino and Stein 1989). However, contrary to the 'bigger is better' hypothesis, predators have been shown to select larger prey due to their increased visibility (Litvak and Leggett 1992). There remains substantial evidence that growth and phenotype have significant effects on individual success, but the direction and context may be system dependent. 
Dispersal typically occurs during the larval stage, and is completed when larvae metamorphose into the adult form at settlement. However, pelagic species may also disperse as juveniles or adults (Cowen and Sponaugle 2009). In particular, migratory species often disperse in their metamorphosed form, meaning they may need to adopt life history strategies to survive in a range of environments. Timing of migration movements can coincide with ontogenetic shifts, and evidence suggests that selective processes may change with ontogeny (Meekan et al. 2006, Gagliano et al. 2007). Studies on reef fish indicate that selective processes often favour fish that settle young and grow fast (Grorud-Colvert and Sponaugle 2011). However, selective pressures may change with settlement, ontogeny, and habitat, and high condition in one life stage may not be an indicator of success in later life stages (Johnson and Hixon 2010). Carry-over effects (i.e., effects of early life history on subsequent life stages), have been documented throughout the animal kingdom (amphibians: Smith 1987, Berven 1990, Scott 1994, insects: Taylor et al. 1998, marine invertebrates: Crean et al. 2011, birds: Norris 2005, Sorensen et al. 2009, and fish: Ward and Slaney 1988, Shima and Findlay 2002, Gagliano et al. 2007, Grorud-Colvert and Sponaugle 2011). Carry-over effects can be widespread in fish due to the prevalence of migratory species that will naturally develop in different habitats over their life cycle. In particular, species with diadromous life cycles, such as amphidromy, make excellent model systems for studying these effects, as many amphidromous fish will develop into juveniles in saltwater, and then into adults in freshwater.

Amphidromy is distinct from its sister categories, anadromy and catadromy, due to the migration across biomes being trophic rather than gametic (McDowall 2007). Whereas anadromous and catadromous fish cross the marine/freshwater biome as reproductively mature adults and immediately undertake spawning (Myers 1949), amphidromous fish continue to develop into adults after migration and will spawn after undertaking further development in freshwater (McDowall 2007). Undertaking diadromous migrations is energetically costly, however the primary benefit appears to be exploiting the food rich marine environment (Gross et al. 1988, Edeline 2007). Food availability in oceans is known to vary with temperature, upwelling, and nutrient supply (Bunt 1975), and there is evidence that migration patterns appear to follow food supply (Gross et al. 1988). Food and temperature are known to be the primary determinants of growth rate (Houde 
and Zastrow 1993), so fish phenotypes are likely to vary during migration as they experience different environmental factors (Schluter et al. 1991, Searcy and Sponaugle 2001, Gagliano et al. 2007, Johnson and Hixon 2010). For species with migratory life cycles, phenotypes conferring high larval fitness may become disadvantageous in the juvenile or adult stages due to new challenges posed by a novel environment.

Fish present an excellent system for studying phenotypic plasticity, carry-over effects, and recruitment dynamics, due to a daily record of their growth history being recorded in their otoliths (small calcium carbonate structures that are found in the inner ear; Campana and Neilson 1985). Otoliths form by regular accumulation of growth rings, which can be used to infer growth history, determine age (Pannella 1971), and identify major events in an individual's life history (Victor 1982). A variety of hard structures have been used for seasonal growth estimation, including vertebrae (Brown and Gruber 1988), opercula (Baker and Timmons 1991), scales (Robillard and Marsden 1996), and fin rays (Cass and Beamish 1983). However, the use of otoliths is the most commonly applied method and allows accurate reconstructions of recruitment patterns (Casselman 1987, Wilson and McCormick 1997). Measuring the distance between successive rings can be used to estimate daily somatic growth (Campana and Neilson 1985). While otoliths provide a powerful analytical tool, they must be treated with caution. Abrupt and intense physiological changes may decouple the relationship between otolith growth and somatic growth (Francis et al. 1993, Hoey and McCormick 2004, Baumann et al. 2005, Baumann and Gagliano 2011). This can often occur at settlement, meaning that post-settlement otolith rings may not be a reliable indicator of growth (Hoey and McCormick 2004). Thus, interpretations of otolith growth and somatic growth must include an understanding of the life history and ecological context of the species of interest.

While the formation of rings is influenced by physical processes, a critical step in the accurate aging of fish is the validation of rings forming in a regular temporal pattern. This has been done for a considerable number of species (Taubert and Coble 1977, Fowler and Doherty 1992, Stewart et al. 1995, Newman et al. 1996, Vigliola 1997, 
Cappo et al. 2000, Vilizzi and Copp 2013, Peel et al. 2016, Taylor et al. 2016), and for the focal species of this thesis, Galaxias maculatus (McDowall et al. 1994).

\subsection{Study species}

The geographically widespread fish Galaxias maculatus provides an excellent study species for observational evaluations of recruitment dynamics. G. maculatus is an amphidromous fish that is found throughout New Zealand, Australia, and South America (McDowall 1978, Berra et al. 1996, Cussac et al. 2004). Adult G. maculatus lay their eggs amongst submerged vegetation during high spring tides (McDowall and Charteris 2006). Eggs are exposed to the air as the tide recedes and develop in this moist environment for approximately two weeks, before hatching with the next spring tide and dispersing into the marine environment (Benzie 1968a). Larvae will spend three to six months developing in the marine environment before migrating back to freshwater streams as metamorphosed juveniles (McDowall et al. 1994). The majority of these migrations take place from August to November (McDowall and Eldon 1980). Juvenile fish settle further up the river and develop into reproductively mature adults over the ensuing six months (Cussac et al. 1992). Mature adults move downstream to spawn in estuaries, and will typically die following spawning (Benzie 1968a). During this thesis I will be discussing recruitment at several life stages, both in the traditional sense of juvenile fish being added to the adult population (Fogarty et al. 1991), and in the sense of migrating juveniles entering the freshwater river. At migration, when juvenile fish enter a freshwater stream they can be considered 'recruiting' to the stream. Therefore, juveniles caught at the river mouth will be referred to in this thesis as 'recruits'.

G. maculatus individuals show very high phenotypic plasticity (Barriga et al. 2012). Studies have validated plastic responses to changes in temperature, food availability, and predation risk. Food rich environments promote deeper bodies with shorter caudal peduncles, and vice versa in food limited environments (Kekalainen et al. 2010). Body size can also change in response to predation risk, favouring streamlined shapes that 
promote efficient swimming (Milano et al. 2006). Furthermore, both the migrating juveniles and the spawning adults can be easily caught, which facilitates identification of shifts in phenotypic distributions across life stages.

\subsection{Thesis research}

This thesis has three primary aims: (a) to characterise the extent of phenotypic variability at recruitment in early life history traits of $G$. maculatus, (b) to estimate mortality rates for spatially and temporally discrete cohorts of juvenile G. maculatus, and (c) to determine the effect of early life history traits on future success. In Chapter 2, I compare phenotypes of recruiting G. maculatus, both spatially across sites and temporally within sites. In Chapter 3, I estimate mortality rates for cohorts of recruits and assess whether these mortality rates vary as a function of larval quality. In Chapter 4, I quantify the early life history traits of adult fish to determine whether specific phenotypes show higher success than others. In Chapter 5, I synthesise the results from the previous three chapters and discuss hypotheses generated from these studies. This thesis represents a longitudinal study that investigates $G$. maculatus recruitment at three distinct life stages, and thus it represents one of the few studies that takes a holistic view of recruitment across the entire life cycle. By considering the entire life history, I provide a more complete understanding of recruitment in an amphidromous fish; a complex and difficult dynamic rate function to understand.

I have prepared the following data chapters in the form of independent manuscripts to facilitate submission to peer-reviewed journals. Therefore, each data chapter has its own Introduction and Discussion section, and consequently, there is some repetition across chapters. 


\section{Chapter 2 - PHENOTYPIC VARIATION OF RECRUITING GALAXIAS MACULATUS OVER SMALL SPATIAL AND TEMPORAL SCALES}

\subsection{Introduction}

Recruitment is notoriously variable within fish populations, both in marine and freshwater systems (Houde 1994, Caley et al. 1996). While most studies focus on fluctuations in the abundance of recruits and their subsequent effects on year class strength (Hjort 1914, Houde and Hoyt 1987, Fogarty et al. 1991, Bailey 1994, Bjørnstad et al. 1999, Bastrikin et al. 2014), there is also extensive variation in the phenotype and developmental histories of these recruits (Houde 1989, Hadfield and Strathmann 1996, Searcy and Sponaugle 2000, Grorud-Colvert and Sponaugle 2006, Sponaugle et al. 2006). Fish populations also experience very high mortality during their early life stages (Dahlberg 1979, Bailey and Houde 1989, Sogard 1997, Chambers and Trippel 2012). Marine larvae will often disperse during their larval stage and settle away from their natal origin (Cowen and Sponaugle 2009). During this dispersal phase, individuals may experience highly fluctuating and unpredictable environments that can shape 
phenotypes, alter the expression of life histories, or ultimately die if they cannot adapt (Stearns 1992). Variation in phenotypes across populations may suggest local adaptation to a larval rearing environment (Harrod et al. 2010). Therefore, phenotype may be useful to infer dispersal patterns, developmental history and successful matches to environments encountered.

Variation in phenotype can result from several different biological processes. Natural levels of genetic variation will produce distributions of phenotypic traits, which have varying levels of representation in the population (Shapiro et al. 2004). These traits may then be further influenced during ontogeny (Losos et al. 2000, Trussell and Smith 2000, Bergenius et al. 2005). For instance, variation in fitness-linked traits may lead to certain individuals experiencing higher levels of mortality than phenotypically different conspecifics (Searcy and Sponaugle 2001), which can reduce the frequency of the more susceptible phenotype. Several studies have demonstrated this selective mortality on variable life history traits, i.e. size and growth rate (Anderson 1988, Sogard 1997), and body condition (Buijse and Houthuijzen 1992, Hoey and McCormick 2004). Alternatively, environmental influences may cause some traits to show plasticity in response to conditions experienced by individuals. Phenotypic plasticity is well documented in fish, and phenotypes have been shown to be responsive to food availability (Günther et al. 2015), temperature (Fouzai et al. 2015), predation pressure (Kekalainen et al. 2010), and water flow (Imre et al. 2002). There is evidence that these early life experiences can shape an individual's developmental trajectory and future success (i.e., carry-over effects) and therefore it is critical to understand the extent of variation in these early life histories (Shima and Findlay 2002).

I chose to examine the recruitment dynamics of the amphidromous fish, Galaxias maculatus, a geographically widespread species native to New Zealand (McDowall 1968). After spending approximately six months developing in the open ocean, $G$. maculatus migrate to freshwater streams as metamorphosed juveniles (McDowall et al. 1994). During this migration, they can be caught just as they enter the mouth of the river. While they are known to migrate year round, peak spawning season is from 
March to June, and peak recruitment season is from August to November (McDowall et al. 1994). It is generally assumed that amphidromous species (and G. maculatus specifically) do not show high levels of natal homing, and therefore adult populations are made up of individuals originating from multiple natal origins (Fitzsimons et al. 1990, Radtke and Kinzie 1996, Waters et al. 2000, McDowall 2003, Hickford and Schiel 2016). Therefore, marine returning cohorts of G. maculatus are likely comprised of individuals of different natal origin and dispersal pathways. Due to spatial variation in environmental factors such as food availability and water temperature, fish with differing dispersal pathways may have experienced different environmental conditions during ontogeny (Moody et al. 2015). These conditions can result in phenotypic changes of fish if they have spent sufficient time in said environment (Chambers 1993).

Recruitment is well known to vary over a range of spatial and temporal scales, both for G. maculatus (McDowall and Eldon 1980, McDowall 1994, Barbee et al. 2011), and in other fish species (Myers et al. 1997). However, comparatively few studies have addressed how variable G. maculatus recruitment might be over very small temporal (i.e., day to day) and spatial (i.e., $<20 \mathrm{~km}$ ) scales. The aim of this chapter was to investigate the extent of phenotypic variation among spatially and temporally discrete cohorts of recruiting juvenile G. maculatus. Specifically, I sampled juvenile fish in the peak recruitment season across two spatially discrete sites through time, and measured individual traits (e.g., growth, size) known to be responsive to environmental variation. I hypothesized that I would find differences in phenotypes over larger temporal scales (i.e., month to month), but not over smaller temporal (i.e., day to day), or spatial scales. I analyse differences in developmental characteristics over these separate scales, and conclude with a discussion of potential causes and consequences of this variation. 


\subsection{Methods}

\subsubsection{Fish collections}

I sampled juvenile Galaxias maculatus from two rivers in the Wellington region: the Hutt River and the Wainuiomata River (Figure 2-1). The two river mouths are spatially separated by approximately $20 \mathrm{~km}$. The Hutt River empties into Wellington Harbour, which is a semi-sheltered, mixed, and productive environment (Maxwell 1956). In contrast, the Wainuiomata River empties into Cook Strait, which is more exposed, with fast flowing currents, and is less nutrient rich (Bowman et al. 1983). I collected fish on a monthly schedule between August and November 2015, fishing over a period of four consecutive days within each month (16 days total, both sites were sampled on each day). Each river was sampled simultaneously during fishing days to minimize temporal variability across sites. All fishing was conducted close to the river mouth $(<500 \mathrm{~m}$ inland for the Hutt River, $<100 \mathrm{~m}$ inland for the Wainuiomata). Standard gear used by whitebaiters generally consists of A-frame set nets $(65$ x $120 \mathrm{~cm}$ frame; $90 \mathrm{~cm}$ long; 2 $\mathrm{mm}$ mesh) or sock nets (75 x $113 \mathrm{~cm}$ frame; $220 \mathrm{~cm}$ long, $3 \mathrm{~mm}$ mesh). Set nets are suited for shallow rivers and correspondingly slow currents, while sock nets fish better in deep rivers with fast currents. For this reason I used two A-frame set nets in the Hutt River, placed within $1 \mathrm{~m}$ of the riverbank, and one A-frame and one sock net in the Wainuiomata River. Nets were set approximately two hours before high tide, and fishing was conducted for approximately four hours. Local fisherman occasionally supplied samples onsite, which I used to supplement my own collections. Collected individuals were returned to the Victoria University Coastal Ecology Laboratory (VUCEL), euthanized in accordance with AEC permit 22038, and preserved in $99.9 \%$ ethanol for further analysis. 


\subsubsection{Evaluating developmental characteristics}

I randomly sub-sampled daily catches for a target sample size of 30 fish per river per day for further analysis. I successfully caught fish on 15 separate days in the Hutt River, and 11 days in the Wainuiomata River. For days in which fewer than 30 fish were available I used all collected individuals (average sample size per day $=23$ fish; 20 days had a sample size > 10 fish. During November, the Wainuiomata River was closed due to gravel build up, preventing juvenile G. maculatus from entering the river. Therefore, no samples were collecting during November in the Wainuiomata River.

To estimate fish size I photographed each fish using an Olympus TG-3 camera with a reference ruler in the photo frame. Standard length measurements were obtained with ImageJ v1.49 (Schneider et al. 2012). I extracted the sagittal otoliths from each fish to measure age and growth history. I cleaned one otolith from each pair by placing it in a solution of $15 \% \mathrm{H}_{2} \mathrm{O}_{2}$ buffered with $\mathrm{NaOH}$ for 16 hours. To expose daily growth rings I embedded the otoliths in resin, and polished them along the sagittal plane using a $3 \mu \mathrm{m}$ diamond lapping film. Otoliths were then photographed at either 200x or 400x magnification using a Canon EOS 70D camera connected to a Leica compound microscope. Between 2 and 5 photographs were taken of each otolith at slightly different focal planes (but with the same field of view) to expose all growth rings; photographs were then stitched together to make a composite image using GIMP v2.8.16 (GIMP Team 2016).

Composite images were analysed using the Otolith M app in Image-Pro Premier v9.1 (Media Cybernetics 2016). I counted the daily rings manually, and I measured the distance between each successive daily ring. I estimated 'age' as the number of daily rings, and average otolith growth rate as the length of the otolith radius divided by total number of daily rings. 


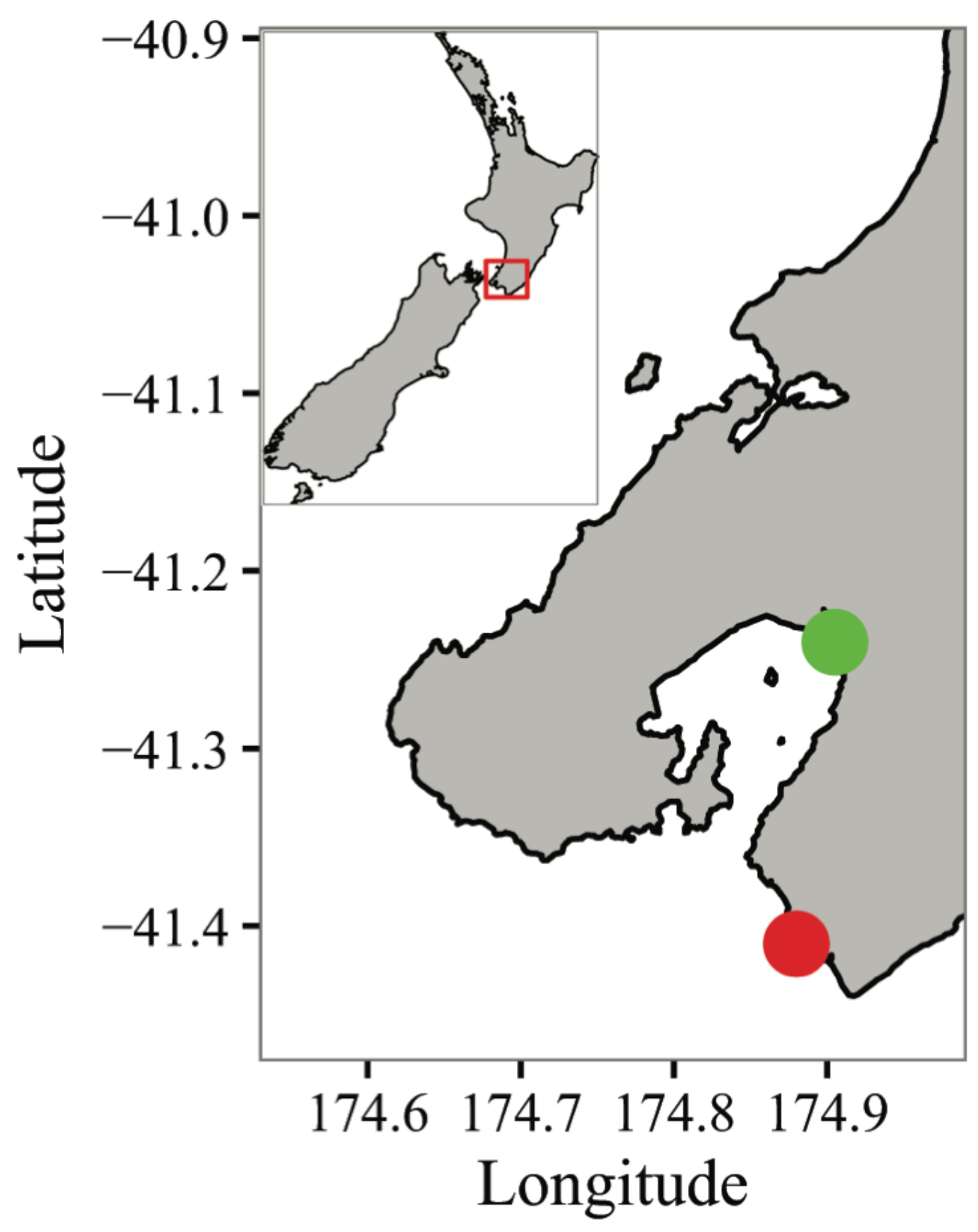

Figure 2-1 Sampling locations for juvenile G. maculatus. Green = Hutt River. Red = Wainuiomata River. River mouths are approximately $20 \mathrm{~km}$ apart. Data for the maps comes from the 'maps' (Becker et al. 2016) and 'mapdata' (Becker et al. 2016) R packages. 


\subsubsection{Statistical analysis}

To evaluate spatio-temporal variation in G. maculatus developmental characteristics I fit three nested linear models (using standard length, average growth rate, and age as response variables in three separate models). Predictor variables included in each model were site (Hutt and Wainuiomata), month (4 months in the Hutt, 3 in the Wainuiomata), and day (4 days per month for each site). I included main effects of site, month, and day, and the interaction term of site $\mathrm{x}$ month. The day effect was nested within the interaction term as I only wanted to compare days that occurred within the same month and site. I hypothesized that all three response variables would show different patterns across months given divergent dispersal patterns and associated environmental conditions experienced. I did not expect to see any differences across days or between sites as I assumed larvae would all have experienced similar environmental conditions (or similar enough that differences would not be detectable). Therefore, I treated all terms in the model as fixed effects so I could specifically evaluate the differences between the levels of each factor. I conducted Tukey post hoc tests, using the 'lsmeans' procedure from the 'Ismeans' package (Lenth 2016), to evaluate 4 aspects of each model: Do developmental characteristics (1) vary between sites (main effect: site); and (2) vary across months (main effect: month). (3) Does the pattern of variation between sites differ across months (interaction: month $\mathrm{x}$ site). (4) Using the nested term I also evaluated variation in developmental characteristics across days within sites and months (nested main effect: day). When there was a significant interaction, I ran post hoc tests to evaluate aspects (1) and (2), see above. If there was no significant interaction, post hoc tests were run on each main effect.

\subsection{Results}

I evaluated spatial and temporal variation in developmental characteristics with a sample of 496 fish. Standard length ranged from 33.7 to $51.2 \mathrm{~mm}($ mean $=45.5, \mathrm{SD}=$ 
2.3). Ages ranged from 105 to 233 days $($ mean $=175, \mathrm{SD}=18.5)$. Otolith growth rates ranged from 1.27 to $2.25 \mu \mathrm{m}^{-1} \mathrm{day}^{-1}$ (mean $\left.=1.67, \mathrm{SD}=0.163\right)$.

\subsubsection{Spatio-temporal variation in standard length}

I found a non-significant effect of the interaction term $\left(F_{2,470}=1.95, p=0.144\right.$, Table 2-1) suggesting that patterns of variation in length across months were similar between sites. Therefore I evaluated main effects. Fish from the Wainuiomata River were longer than fish from the Hutt River (main effect of site variable, $F_{1,470}=10.74, p=0.001$, Figure 2-2).

Table 2-1 Spatio-temporal variation in length, growth rate, and age of juvenile G. maculatus. "Site:Month" represents the interaction term, and "(Site:Month)/Day" represents the day term, nested within the month and site interaction term.

\begin{tabular}{|c|c|c|c|c|c|c|c|c|c|}
\hline & \multicolumn{3}{|c|}{ Standard length } & \multicolumn{3}{|c|}{ Growth rate } & \multicolumn{3}{|c|}{ Age } \\
\hline & d.f. & $\mathrm{F}$ & $\mathrm{p}$ & d.f. & $\mathrm{F}$ & $\mathrm{p}$ & d.f. & $\mathrm{F}$ & $\mathrm{p}$ \\
\hline Site & 1 & 10.74 & 0.001 & 1 & 2.88 & 0.090 & 1 & 11.97 & $<0.001$ \\
\hline Month & 3 & 38.11 & $<0.001$ & 3 & 6.95 & $<0.001$ & 3 & 6.45 & $<0.001$ \\
\hline Site:Month & 2 & 1.95 & 0.144 & 2 & 6.49 & 0.002 & 2 & 7.74 & $<0.001$ \\
\hline (Site:Month)/Day & 19 & 5.21 & $<0.001$ & 19 & 5.27 & $<0.001$ & 19 & 5.35 & $<0.001$ \\
\hline Residual & 470 & & & 470 & & & 470 & & \\
\hline
\end{tabular}




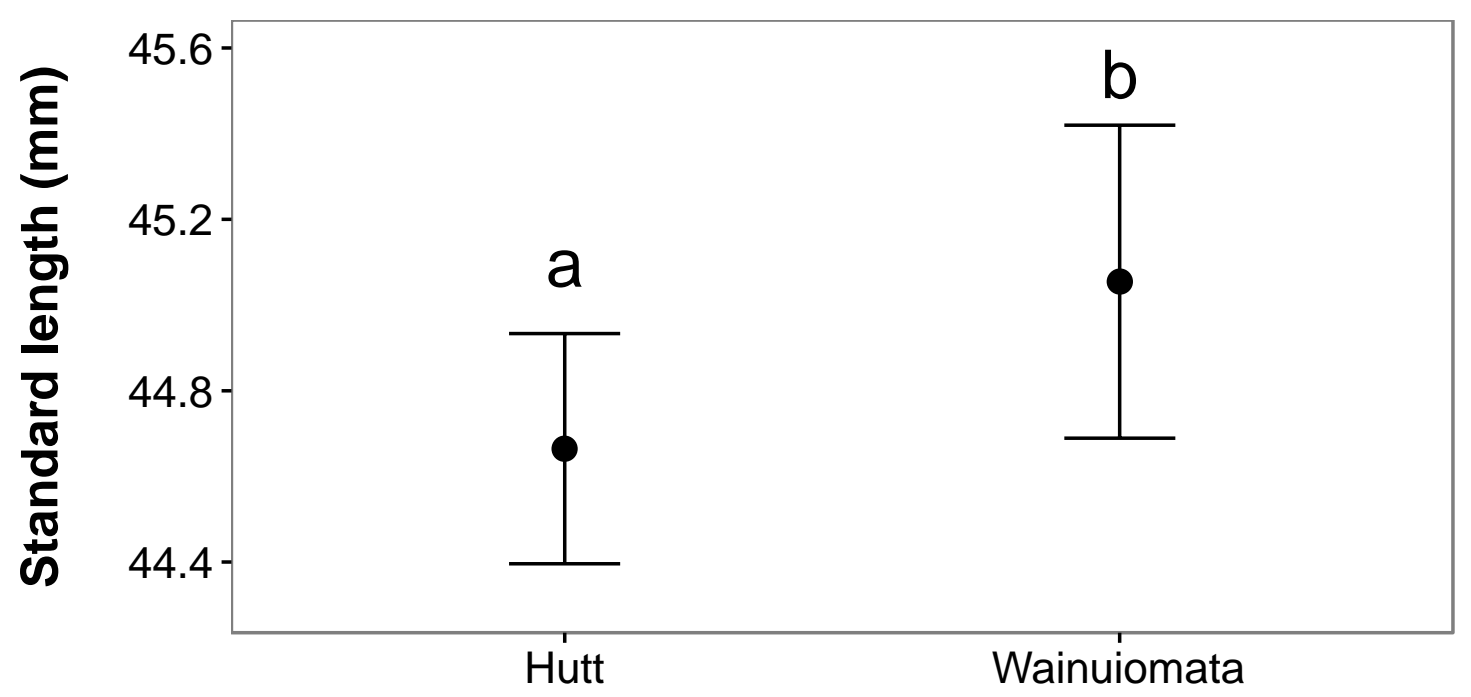

Site

Figure 2-2 Spatial variation in standard length of juvenile G. maculatus collected from two sites (Hutt River and Wainuiomata River). Given are L-S means (i.e. corrected for other sources of variation in the statistical model, see table 2-1) $\pm 95 \%$ CI. Dissimilar lowercase letters indicate a significant difference based upon post hoc tests.

Length also varied across months (main effect of month variable, $F_{3,470}=38.11$, $p<$ 0.001, Figure 2-3). A post hoc test revealed that fish caught in August were significantly larger than fish from September $(\mathrm{p}<0.0001)$, October $(\mathrm{p}=0.0026)$, and November $(\mathrm{p}<$ 0.0001). Fish from September and October were both significantly larger than November fish ( $p<0.0001$ for both) but not different from one another $(\mathrm{p}=0.4505)$. 


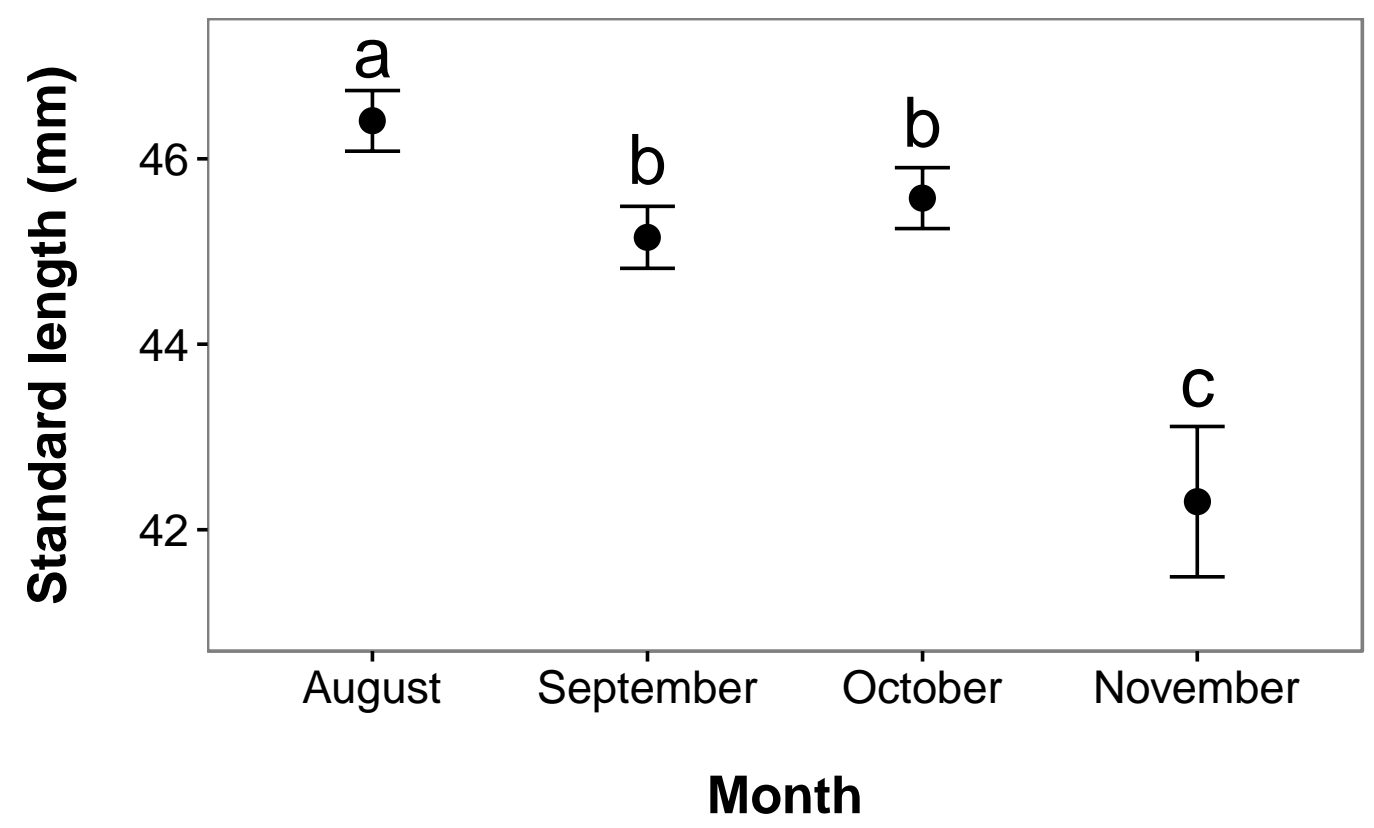

Figure 2-3 Temporal variation in standard length of juvenile G. maculatus collected from two sites. Given are LS means $\pm 95 \%$ CI. Dissimilar lowercase letters indicate a significant difference based upon post hoc tests.

The standard length of $G$. maculatus varied significantly among days nested within sites $\left(\mathrm{F}_{19,470}=5.210, \mathrm{p}<0.0001\right.$, Figure 2-4). A post hoc test (Table 2-2) indicates that a small number of pairwise comparisons appear to be driving the significance of this effect. Figure 2-4 suggests that sizes of G. maculatus are heterogeneous across consecutive days within some months (i.e. October, November) for the Hutt River in particular. 


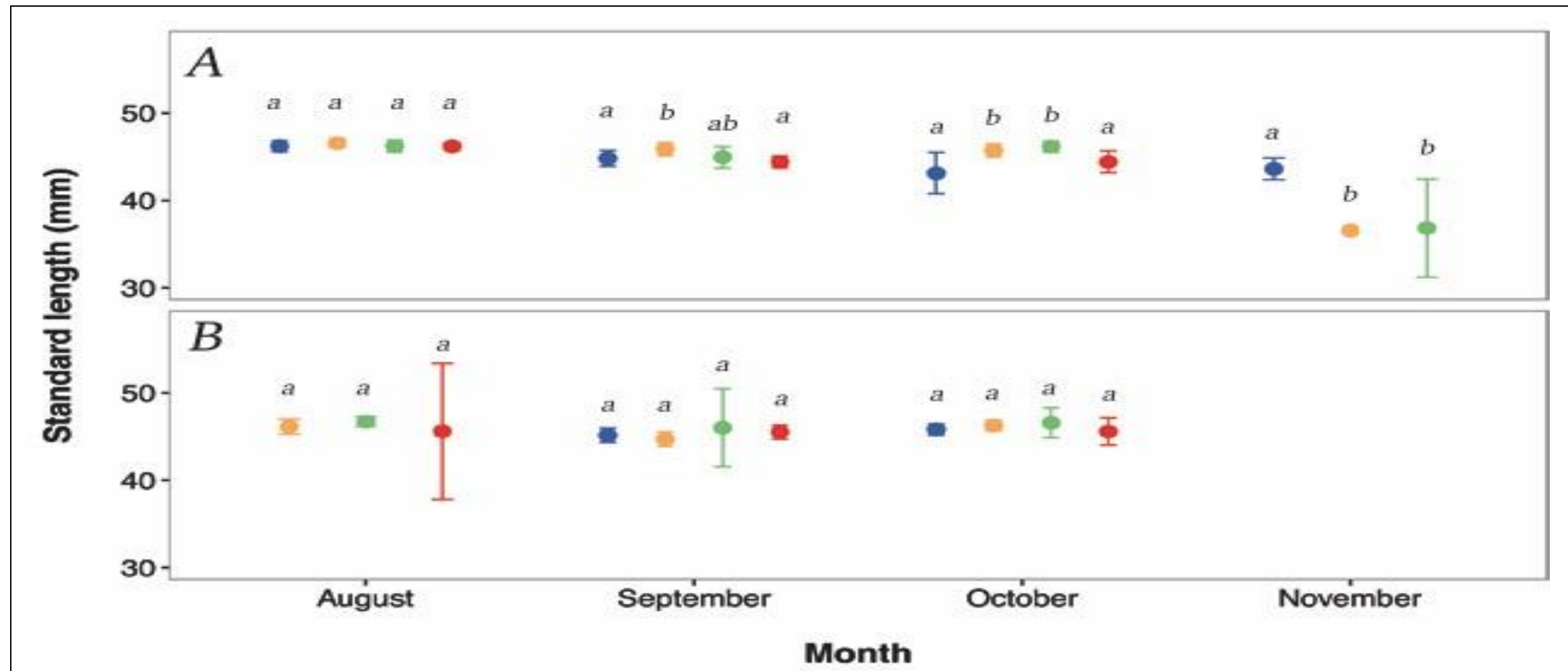

Figure 2-4 Daily (within month) temporal variation in standard length between (A) Hutt River, and (B) Wainuiomata River. Given are LS means $\pm 95 \%$ CI. Different colours represent the different sampling days. Blue=day 1, orange=day 2, green=day 3, red=day 4. Missing symbols indicate days were no fish were sampled. Confidence intervals are obscured by size of symbols for several observations. Dissimilar lowercase letters indicate a significant difference based upon post hoc tests; separate analyses were conducted for each site and month. Sampling did not occur in the Wainuiomata River during November due to river mouth closure. 
Table 2-2 Pairwise comparisons of standard length between days nested within months and sites. No fishing was conducted in the Wainuiomata during November due to river mouth closure. No fish were successfully caught on the $1^{\text {st }}$ day in August in the Wainuiomata or the $4^{\text {th }}$ day in November in the Hutt (as indicated by "NA"). Asterisks indicate a significant difference in length between day pairs.

\begin{tabular}{|c|c|c|c|}
\hline Month & Day pairs & $\begin{array}{l}\text { Hutt River } \\
\text { p-values }\end{array}$ & $\begin{array}{l}\text { Wainuiomata } \\
\text { p values }\end{array}$ \\
\hline \multirow{6}{*}{ August } & 1 and 2 & 0.498 & NA \\
\hline & 1 and 3 & 0.994 & NA \\
\hline & 1 and 4 & 0.972 & NA \\
\hline & 2 and 3 & 0.503 & 0.296 \\
\hline & 2 and 4 & 0.481 & 0.701 \\
\hline & 3 and 4 & 0.966 & 0.429 \\
\hline \multirow{6}{*}{ September } & 1 and 2 & $0.048 *$ & 0.470 \\
\hline & 1 and 3 & 0.835 & 0.455 \\
\hline & 1 and 4 & 0.488 & 0.529 \\
\hline & 2 and 3 & 0.1556 & 0.278 \\
\hline & 2 and 4 & $0.008 *$ & 0.230 \\
\hline & 3 and 4 & 0.434 & 0.675 \\
\hline \multirow{6}{*}{ October } & 1 and 2 & $<0.001 *$ & 0.381 \\
\hline & 1 and 3 & $<0.001 *$ & 0.299 \\
\hline & 1 and 4 & 0.060 & 0.763 \\
\hline & 2 and 3 & 0.443 & 0.692 \\
\hline & 2 and 4 & $0.021 *$ & 0.375 \\
\hline & 3 and 4 & $0.003 *$ & 0.288 \\
\hline \multirow{3}{*}{ November } & 1 and 2 & $<0.001 *$ & NA \\
\hline & 1 and 3 & $<0.001 *$ & NA \\
\hline & 2 and 3 & 0.890 & NA \\
\hline
\end{tabular}




\subsubsection{Spatiotemporal variation in average growth rate}

I found a significant interaction between month and site $\left(F_{2,470}=6.489, p=0.0017\right.$, Figure 2-5), indicating that growth rate changes over time and sites (Table 2-1). A post hoc test showed that, in the Hutt River, fish caught in August grew faster than fish caught in September $(\mathrm{p}<0.0001)$, October $(\mathrm{p}=0.0265)$ and November $(\mathrm{p}=0.0134)$. September did not differ to October $(\mathrm{p}=0.3105)$ or November $(\mathrm{p}>0.9999)$. October and November also did not differ $(\mathrm{p}=0.6749)$. In the Wainuiomata River, August fish did not have a significantly different growth rate to fish caught in September ( $p$ > $0.9999)$ or October $(p=0.3072)$. Fish from September and October also did not differ significantly $(\mathrm{p}=0.5708)$. 


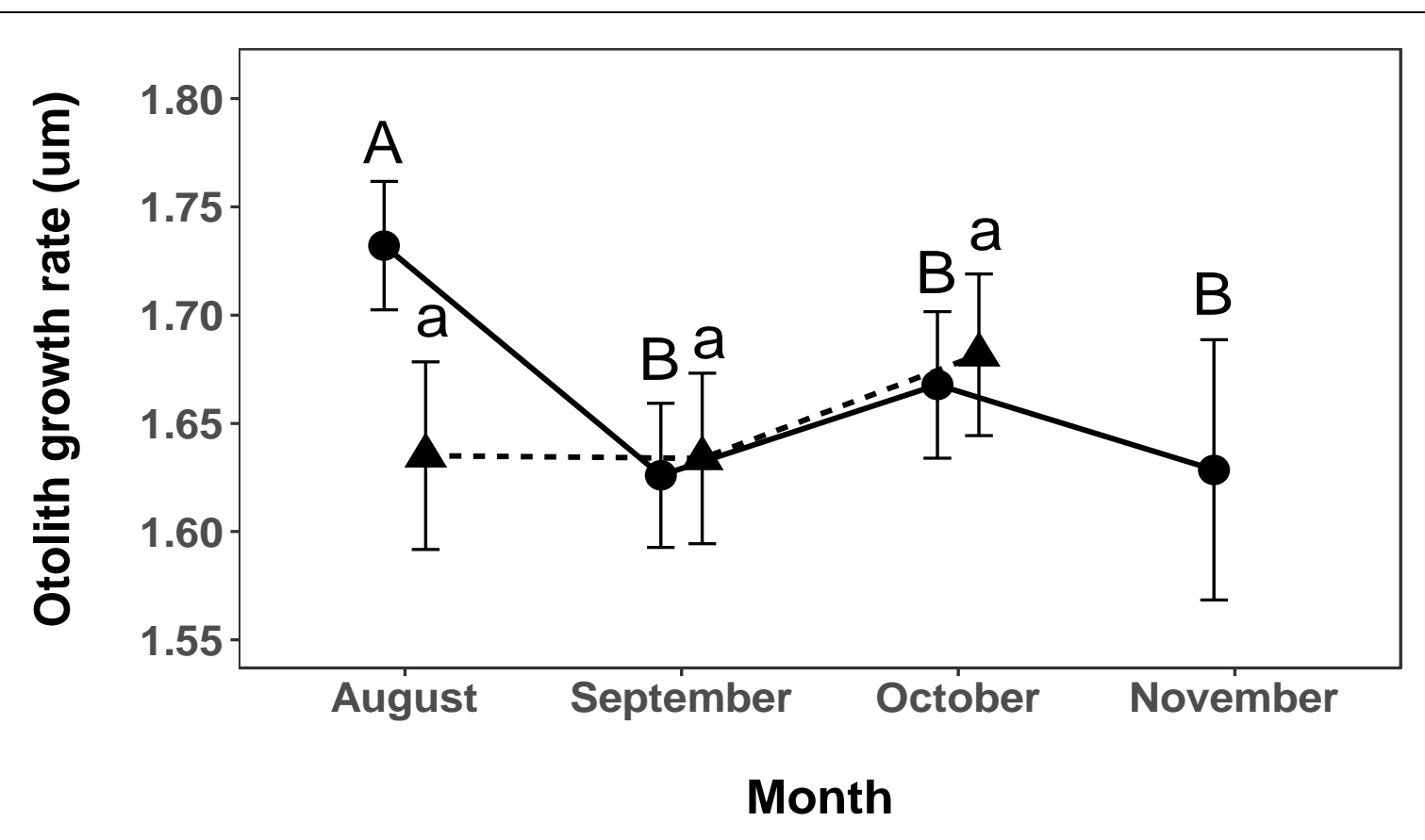

Figure 2-5 Spatial and temporal variation in otolith growth rate of juvenile G. maculatus collected from two sites (circles/uppercase letters: Hutt River, triangles/lowercase letters: Wainuiomata River). Given are LSmeans (i.e. corrected for other sources of variation in the statistical model (Table 2-1) \pm 95\% CI. Dissimilar letters indicate a significant difference within sites, across time (e.g., no difference across months within the Wainuiomata River). Sampling did not occur in the Wainuiomata River during November due to river mouth closure.

The otolith growth rate varied significantly among days nested within months and sites $\left(\mathrm{F}_{19,470}=5.2703, \mathrm{p}<0.0001\right.$, Figure 2-6). A post hoc test (Table 2-3) indicates that a small number of pairwise comparisons are driving the significance of this effect. Figure 2-6 suggests that otolith growth rates of G. maculatus are heterogeneous across days within all months for the Hutt River and homogenous across days within all months for the Wainuiomata River. 


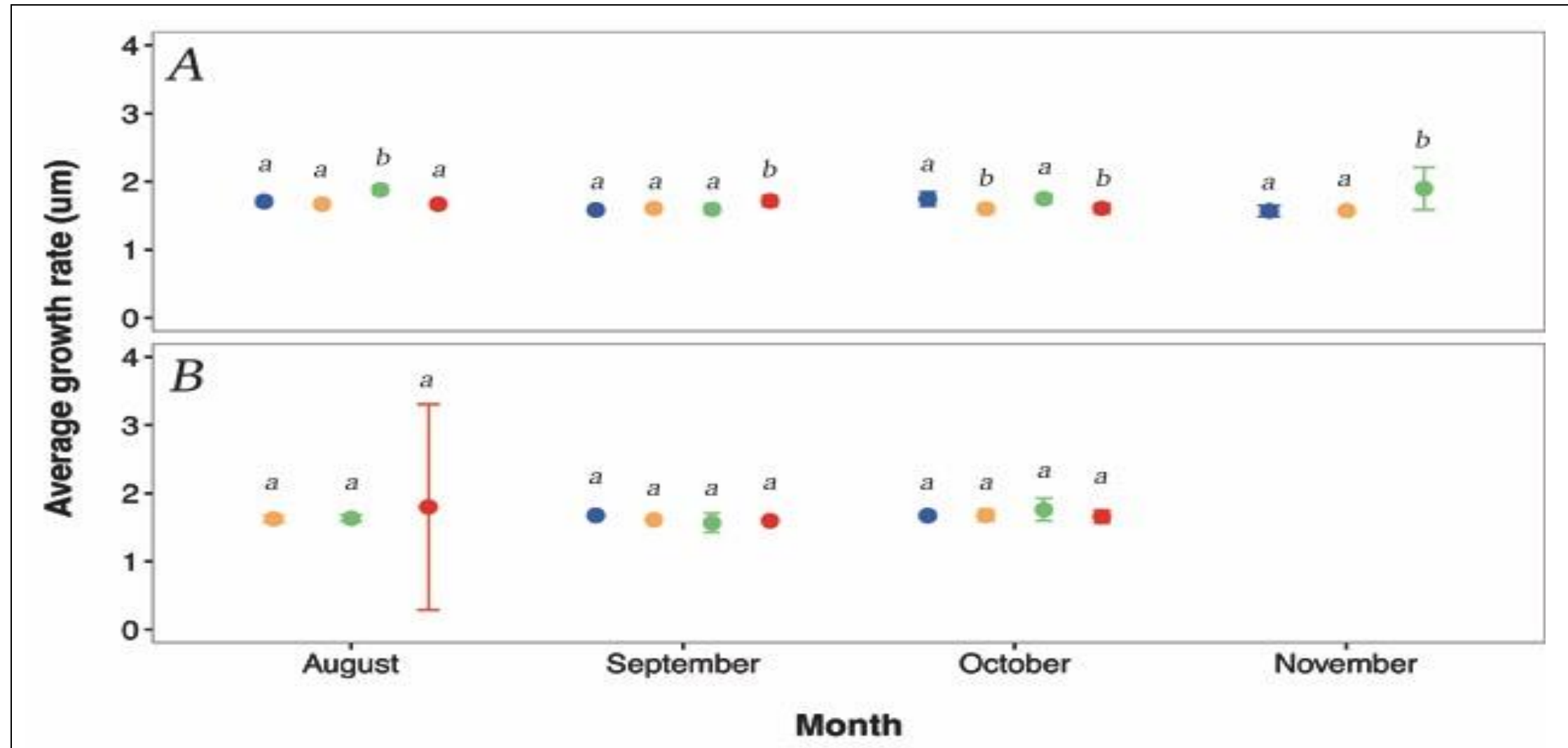

Figure 2-6 Daily (within month) temporal variation in average growth rate between (A) Hutt River, and (B) Wainuiomata River. Given are LS means $\pm 95 \%$ CI. Different colours represent the different sampling days. Blue=day 1 , orange=day 2, green=day 3 , red=day 4 . Missing symbols indicate days were no fish were sampled. Confidence intervals are obscured by size of symbols for several observations. Dissimilar lowercase letters indicate a significant difference based upon post hoc tests; separate analyses were conducted for each site and month. Sampling did not occur in the Wainuiomata River during November due to river mouth closure. 
Table 2-3 Pairwise comparisons of average otolith growth rate between days nested within months and sites. No fishing was conducted in the Wainuiomata during November due to river mouth closure. No fish were successfully caught on the $1^{\text {st }}$ day in August in the Wainuiomata or the $4^{\text {th }}$ day in November in the Hutt (as indicated by "NA"). Asterisks indicate a significant difference in length between day pairs.

\begin{tabular}{|c|c|c|c|}
\hline Month & Day pairs & $\begin{array}{l}\text { Hutt River } \\
\text { p-values }\end{array}$ & $\begin{array}{l}\text { Wainuiomata River } \\
\text { p-values }\end{array}$ \\
\hline \multirow{6}{*}{ August } & 1 and 2 & 0.303 & NA \\
\hline & 1 and 3 & $<0.001 *$ & NA \\
\hline & 1 and 4 & 0.315 & NA \\
\hline & 2 and 3 & $<0.001 *$ & 0.805 \\
\hline & 2 and 4 & 0.988 & 0.109 \\
\hline & 3 and 4 & $<0.001 *$ & 0.129 \\
\hline \multirow{6}{*}{ September } & 1 and 2 & 0.589 & 0.186 \\
\hline & 1 and 3 & 0.867 & 0.221 \\
\hline & 1 and 4 & $0.002 *$ & 0.081 \\
\hline & 2 and 3 & 0.784 & 0.626 \\
\hline & 2 and 4 & $0.009 *$ & 0.790 \\
\hline & 3 and 4 & $0.016 *$ & 0.730 \\
\hline \multirow{6}{*}{ October } & 1 and 2 & $0.005 *$ & 0.936 \\
\hline & 1 and 3 & 0.936 & 0.110 \\
\hline & 1 and 4 & $0.010 *$ & 0.814 \\
\hline & 2 and 3 & $<0.001 *$ & 0.133 \\
\hline & 2 and 4 & 0.890 & 0.775 \\
\hline & 3 and 4 & $0.001 *$ & 0.147 \\
\hline \multirow{3}{*}{ November } & 1 and 2 & 0.976 & NA \\
\hline & 1 and 3 & $<0.001 *$ & NA \\
\hline & 2 and 3 & $0.044 *$ & NA \\
\hline
\end{tabular}




\subsubsection{Spatio-temporal variation in ages}

I found a significant interaction between month and site $\left(F_{2,470}=7.7421, p=0.0004\right.$, Figure 2-7), indicating that patterns of age variation changed across time and sites. A post hoc test showed that, in the Hutt River, fish caught in August were significantly younger than fish caught in September $(\mathrm{p}<0.0001)$, and October $(\mathrm{p}=0.0029)$ but not November $(\mathrm{p}=0.3783)$. Fish caught in September did not differ to fish from October ( $p$ $=0.4134)$ or November $(\mathrm{p}=0.2774)$. There was also no difference in fish caught from October and November $(\mathrm{p}=0.8869)$. In the Wainuiomata River, fish caught in August showed no difference in age to fish caught in September $(\mathrm{p}=0.9934)$ or October $(\mathrm{p}=$ 0.7513). Fish caught in September also showed no difference to fish caught in October $(\mathrm{p}=0.8709)$. 


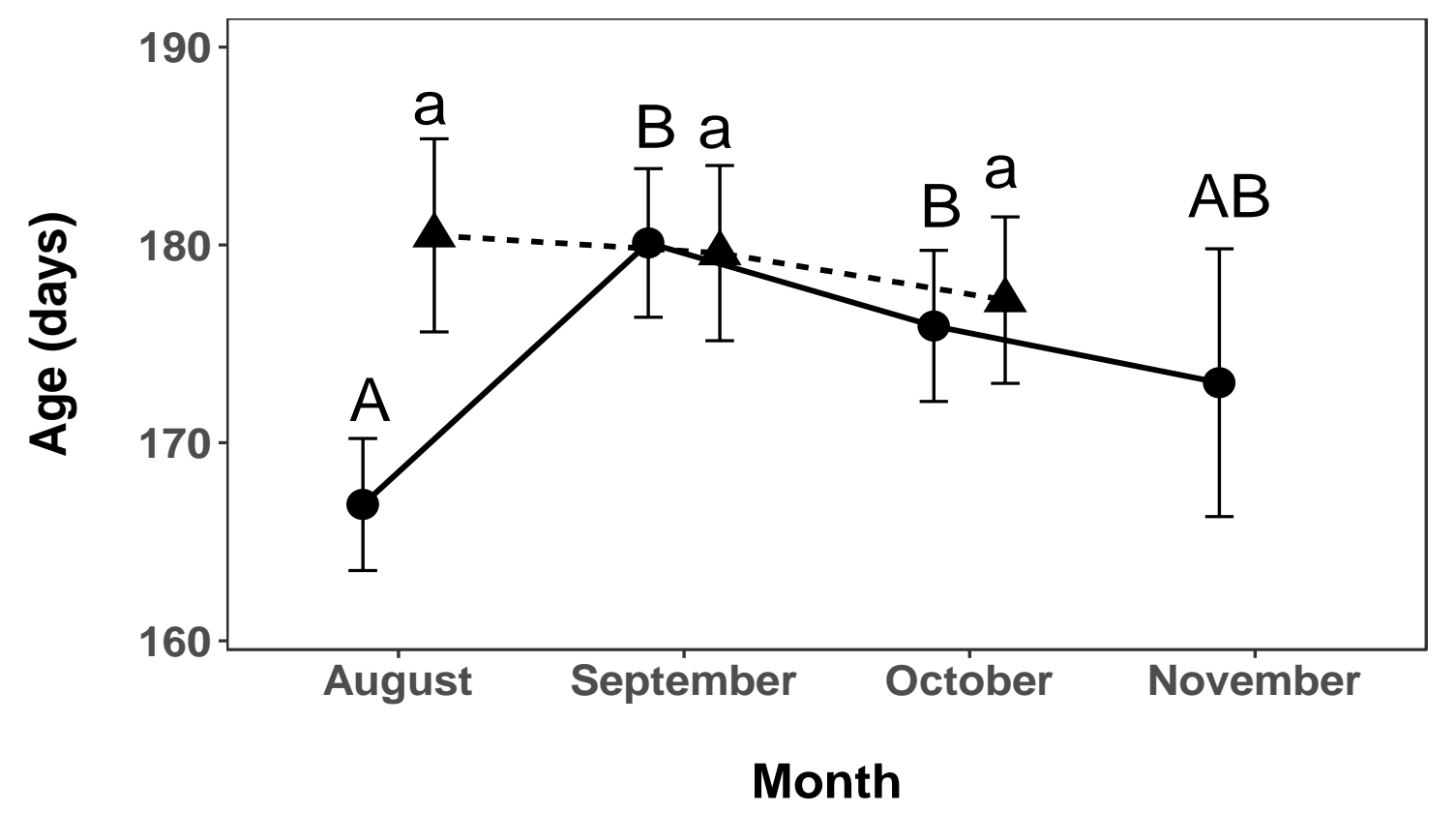

Figure 2-7 Spatial and temporal variation in ages of juvenile G. maculatus collected from two sites (circles/uppercase letters: Hutt River, triangles/lowercase letters: Wainuiomata River). Given are LS-means (i.e. corrected for other sources of variation in the statistical model (Table 2-1) \pm 95\% CI. Dissimilar letters indicate a significant difference within sites, across time (e.g., no difference across months within the Wainuiomata River). Sampling did not occur in the Wainuiomata River during November due to river mouth closure.

The ages of juvenile $G$. maculatus differed significantly among days nested within month and site $\left(\mathrm{F}_{19,470}=5.3537, \mathrm{p}<0.0001\right.$, Figure 2-8). A post hoc test (Table 2-4) again indicates that the significance of this effect is driven by a small number of pairwise comparisons in the Hutt River. Figure 2-8 suggests that ages of G. maculatus are heterogeneous across days within all months for the Hutt River and homogenous across days within all months for the Wainuiomata River. 


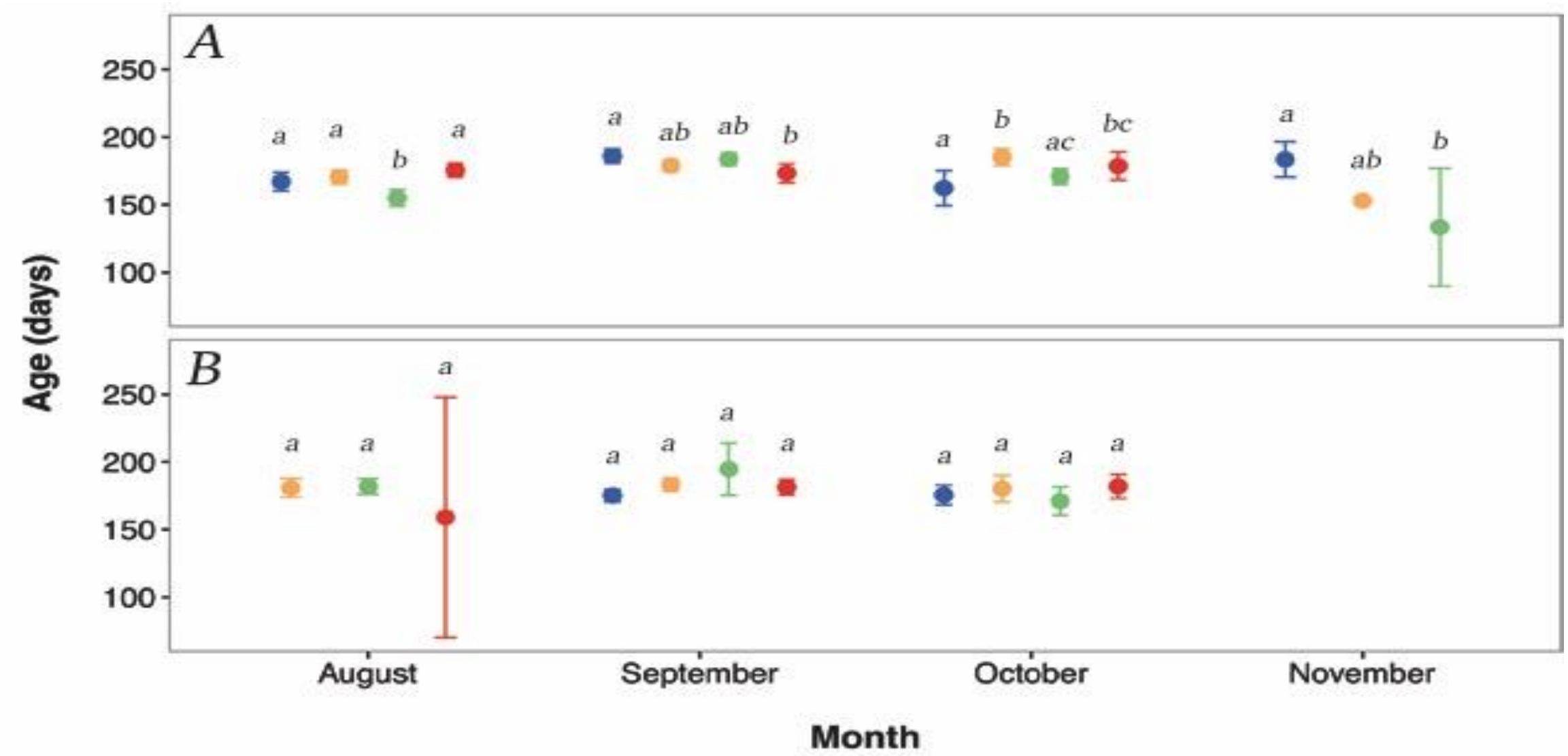

Figure 2-8 Daily (within month) temporal variation in age between (A) Hutt River, and (B) Wainuiomata River. Different colours represent the different sampling days. Blue=day 1, orange=day 2 , green=day 3, red=day 4 . Missing symbols indicate days were no fish were sampled. Error bars represent $95 \%$ confidence intervals. Confidence intervals are obscured by size of symbols for several observations. Dissimilar lowercase letters indicate a significant difference based upon post hoc tests; separate analyses were conducted for each site and month. Sampling did not occur in the Wainuiomata River during November due to river mouth closure. 
Table 2-4 Pairwise comparisons of average growth rate between days nested within months and sites. No fishing was conducted in the Wainuiomata during November due to river mouth closure. No fish were successfully caught on the $1^{\text {st }}$ day in August in the Wainuiomata or the $4^{\text {th }}$ day in November in the Hutt. Asterisks indicate a significant difference in length between a pair of days.

\begin{tabular}{|c|c|c|c|}
\hline Month & Day pairs & $\begin{array}{l}\text { Hutt River } \\
\text { p-values }\end{array}$ & $\begin{array}{l}\text { Wainuiomata River } \\
\text { p-values }\end{array}$ \\
\hline \multirow{6}{*}{ August } & 1 and 2 & 0.439 & NA \\
\hline & 1 and 3 & $0.007 *$ & NA \\
\hline & 1 and 4 & 0.058 & NA \\
\hline & 2 and 3 & $<0.001 *$ & 0.826 \\
\hline & 2 and 4 & 0.258 & 0.075 \\
\hline & 3 and 4 & $<0.001 *$ & 0.061 \\
\hline \multirow{6}{*}{ September } & 1 and 2 & 0.129 & 0.127 \\
\hline & 1 and 3 & 0.674 & 0.051 \\
\hline & 1 and 4 & $0.008 *$ & 0.206 \\
\hline & 2 and 3 & 0.410 & 0.280 \\
\hline & 2 and 4 & 0.225 & 0.741 \\
\hline & 3 and 4 & 0.073 & 0.197 \\
\hline \multirow{6}{*}{ October } & 1 and 2 & $<0.001 *$ & 0.299 \\
\hline & 1 and 3 & 0.131 & 0.485 \\
\hline & 1 and 4 & $0.006 *$ & 0.329 \\
\hline & 2 and 3 & $0.001 *$ & 0.157 \\
\hline & 2 and 4 & 0.182 & 0.801 \\
\hline & 3 and 4 & 0.116 & 0.177 \\
\hline \multirow{3}{*}{ November } & 1 and 2 & 0.073 & NA \\
\hline & 1 and 3 & $<0.001 *$ & NA \\
\hline & 2 and 3 & 0.280 & NA \\
\hline
\end{tabular}




\subsection{Discussion}

\subsubsection{Summary of results}

I found site-specific trends in the developmental histories of $G$. maculatus. Juvenile $G$. maculatus entering the Wainuiomata River showed no difference in growth rate or age across months, although they did show a decrease in standard length across months. Fish from the Hutt River also shared this decrease in standard length, but also showed a decrease in otolith growth rate. Age showed a dome shaped curve, where the youngest recruiting fish were in August and November. Fish in the Hutt River during August, were the youngest, fastest growing, and largest, a pattern that was not reflected in the Wainuiomata. However, while fish from the Wainuiomata River did not show significant differences in otolith growth rate and age, there did appear to be nonsignificant trends that matched the results from the Hutt River.

There was no day-to-day variation in any developmental characteristics of fish sampled from the Wainuiomata River. While fish from the Hutt River did show day-to-day variation, there was significant variation in the direction and magnitude of trends. Therefore, the two main points of interest become (1) why was there daily and monthly variation through time, and (2) why was there more variation in the Hutt River?

\subsubsection{Spatial differences in developmental histories}

I propose two hypotheses that could explain my results (and these are not mutually exlusive): (1) the Hutt River may be replenished by fish from a wider variety of source populations than the Wainuiomata River, which could lead to greater variation in developmental histories among cohorts (natal source hypothesis), and/or (2) recruits 
from the Hutt River may have experienced greater environmental variability during their pelagic larval dispersal phase, which could lead to different phenotypic distributions through individual fish experiencing phenotypic plasticity or selective mortality (environmental experience hypothesis).

A difference in the composition of source populations entering each river is dependent on the extent of dispersal. G. maculatus have very strong swimming capabilities (Barker and Lambert 1988), and considerable research has examined the extent of population mixing and natal return (Barker and Lambert 1988, Berra et al. 1996, Waters and Burridge 1999, Waters et al. 2000) with current paradigms suggesting that G. maculatus does not show extensive natal homing (Waters et al. 2000, Hickford and Schiel 2016). However most evidence is based off a lack of genetic structure among sampled populations, and genetic structuring may be mediated by only a small number of mixing individuals (Hartl 1988). Furthermore, most studies have been concerned with broad spatial hypotheses (Barriga et al. 2007, Barbee et al. 2011, Barriga et al. 2012), rather than considering the characteristics of individual systems that may facilitate a higher level of retention than the majority of source populations. Harbour systems have been shown to have highly retentive properties due to physical and hydrodynamic processes acting on the water currents (Maxwell 1956, Bowman et al. 1983, Anderson 1988). Therefore I suggest that the hydrodynamic characteristics of the Wellington Harbour may promote higher retention of larval G. maculatus than would be expected by a coastally positioned system, thus promoting self recruitment (Jones et al. 2005, Levin 2006, McDowall 2009). However, I do not assume that the Wellington Harbour is completely isolated from other (perhaps coastally derived) G. maculatus populations, and I would expect it to still receive input from other source populations around New Zealand (McDowall et al. 1975, Caley et al. 1996, McDowall 2002, Swearer et al. 2002). The combined input of recruits from other source populations (with their own variations in phenotype), plus the resident population in the Wellington Harbour, may combine to produce a more heterogeneous population of G. maculatus (Shima and Swearer 2009). Fish from the Wellington Harbour would therefore show a wider distribution in phenotypes than the Wainuiomata River, which may not have a resident population, and is only replenished by regional source populations (that shared more 
similar environmental conditions). These differences in the spread of potential phenotypes may be driving the lack of significant differences in the Wainuiomata, while accounting for the range of patterns documented in the Hutt River.

Marine habitats can show considerable variation in temperature, water flow, light availability, and salinity (Johnston 2006) which may vary extensively through time. Pelagic fish may experience phenotypic plasticity as a result of this environmental variability, and therefore their phenotype may correlate with conditions experienced during dispersal. If my two study sites are replenished by different combinations of source populations, with differing dispersal histories, then the environmental conditions experienced may be driving these site specific differences. During dispersal, cohorts may encounter novel environments that impose directional selection on phenotypic traits (Reznick and Ghalambor 2001, Grether 2005), which shifts the mean phenotype to a new peak (Lande and Arnold 1983). Environmental pressures may be either biotic (Handelsman et al. 2013) or abiotic (Carrera et al. 2012) but all have the potential to drive phenotypic shifts (Agrawal 2001). This hypothesis is dependent upon Wellington Harbour showing a higher degree of temporal variability in its biotic and abiotic conditions. Under the assumption that it is more variable, individuals with recent resident periods in the harbour may have experienced phenotypic plasticity, and therefore developed phenotypic characteristics representative of the conditions at the time (Agrawal 2001, Barriga et al. 2012, Chapman et al. 2015). Depending on the scale of this variability it may account for both monthly and daily differences. In contrast, if the Cook Strait shows a less temporally variable environment then that may explain the fairly consistent trends in phenotypes of recruits.

General trends in harbour systems have shown evidence of circulation currents leading to high levels of nutrients (Mackas and Harrison 1997) and zooplankton (Soetaert and Herman 1994). They have also shown that abiotic conditions can be highly variable between seasons (Muylaert and Raine 1999). Results by Maxwell (1956) indicate average water temperatures in the Wellington Harbour increase from August to November, yet there is also considerable fluctuation over shorter time scales, with 
changes of up to $2.5^{\circ} \mathrm{C}$ within a three day period. Maxwell (1956) also postulated that the causes of this high variability was due to the sheltered positioning of the harbour. In contrast, Cook Strait has very high energy, fast flowing currents (Bowman et al. 1983), and its lack of shelter may not promote high levels of abiotic variability. Cook Strait is highly dynamic with complex patterns of water circulation, but there is little evidence for its low productivity waters being temporally variable (Bowman et al 1983). While it may be a high energy environment, I argue that the consistent nature of it is not enough to drive phenotypic differences in resident cohorts of G. maculatus. 


\section{Chapter 3 - IMPLICATIONS OF VARIABLE LARVAL QUALITY ON JUVENILE MORTALITY IN GALAXIAS MACULATUS}

\subsection{Introduction}

Marine organisms with stage structured life histories can experience very high mortality rates during their planktonic phase (Hjort 1914, Bailey and Houde 1989). This level of mortality can be mediated by growth rates, where selective mortality favours individuals with specific patterns of growth (Anderson 1988). Fast growth may be beneficial if it enables fish to outgrow gape limited predators (Hambright 1991), improve upon their swimming ability to escape predators (Litvak and Leggett 1992), and/or store sufficient energy to avoid starvation (Shuter et al. 1980, Conover and Schultz 1997). Conversely, slow growth can be beneficial if fish become more inconspicuous to predators (Biro et al. 2004) or undertake behavioural changes to minimise their vulnerability (Meekan et al. 2010)

An individual's growth rate may be correlated with its rearing environment. Biotic and abiotic factors may influence the magnitude of growth rate, resulting in phenotypes being partially influenced by developmental environment (Agrawal 2001). Environmental variables known to influence growth rate include temperature (Green and Fisher 2004), presence of predators (Milano et al. 2006), water movement 
(Kekalainen et al. 2010), and food availability (Jones 1986), although relationships may be positive, negative, and/or non-linear. Optimal temperatures and food availability will usually promote higher levels of growth (MacDonald and Thompson 1985) although these relationships can be complex and context dependent (Nicieza and Metcalfe 1997). A substantial body of evidence indicates that growth is also linked with fitness (Cowan et al. 1996, Searcy and Sponaugle 2001, Shima and Findlay 2002, Raventós and Macpherson 2005, Grorud-Colvert and Sponaugle 2006, Shima and Swearer 2009), with further evidence indicating that increases in fitness may be linked with growth in early life (Shima and Findlay 2002, Gagliano et al. 2007), and growth immediately preceding life stage transitions (Hamilton 2008, Hamilton et al. 2008). In species with protracted spawning and a pelagic dispersal phase, separate cohorts of fish may experience different conditions due to natural temporal variation in the environment (i.e. across seasons). Long distance dispersal can be a physiologically demanding event, and often results in high levels of mortality (Baker and Rao 2004).

There are well defined conceptual frameworks for the relationship between growth and mortality (Anderson 1988). The growth-mortality hypothesis (Ware 1975, Shepherd and Cushing 1980) generally predicts that growth will be related to mortality, typically through the mechanisms of starvation and/or predation. However, both of these processes typically elucidate different relationships between growth and mortality (Anderson 1988, Leggett and Deblois 1994). Limitation by food can lead to a relationship where fish with higher growth rates experience lower mortality. Prey can often be distributed non-uniformly, and it has been suggested that ambient prey density in the ocean is too low to support growth and survival of larval fish (Anderson 1988). Larger larvae are less susceptible to starvation than smaller conspecifics, due to having excess fat reserves (Hjort 1914), and therefore are more likely to survive intense periods of starvation (i.e., over winter mortality). Growth and mortality would therefore show an inverse relationship, where fish with higher growth rates would experience lower levels of mortality. 
Limitation by predators can show a different relationship, where prey mortality follows a dome shaped curve. Under this model, fish with the highest and lowest growth rates will experience the highest levels of mortality. Fish are the most significant predators of fish larvae (Pepin 1987, Bailey and Houde 1989) and they are known to cause significant levels of mortality (Ware 1975, Sissenwine 1984, Gaines and Roughgarden 1987, Bailey and Houde 1989). Predation by fish requires larvae to be encountered, attacked, and captured (Pepin 1992). Small fish with have a low encounter rate, but a high capture rate, whereas large fish will have a high encounter rate with a low capture rate, thus producing the relationship where intermediate sizes convey the highest fitness (Leggett and Deblois 1994).

Here, I examine how mortality varies as a function of larval quality in an amphidromous fish (Galaxias maculatus) during a migratory phase in its life cycle. Adult G. maculatus are primarily semelparous (McDowall 1968, but see Stevens et al 2016). Across a population, however, spawning occurs over a period of several months. Larvae spend 36 months developing in the open ocean before migrating (as metamorphosed juveniles) to freshwater streams, where they develop for a further six months before spawning (McDowall 1990). In New Zealand, upstream migration occurs year round, however migration peaks from August to November (McDowall et al. 1994). Environmental conditions (e.g. temperature, food availability) vary over the recruitment period, setting up an expectation for temporal variation in the quality of incoming recruits. I build on my results from chapter 2 by exploring the relationship between phenotypic 'quality' and mortality rates. Specifically, I used the same samples of fish from the methodology in chapter 2 and used otolith based reconstructions of fish life histories to derive a measure of larval quality. I quantified the mortality rates experienced by each daily cohort, and investigated whether these two traits were interrelated. As larval fish are susceptible to both starvation and predators, I hypothesised that the relationship between mortality and larval quality would follow either the linear, food-limited trend, or the dome-shaped, predation-limited trend. 


\subsection{Methods}

\subsubsection{Fish collections}

Briefly, I sampled incoming G. maculatus recruits from two rivers in the Wellington area. Sampling was conducted so that fish were collected across the main recruitment season (August to November). For a full description of juvenile sampling, see chapter 2.

\subsubsection{Characterising larval quality}

Following the general approach of Shima and Swearer (2009), I used the daily otolith increments to estimate four variables that describe the phenotypic 'quality' of incoming G. maculatus recruits: (1) "Pelagic larval duration" (PLD) is an estimate of the time the individual has spent developing as a larvae, and was estimated as the number of daily rings. (2) "Average growth rate" is a measure of the average amount of somatic growth an individual experienced on a given day, and was estimated as the average distance between successive daily rings. (3) "Early growth rate" was estimated as the average distance between the first 20 daily rings. (4) "Late growth rate" was estimated as the average distance between the last 20 daily rings.

I centered and scaled the four variables (mean $=0, \mathrm{SD}=1$ ) and performed a principal components analysis, using the 'prcomp' function in RStudio v0.99.903 (RStudio Team 2015) , to derive a composite metric of 'larval quality' score (i.e., first principal component). 


\subsubsection{Estimating mortality rates}

To estimate mortality rates I used the Chapman-Robson approach to catch-curve analysis (Chapman and Robson 1960, Robson and Chapman 1961). Catch curve analysis is used to estimate mortality by measuring the decline of the number of individuals in the age classes of a cohort (Pauly 1990). Traditional catch-curve analysis (Ricker 1975) would fit a linear regression to the descending limb of an age-frequency curve, under the assumption that the ascending limb of the curve contains fish too young to recruit to the fishery or gear. The Chapman-Robson method instead treats the descending limb of the curve as following a geometric probability distribution, and computes a maximum likelihood estimator for annual survival (Chapman and Robson 1960, Robson and Chapman 1961). Instantaneous mortality rates (Z) can then be computed using $\mathrm{Z}=-\log$ (annual mortality), however these estimates have be shown to be slightly biased, so I instead used the correction offered by Hoeing et al (1983). The Chapman-Robson approach was chosen over more traditional methods due to the findings of Dunn et al (2002) and Smith et al (2012) who showed that this method is the most precise, and produces the least variance. All calculation of $\mathrm{Z}$ scores was done with the 'FSA' package (Ogle 2016) in RStudio v0.99.903 (RStudio Team 2015).

\subsubsection{Evaluating the relationship between mortality and quality}

For this analysis, I assumed that samples collected on different days were independent of one another (i.e. I did not model the temporal structure of my sampling design; c.f. Chapter 2). For each sample day at each site I computed average larval quality and instantaneous mortality rate (i.e., estimated for fish collected from a given site on the same day). Because preliminary analysis (loess regression) indicated a linear relationship between instantaneous mortality and larval quality, I used a linear model for my formal analysis. Specifically, I used an ANCOVA model to evaluate the 
relationship between instantaneous mortality (the response variable) and larval quality (the covariate), and whether the intercept and/or the slope of this relationship varied between sites.

\subsection{Results}

The first principal component accounted for $54 \%$ of the variation in the larval quality variables. PLD loaded positively on PC1, while the three growth variables all loaded negatively. Fish with higher PC1 scores therefore had long PLDs with slow growth. Since a low PC1 score would indicate a fish of higher 'quality' (i.e., faster growth and development time), I multiplied all PC1 scores by -1 for purposes of presentation (i.e. so that the re-expressed PC1 scores scale more intuitively with traits often associated with 'larval quality'.

\subsubsection{Relationship between mortality and larval quality}

The relationship between instantaneous mortality rate and average larval quality was consistent across sites (interaction term: $F_{1,17}=1.3262, p=0.2654$ ). Therefore $\mathrm{I}$ evaluated a reduced model using only main effects of larval quality and site. Instantaneous mortality rates did differ between sites $\left(F_{1,18}=0.0891, p=0.7688\right)$, and there was no significant relationship between instantaneous mortality rates and larval quality $\left(\mathrm{F}_{1,18}=3.2712, \mathrm{p}=0.0872\right)$. Although the model was not significant, there does appear to be a trend towards higher quality fish experiencing lower mortality (Figure 3-1). The power of the model was very low (0.2751) based off detecting a 'medium' effect size, so non-significance may be attributable to insufficient sample size. Power analysis indicated that a sample of $\sim 60$ would give the model a more reasonable power of 0.8 . 


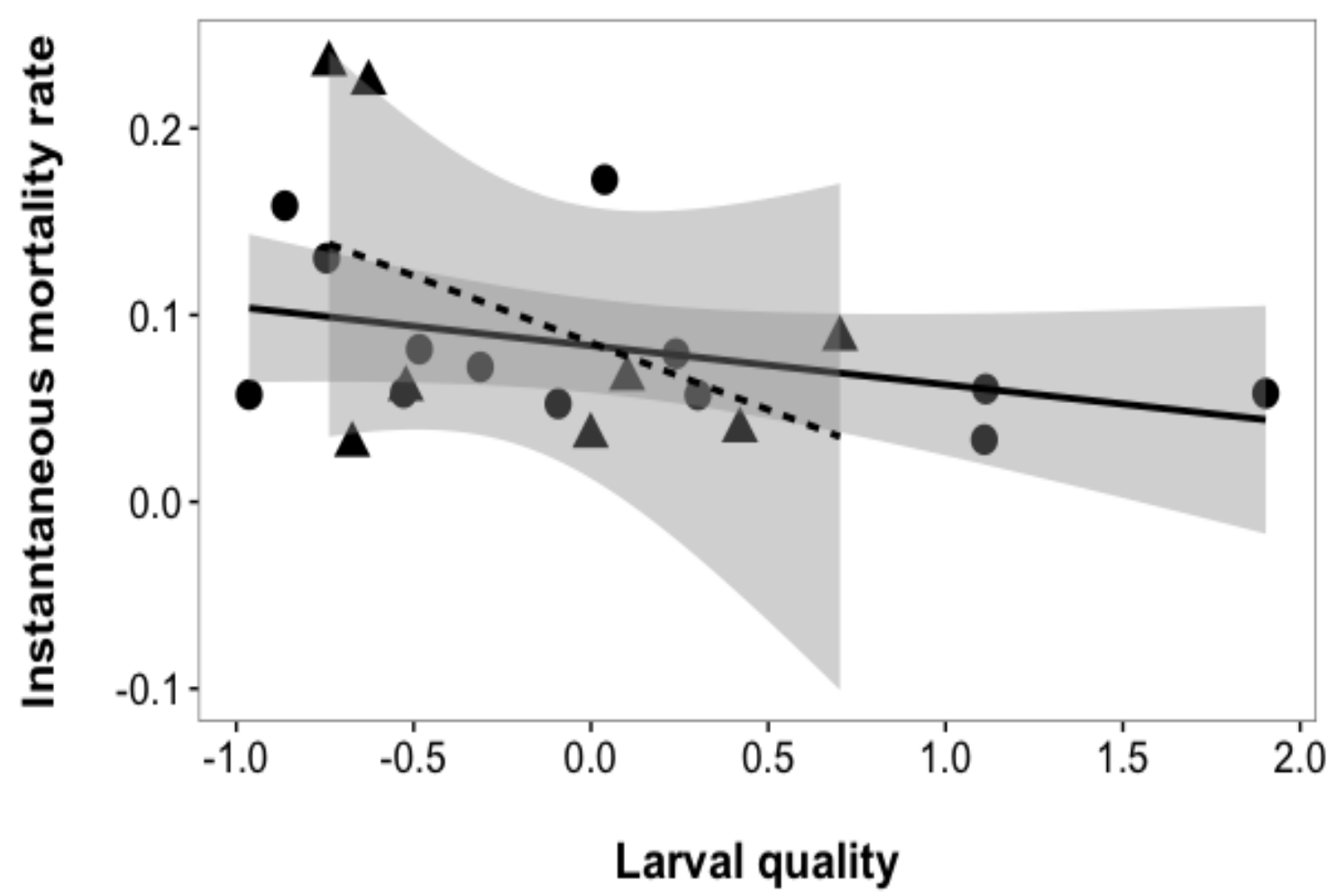

Figure 3-1 Relationship between instantaneous mortality rate (Z score) and average larval quality (PC1) for each daily cohort of G. maculatus from two sites: circle/solid line = Hutt River, triangle $/$ dashed line = Wainuiomata River. Shaded lines represent the 95\% confidence interval around the regression lines.

\subsection{Discussion}

Few studies have addressed threats during the marine phase of the G. maculatus life cycle (Barriga et al. 2007, Jellyman and McIntosh 2008). Fish undertaking dispersal in the open ocean can be subject to environmental factors, such as temperature (Pepin 1991) and food (Einum 2003) fluctuations, that may cause changes in growth rate. Understanding changes in growth, and how it relates to mortality rates, may provide information on factors that constrain fish populations during dispersal. Growthmortality relationships are often non-linear (e.g. U-shaped), where highest mortality is experienced by the fastest and slowest growers (Anderson 1988, Staudinger and Juanes 
2010), or negatively linear, where highest mortality is experienced by the slowest growers (Leggett and Deblois 1994). However, my results did not appear to follow either of these trends.

Phenotype is at least partially influenced by environment (Meekan et al. 2003, Sponaugle et al. 2006), and cohorts of G. maculatus with varying dispersal pathways may show evidence of this through their phenotype. My previous chapter demonstrated site specific differences in growth rates, yet here site was unrelated to differences in mortality rates. These results suggest that mortality is not a function of dispersal pathway (assuming different phenotypes from Chapter 2 would result in different mortality rates), and is experienced consistently across spatial scales. While environmental variation may be strong enough to significantly differentiate phenotypes between spatially separated cohorts, it may not cause differing levels of mortality in larval G. maculatus. While G. maculatus are known to have high levels of phenotypic plasticity (Barriga et al. 2002), it appears that factors governing mortality are either unrelated to phenotype, or they are shared, both in direction and magnitude, producing similar larval quality distributions.

Instantaneous mortality rate also appeared to be unrelated with larval quality. My results did show a weak negative trend, which would be a characteristic of food limitation, however this trend was non-significant. The model used to evaluate this relationship had very low power $(0.2751)$, which may have constrained its ability to detect a significant relationship, however my results seem to suggest that a factor other than food or predators is causing mortality in cohorts of $G$. maculatus. While starvation and predation are some of the strongest forces affecting larval survival (Leggett and Deblois 1994), it is important to consider that there are multiple sources of mortality that affect larvae (Pineda et al. 2009). Specifically, catch-curve analyses do not consider mortality due to advection, and transport away from suitable settlement habitat (White et al. 2014). Therefore, an alternative interpretation is that my mortality estimates have assumed the mortality of recruits that are still alive, but were transported away from my study areas and settled elsewhere. Thus, they are presumed dead by the catch-curve 
model (due to not being sampled). Therefore, while the study of larval transport and retention is important in understanding phenotypic patterns (c.f. Chapter 2), it may also be important in understanding mortality patterns.

An alternative explanation for my results is that my sampling may reflect a population that has already experienced extensive selective mortality. Sampled fish may only represent the survivors, and therefore my sampling may have not captured the 'larval quality' scores of fish that experienced strong mortality pressures. Therefore, the relationship between quality and mortality may have originally followed a more typical U-shaped relationship (Anderson 1988) but, post-mortality, only the centre of this spectrum remains (or some segment of this pattern). As the more extreme edges of the growth-mortality curve may not be able to be detected, the non-linear relationship becomes masked to this analysis. Overcoming this limitation in future studies may be difficult, and require extensive sampling of larval G. maculatus during their marine dispersal phase.

This lack of mortality due to abiotic factors ties in further with my results from Chapter 2. While not explicitly evaluated in this chapter, fish from the Hutt River appears to have a wider range of larval quality scores, but a smaller range of mortality rates, than fish from the Wainuiomata River (Figure 3-1). These are similar results to Chapter 2, where I found strong spatial differences in phenotypes between each river. Similarly to Chapter 2, this result could indicate a more heterogeneous rearing environment (i.e., environmental experience hypothesis), which allows a greater scope for extreme phenotypes to persist. Wellington Harbour may act as a 'nursery' ground, where environmental heterogeneity drives phenotypic differentiation, but also provides more refuge from lethal effects (i.e., as seen in the lower variability in mortality rate, Figure 3-1).

Estimates of instantaneous mortality rates based upon catch-curve analyses depend upon several important assumptions (Ricker 1975). Specifically, it assumes that the 
population being tested is closed, with no immigration or emigration, and that all age classes are equally recruited to the fishing gear. Populations of $G$. maculatus are generally considered to be demographically open (Waters et al. 2000), due to their significant dispersal capabilities, however, other studies have used this technique on open populations (Sandström and Thoresson 1988, Irvine et al. 2007, Windsland 2014). The assumption of a closed population is assuming a study system with a standing stock of individuals, of which recruits are added to through time (Ricker 1975). G. maculatus typically die at one year of age, and so my sampling does not reflect mortality in a standing stock, rather, it is only considering these new recruits. In essence, this analysis is based around a daily stock recruitment model, rather than an annual one. Furthermore, Ricker's initial methodology was based around using fish that were grouped into year classes rather than day classes, and most subsequent applications of the method have used year class fish (Hoffnagle and Timmons 1989, Restrepo et al. 2007, Kell et al. 2013). However, the technique has been applied to day class fish (Essig and Cole 1986) and to G. maculatus specifically (Barriga et al. 2012). Due to the prevalence of this technique, and that I am only treating each daily cohort as a closed population, I believe that my results are robust enough to be interpreted with caution. While I do not claim they represent a 'true' measure of mortality, they are still useful to draw inference from.

This study has demonstrated that there appears to be little relationship with the quality of recruiting G. maculatus and their relative mortality rates. There did appear to be a trend towards lower rates of mortality when fish were higher quality, but this may require higher sample sizes and longitudinal sampling of a cohort to validate. These results suggest that understanding dispersal may be a critical factor in studies of mortality, and that sources of mortality may operate indiscriminately on phenotypically different populations. They also suggest that a 'phenotypically' superior G. maculatus individual may not experience lower mortality, and have therefore have implications for the carry-over effects that individuals may experience post-settlement. 


\section{Chapter 4 - ADULT GALAXIAS MACULATUS RECRUITMENT IS SHAPED BY JUVENILE GROWTH AND HATCH DATE}

\subsection{Introduction}

An individual's chance of surviving to successfully reproduce may be affected by a variety of factors. Fitness may be linked to size, condition, growth, and hatch date (Anderson 1988, Jakob et al. 1996, Jacob et al. 2009, Buston and Elith 2011) and therefore fish may experience selective mortality by any or all of these characteristics. Selection on phenotypes is widely recognised across ecosystems, but the mechanisms are often system- (Houde 1989, Kaemingk et al. 2013) and context-dependent (Cargnelli and Gross 1996, Garvey et al. 2002). Temporal variation in the biotic and abiotic factors of an environment can lead to selective pressures on larval fish that vary based on an individual's hatch date (Cargnelli and Gross 1996). Both hatch date (Lande and Arnold 1983, Kohler et al. 1993, Cargnelli and Gross 1996, Santucci Jr and Wahl 2003) and growth history (Leggett and Deblois 1994, Sogard 1997) have been linked to survivorship in fish. Selective pressures may act on both these traits to preferentially favour fish that have hatched at the 'right time' (Garvey et al. 2002), grew at an optimum rate (Crecco and Savoy 1985), or some combination of these two factors. If larval fish show high phenotypic plasticity, which may offer increased survivorship 
(Burgess and Marshall 2011, Burgess et al. 2012), then the combination of phenotypic plasticity and hatching over a broad temporal time scale may offer a population the best chance of successful recruitment.

A substantial body of evidence indicates that hatching at the 'right time' can positively influence an individual's developmental trajectory and future success. Early hatch dates may be beneficial due to increased developmental time (Divino and Tonn 2007), as older and larger fish often experience the highest survival to year one (Cargnelli and Gross 1996). Old and large fish may also be the first to spawn in a population, and also produce the largest eggs (Simpson 1959), which creates a feedback loop where the offspring of early spawners may be more likely to become early spawners in the next generation. Larger fish may also experience higher survivorship due to having excess fat reserves to exploit in periods of starvation (Bagenal 1971). However, while there may be ecological benefits to early hatching, potential benefits may simply be a function of hatching at the 'right time.' For example, variation in hatch date may lead to different cohorts of larvae experiencing different seasonal characteristics such as food availability or temperature differences (Cushing 1969, Kohler et al. 1993, Santucci Jr and Wahl 2003, Kaemingk et al. 2013). Specific hatch dates may increase fitness in early life stages, but subsequently decrease fitness in later stages (Langerhans et al. 2004, Bogner et al. 2016). This variation in fitness is often linked to hatch-dependent growth rate (Divino and Tonn 2007), where post-hatch experiences have subsequent effects on an individual's growth rate. Earlier hatch dates are often linked with sizedependent mortality as fish born earlier have more time to grow and are less likely to perish (Divino and Tonn 2007). This 'bigger-is-better' hypothesis works under the assumption that a larger fish is either too big for a predator to consume (i.e., gape limited) and/or has the swimming ability to evade capture (Hovenkamp 1992, Meekan and Fortier 1996). However, there is also evidence of slower growth being beneficial, as this can lead to higher levels of predator avoidance (Amara et al. 1994, Gleason and Bengtson 1996). Selection can operate on growth rates (Shima and Findlay 2002), and therefore ultimately determine survivorship (Rosenberg and Haugen 1982). 
In species with high variation in demographic rates, early life history can be an indicator of rearing environment (Svanback and Eklov 2002). Fish that have developed in warm, productive environments are more likely to be larger, have a faster growth rate, and have more energy reserves to dedicate to reproduction (Houde 1989). Therefore, early life history can be used to predict future success if we know that a certain set of traits will be beneficial for an individual at a later life stage (Houde 1997). By sampling a population repeatedly through time it is possible to identify changes in the distribution of phenotypes (Vigliola et al. 2007). In species with recruitment that occurs over a period of time, the range of recruiting phenotypes may vary through time, and therefore the survivors among these cohorts would possess traits necessary for future success (Cargnelli and Gross 1996).

The aim of this chapter is to understand how both hatch date and growth rate of juvenile fish independently shape adult populations. To address this question I sampled discrete populations of pre-settlement juveniles throughout the peak recruitment season (McDowall et al. 1994). I sampled the populations again six months later (postsettlement), after those cohorts of fish had reached maturity. As fish will likely experience different sources of mortality post-settlement and pre-settlement, I hypothesized that mortality would be selective with respect to hatch date and/or growth rate. Therefore, I expect to see reduced variation in these traits when the surviving adults are sampled. Given that fish entering the rivers early in the recruitment season have faster average growth rates (see chapter 2) that may confer increased fitness, I hypothesized that early hatched recruits would have increased chances of survival. Therefore, I expected fish that entered the river in August to comprise the majority of the adult population. 


\subsection{Methods}

\subsubsection{Fish collections}

I used otolith daily ring formations to characterize hatch dates and growth histories for two life stages of the amphidromous fish Galaxias maculatus. After hatching from eggs laid in riparian vegetation, larvae spend approximately 6 months developing in marine areas where they have opportunity to disperse (McDowall 1968). Fish will then migrate to, and settle in, freshwater streams where they will spend another six months developing into reproductively mature adults (McDowall 1968). I caught fish from each life stage at two rivers to test whether adult fish had similar growth histories and hatch dates to juvenile fish.

I sampled juveniles and adults from the Hutt River and the Wainuiomata River. Juveniles were sampled over a period of months, and details of this sampling are given in chapter 2. For analysis of growth rate I assigned sampled fish to specific 'cohorts' based upon their month of collection. Juvenile fish were not grouped into cohorts for analysis of hatch date.

I sampled these cohorts again approximately six months later, after the juveniles had developed into adult fish and were ready to spawn. My sampling regime makes the assumption that I am sampling the same set of cohorts in each life history stage without any bias. It also assumes that G. maculatus lives for one year and is semelparous (but see Stevens et al. 2016). While recent evidence suggests that some individuals survive through to year 2 and display iteroparity, the aging of all samples would detect any year 2 fish, and therefore would not skew the results. I sampled adult G. maculatus from spawning grounds (i.e. riparian vegetation covering moist riverbanks, Benzie 1968a) and used two unbaited sock nets to catch adult fish. I only fished on days where the high tide was $\geq 1.8$ metres. The nets were set $2-3$ hours before the high tide, and were taken down approximately one hour after high tide. The total sample size was 50 adult fish. 
Twenty fish were caught from the Wainuiomata River on $19^{\text {th }}$ March 2016 . Thirty fish were caught from the Hutt River over 8 separate fishing days, spread from $25^{\text {th }}$ March to 5 June 2016.

\subsubsection{Otolith analyses}

Adult otoliths were prepared identically to the juvenile otolith preparation described in chapter 2. Briefly, age was estimated as the number of daily rings visible between the core and the edge of the otolith along the postrostral axis. The complete otolith growth history was characterised by measuring the distance between each successive ring along the postrostral axis. I used the age of each fish to back-calculate hatch dates of individuals. For analysis, I converted hatch dates to a numerical 'day of the year' (Julian date).

\subsubsection{Statistical analysis}

I hypothesised that the sample of adult fish would show a different hatch distribution to that of the juvenile fish sample due to selective mortality. I also hypothesised that the sample of adult fish would show a similar growth history to one or more of the monthly cohorts of juveniles sampled, likely favouring faster growth.

I tested each site separately for the null hypothesis that both adult and juvenile fish hatch dates were drawn from a common population using an Anderson-Darling test and a one-way ANOVA test. The Anderson-Darling test compares the shape of the hatch date distributions (Scholz and Stephens 1987) while the ANOVA compares the mean value of the distributions, under the assumption of a normal distribution. Significant differences in these tests would therefore suggest the adult population hatched at a different time to the juveniles. The Anderson-Darling test does not have its own unique distribution. Therefore, although a test statistic and an approximate p-value can be calculated, there is no way to calculate critical values or degrees of freedom (Anderson 
and Darling 1954). Results of the Anderson-Darling test and the ANOVA result are presented as density plots to account for the large difference in sample sizes between adults and juveniles.

I used a linear mixed-effects model to test whether cohorts of juvenile fish had different otolith growth curves to the adult fish cohort. I truncated all otolith growth data to a maximum of 180 days (the average juvenile age) to avoid any effect of post-settlement otolith growth from the adult fish. I modelled individual growth trajectories for each fish (juveniles and adults) by using size-at-age of the otolith as the response variable. Therefore, each fish had $n$ repeated measures where $n$ is equal to the age of the fish, up to a maximum of 180 days. I included a random slope and intercept for 'Fish ID' to (1) allow for the relationship between age and otolith growth to vary across individuals and (2) allow for correlation in daily rings within each individual. I used 'age' (in days) as the continuous variable to predict the size of the otolith. The model also included a cohort variable that accounted for four monthly juvenile groups (August, September, October, November) and one adult group of fish (5 levels total). The cohort variable was included as a fixed effect to test differences in growth histories between the adult fish and each monthly cohort of juvenile fish. I was not interested in comparing any of the juvenile cohort's otolith growth histories to each other: each juvenile cohort was only compared to the adult otolith growth history, as my hypothesis was based around which juvenile cohort(s) was similar to the adult population. This model calculated an overall slope for each level of cohort (based on the relationship between otolith size and age), which I interpreted as an estimate of otolith growth rate for each cohort. I used Wald t scores to compare the otolith growth estimate of each juvenile cohort to the otolith growth estimate of the adult cohort. Each site was modelled separately to facilitate these comparisons, and to account for potential site-specific patterns (see Chapter 2). All mixed models were run using 'Ime' from the 'nlme' package (Pinheiro et al. 2016) in RStudio v0.99.903 (RStudio Team 2015).

From the mixed model I obtained estimates of the otolith growth rate for each juvenile cohort. Wald t tests were calculated in the mixed model by setting one level of the 
categorical factor (the cohort variable) as a reference level. Adult fish were set as the reference level, and so all estimates of juvenile growth are calculated relative to the adult fish. Therefore any juvenile cohorts that had an equal growth rate to the adult cohort would have an estimate equal to zero.

\subsection{Results}

\subsubsection{Shifts in juvenile hatch dates}

Results of the Anderson-Darling test suggest that the distributions of hatch dates for adult and juvenile fish in the Hutt River did not come from a common distribution $(\mathrm{T}=$ $26.09, \mathrm{p}<0.0001)$. On average, juveniles had a hatchdate 47 days earlier than adult fish $\left(F_{1,339}=49.602, \mathrm{p}<0.0001\right.$, Figure 4-1). Adult and juvenile fish in the Wainuiomata River had hatchdates that were drawn from a common distribution $(\mathrm{T}=0.1761, \mathrm{p}=$ 0.2937). Adult and juvenile fish had hatchdates approximately 7 days apart, but this difference was not significant $\left(\mathrm{F}_{1,201}=0.88, \mathrm{p}=0.3493\right)$. A density plot represents the probability density function of a continuous random variable (in this case, day of the year). Therefore, it allows for easy visualisation of the two distribution curves, despite the difference in sample sizes. 


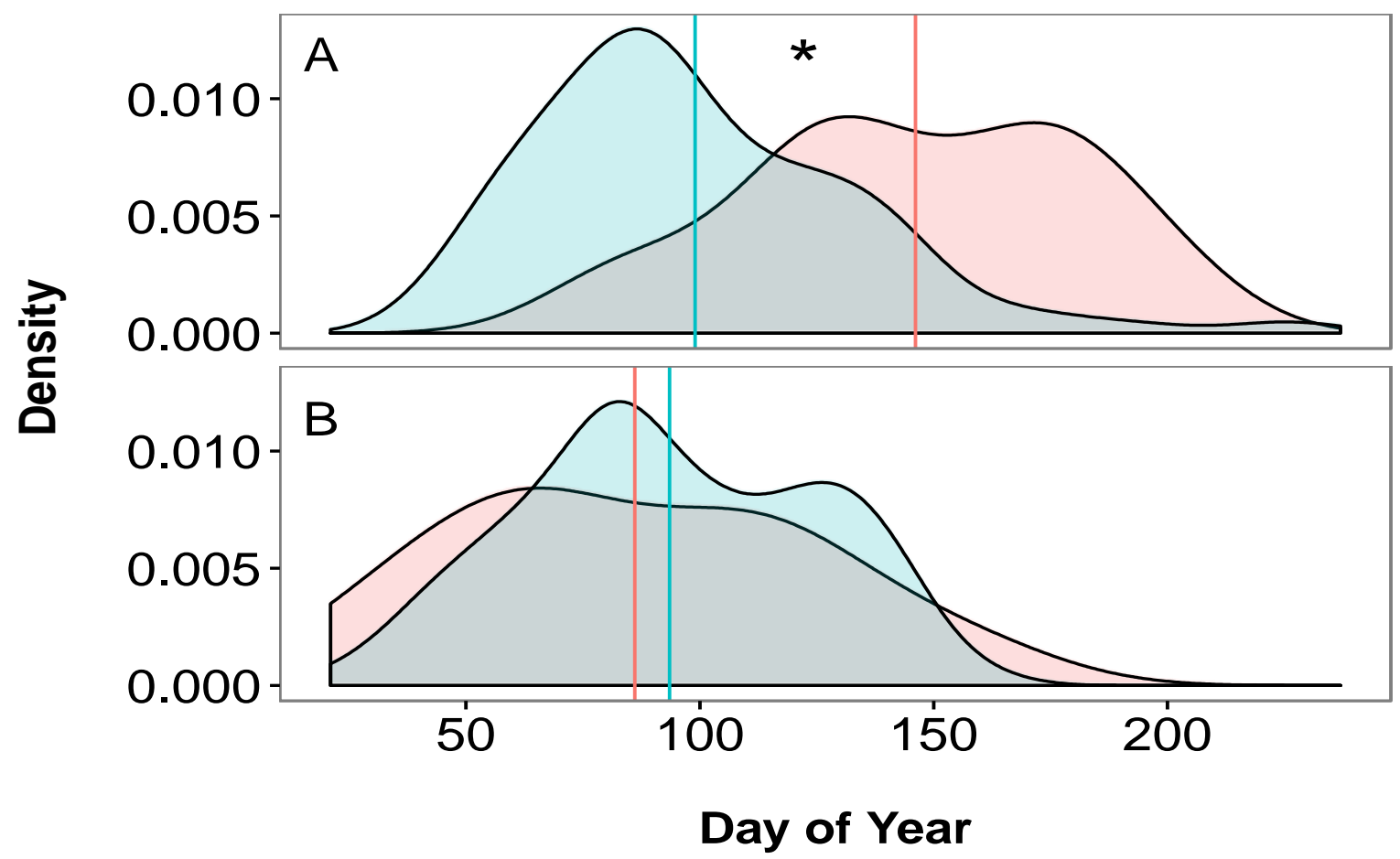

Figure 4-1 Comparisons of hatch date distributions (estimated from otolith-based reconstructions) for sampled adults (pink) and juveniles (blue) of G. maculatus. Panel (A): Hutt River. Panel (B): Wainuiomata River. Vertical line indicates mean hatch date for each group. Asterisk indicates dissimilar distributions and mean values based on the Anderson-Darling test and one-way ANOVA.

\subsubsection{Shifts in juvenile growth histories}

Growth histories of fish sampled from the Hutt River differed significantly among sampled dates (i.e., among cohorts and/or between juvenile and adult age classes; $\mathrm{F}_{4,339}$ $=13.091, \mathrm{p}<0.0001)$, indicating that different groups of fish had different otolith growth curves. The parameter estimates of the model showed that the otolith growth histories of fish caught in August, September and October all had significantly faster otolith growth rates relative to the adult fish (Aug: $\mathrm{T}_{339}=5.1774$, $\mathrm{p}<0.0001 ;$ Sep: $\mathrm{T}_{339}$ $=4.7295, \mathrm{p}<0.0001 ;$ Nov: $\mathrm{T}_{339}=2.2944, \mathrm{p}=0.0224$, Figure 4-2A). Fish caught in November did not show a significantly different otolith growth curve to the adult fish $\left(\mathrm{T}_{339}=0.2103, \mathrm{p}=0.8336\right.$, Figure 4-2A $)$. 
Growth histories of fish sampled from the Wainuiomata River also varied significantly among sampled dates $\left(\mathrm{F}_{3,198}=5.636, \mathrm{p}=0.001\right)$. Parameter estimates of the model showed that the otolith growth histories of fish from August and September were significantly different to the adult fish (Aug: $\mathrm{T}_{198}=2.3467, \mathrm{p}=0.0199$; Sep: $\mathrm{T}_{198}=$ $2.2317, \mathrm{p}=0.0268$, Figure 4-2B). Fish caught in October did not show significantly different otolith growth histories to the adult fish $\left(\mathrm{T}_{198}=0.1748, \mathrm{p}=0.8614\right.$, Figure 4-2B).

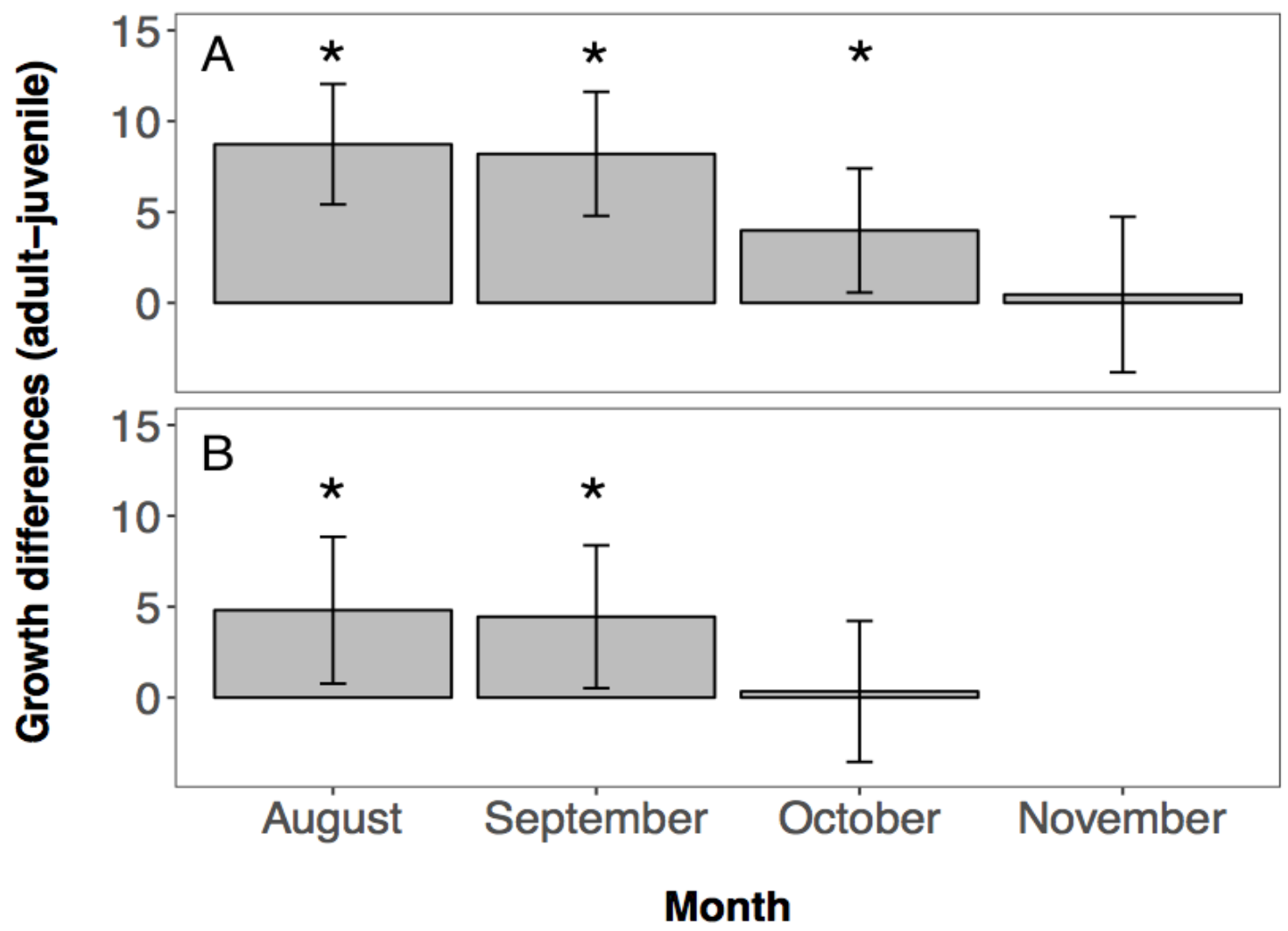

Figure 4-2 Estimates of otolith growth for each juvenile cohort from (A) the Hutt River, and (B) the Wainuiomata River $\pm 95 \%$ CI. Model calculates juvenile growth estimates relative to the adult growth estimates. Therefore any estimate that is approximately zero represents a juvenile otolith growth that is equal to the adult otolith growth. Values above zero reflect faster juvenile growth compared to adult survivor growth. Asterisks represent otolith growth estimates significantly different from zero. No fishing was conducted in the Wainuiomata River in November due to river mouth closure. 


\subsection{Discussion}

The main purpose of this chapter was to understand how hatch date and growth history collectively shape survival in post-settlement fish. Similarly to results from Chapter 2, each site exhibited different patterns. In the Hutt River, hatch date distributions differed strongly between adult fish and juvenile fish. However, in the Wainuiomata River, there was no difference in hatch date distribution between life stages. Adult populations from both rivers had relatively slow growth compared to the juvenile fish. This slower growth also correlated with the growth rate of juvenile fish entering the river in November (in the Hutt River) and October (in the Wainuiomata River).

Shifts in hatch date distributions differed between each site. The interpretation of this result is constrained by the mismatch in sampling of adult $G$. maculatus between the two study sites, and the overall limited sampling of adult fish. However, if the samples are an accurate reflection of hatch date distributions, then the spatial differences observed here could potentially be attributed either to different post-settlement processes operating in each river, or it may be a function of different phenotypic mixtures of juvenile fish entering each river. Chapters 2 and 3 indicated that there were considerable differences in the phenotypes of juvenile fish between each site. Therefore, the input of phenotypically distinct cohorts into each river may be responsible for the observed difference in adult composition. Fish entering the Wainuiomata River were more phenotypically homogenous, whereas fish entering the Hutt River were more phenotypically heterogeneous (based on Chapter 2 results). If the Hutt River has a more phenotypically diverse population of G. maculatus, then fitness linked traits like hatch date and growth rate may have larger population level effects, relative to a more homogenous population (McCauley et al. 1993). Juvenile fish entering the Hutt River may have spent time in different environments and/or were from different natal sources. This environmental heterogeneity may drive differences in growth rate, which in turn 
affected their freshwater survival (Shima and Swearer 2010). Therefore, post-settlement processes in each river may actually be identical, but they produce different results in each river as they are acting on the phenotypes of the G. maculatus population. This may have interesting implications for my results from Chapter 3, as there I suggested that mortality patterns were indiscriminate to phenotype. Correlations between fitness and phenotypic traits may vary depending on G. maculatus life stage, and therefore early life experiences may have considerable flow on effects to later life stages (Meekan et al. 2010)

Fish from both rivers showed similar (but not identical) shifts in growth rate distributions. My results suggest that adult fish had comparatively slow otolith growth rates in their early life history. Again, interpretation of these results is constrained by the limited adult sampling. Shifts in the phenotypic distributions between juveniles and adults may simply be the result of sample bias. However, if they are an accurate reflection of traits at each life stage, then there are several possibilities for these patterns. In many systems, growth rate may be linked to fitness, and fish often experience selective mortality on life history traits after settlement (Vigliola and Meekan 2002, Raventós and Macpherson 2005, Vigliola et al. 2007, Shima and Swearer 2010). Predation has been shown to be an important source of post-settlement mortality in other systems (Shulman 1985, Hixon 1991, Connell 1996, Webster 2002), and is known to be a strong factor in structuring freshwater fish communities (Goodgame and Miranda 1993, Kohler et al. 1993, Jackson et al. 2001, Santucci Jr and Wahl 2003), particularly when the predators are introduced species (Li and Moyle 1981). G. maculatus are preyed on by introduced trout (Crowl et al. 1992, Glova 2003, Bonnett and McIntosh 2004, Vigliano et al. 2009), and this predation may be selective towards certain life history traits (Werner and Hall 1974, Hambright 1991, Green and Côté 2014). Therefore, a potential explanation for the shift in adult phenotypes towards slower growth rates may be that selective mortality is operating on post-settlement $G$. maculatus. 
Adult fish in the Hutt River had significantly different hatch dates to the juvenile fish hatch dates. A considerable body of literature has indicated that hatch date can influence survival, with evidence that either early (Confer and Cooley 1977, Houde 1989, Schupp 1990, Cargnelli and Gross 1996), or late hatching (Garvey et al. 2002, Santucci Jr and Wahl 2003, Kaemingk et al. 2013) can benefit survival. However, my results indicate that an early vs late dichotomy may not be representative for this species. Instead, fitness may be dependent upon hatching at an 'optimal' time that maximizes exposure to the best environmental conditions, affording suitable growth rates for the next life stage and environments. Hatching at the 'wrong' time may result in larvae having lower food availability (Cargnelli and Gross 1996), or experiencing less favourable environmental conditions (Kramer and Smith Jr 1962, Mooij et al. 1994). These conditions may influence phenotypic variation (i.e. alter growth rates), which may set them up better for future success (Shima and Swearer 2010). Therefore, hatch date may not directly influence freshwater survival, but it could expose fish to a range of time- (or seasonally-) dependent conditions during their marine dispersal phase.

While there is evidence that slow growth can be detrimental to young fish (Crecco and Savoy 1985, Post and Prankevicius 1987, Danylchuk and Tonn 2001, Vigliola et al. 2007), most of the support for the 'bigger-is-better' hypothesis comes from systems where predators become gape-limited (Perez and Munch 2010). In systems where prey never outgrow the gape of predators, fast growth may prove to be detrimental (Litvak and Leggett 1992, Bertram and Leggett 1994). Larger fish are more likely to be encountered, and attacked by predators (Fuiman 1989, Litvak and Leggett 1992), whereas smaller fish can be more inconspicuous. Larger fish are also known to feed in food rich microhabitats, which often increases susceptibility and vulnerability to predators (Biro et al. 2006). Cushing (1990) suggested that the best survival came from fish that could spend the least amount of time at a vulnerable size (i.e., the stageduration hypothesis). However, it is unlikely that G. maculatus ever reach a size where they are not vulnerable to predation (Glova 2003), and therefore, remaining small and inconspicuous may offer them the best chances for survival. 
All fish that were older than 180 days had their growth profiles truncated so that 180 was the maximum age observed. Otolith growth can decouple from somatic growth post settlement (Hoey and McCormick 2004) and I did not want this post-settlement growth to be considered by the mixed effects model. 180 days was chosen as it was the approximate age of the average juvenile fish, and therefore I considered it a good approximation of the adult fish age at settlement. However, this approach makes the assumption that the adult fish are part of the same cohort as the juvenile fish, and indeed that using an 'average age' is a good way to estimate their pre-settlement growth. The missing link to this puzzle lies in the adult fish age-at-settlement. A 'settlement mark' has been validated for G. maculatus (Hale and Swearer 2008), however I was unable to locate a settlement mark in any of the adult otoliths, and thus I was unable to estimate age-at-settlement. In reality, adult survivors may be settling at a very different age to the recruiting juvenile fish population and this 'age effect' may be the factor driving survivorship for certain individuals. As this data simply isn't known, I believe that using an 'average age' is an acceptable method for analysis of growth histories. Future studies could use more sophisticated techniques (i.e. LA-ICPMS, as per Hale and Swearer 2008) to consistently identify this settlement mark and confirm whether adult fish are settling at similar ages.

Although the evidence presented in this chapter is circumstantial, it has generated a novel hypothesis for the role of growth rate on individual success in G. maculatus. Growth rate appears to be important in freshwater populations of G. maculatus, however, results from Chapter 3 indicated that growth may not be tightly linked with fitness in marine populations. This has implications for our understanding of the ecology of G. maculatus, and suggests that fitness linked traits may change with ontogeny. Hatch date may also have strong influences, as larval rearing environment will likely shape juvenile growth rates. Future directions should use experimental approaches to investigate predator-induced selective mortality on G. maculatus (i.e. through mesocosm approaches, Parker 1971), and unravel the role of growth rate in both marine and freshwater populations. 


\section{Chapter 5 - DisCUSSION}

\subsection{Summary}

The aim of this thesis was to investigate how recruitment of the amphidromous fish Galaxias maculatus varied across both spatial and temporal scales, and the demographic consequences of this variation. New Zealand has been a place of extensive research on G. maculatus, and Galaxiids in general (Benzie 1968a, McDowall 1969, McDowall 1972, McDowall et al. 1994, Hickford et al. 2010, Hickford and Schiel 2013). Four of the five native Galaxiid species are currently threatened, and this fishery is recognised as being socially, culturally, and economically important to New Zealand (McDowall 1968, McDowall 1984, Rowe et al. 1999). Therefore, studies pertaining to recruitment dynamics of native Galaxiid fish are important for understanding how conservation and management plans can be structured for the long term preservation of these species.

This thesis concluded that 1) significant phenotypic variation can arise in populations that recruit in close spatial $(20 \mathrm{~km}$ ) and temporal (one day) proximity, 2) that mortality rates are, at best, weakly related to larval quality, and 3) that adult freshwater populations of G. maculatus may be partially shaped by growth rates experienced at sea, 
and hatch dates. My results have revealed the importance of considering subtle (and putatively minor) spatial and temporal differences in the context of recruitment patterns, and ignoring these differences could lead to poor interpretations and decisions. In addition, this work shows further support for the idea that early life history can influence and predict measures of adult survival. This thesis raises new questions, primarily around the potential of local retention in harbour systems, the extent to which recruitment can vary over seemingly small and insignificant spatial and temporal scales, and of optimal growth strategies in the post-settlement phase.

\subsection{Landscape features and dispersal potential}

Considerable research effort on G. maculatus has focussed on determining the extent of natal homing (Barker and Lambert 1988, Waters et al. 2000, Hickford and Schiel 2016), with recent genetic and otolith studies suggesting that $G$. maculatus shows very little homing. Mitochondrial DNA results from Waters et al (2000) suggests that $G$. maculatus show very little population structure, due to the extent of gene flow during marine dispersal. Similarly, otolith microchemistry results from Hickford and Schiel (2016) suggest that less than three percent of individuals return to their natal stream. However, there is also evidence that G. maculatus larvae hatched on the east coast of New Zealand will typically return to east coast rivers, and vice versa (Hickford and Schiel 2016). Therefore, it seems unlikely that G. maculatus larvae will regularly cross from the east to west coasts of New Zealand, and there may be physical barriers (i.e. water currents) that prevent this level of dispersal (Chiswell and Rickard 2011).

Despite this apparent high level of larval mixing and low level of natal return, one hypothesis I have proposed to explain my results throughout this thesis is that the Hutt River shows an uncharacteristically high level of philopatry, primarily due to the physical retentive properties of the Wellington Harbour. There is extensive evidence that harbour systems can promote retention of larvae by virtue of circulating currents 
(Jessopp and McAllen 2007, Shima and Swearer 2009, Morgan et al. 2011), and Wellington Harbour specifically has been suggested to promote retention of fish larvae (Swearer and Shima 2010). Furthermore, Wellington Harbour may act as a 'nursery' ground, as it is nutrient rich, supports high standing stocks of plankton (Helson et al. 2007), and stays at optimal temperatures for G. maculatus growth (Maxwell 1956, Mitchell 1989, Richardson et al. 1994). Nursery habitats are known to retain and attract larvae (Caputi et al. 1996, Condie et al. 2011, Beldade et al. 2016), and larvae are less likely to disperse far when local conditions present a favourable and productive environment (Swearer et al. 1999). Theoretically, Wellington Harbour appears to show the characteristics of a retentive system, however this thesis has not been a study of local retention and natal homing. While I can speculate on the retentive properties of Wellington Harbour, this is a hypothesis that needs to be empirically validated, and I discuss experimental suggestions for this validation below.

\subsection{Variation in recruitment over spatial scales}

The hypothesis of retention in harbour systems is closely linked with my overall result that recruitment patterns vary over small spatial scales. The explanations I have suggested above (i.e., water currents affecting dispersal) may also play a strong role in driving the observed difference between the juvenile fish entering the Hutt River compared to the Wainuiomata River. The processes of recruitment are fundamentally influenced by the availability of larvae (Gaines et al. 1985, Victor 1986, Milicich et al. 1992), and spatial variability in recruitment will often arise from spatial differences in larval availability (Koslow et al. 1987, Mann 1993). Larvae may drift passively with strong currents (Williams et al. 1984, Cowen and Castro 1994, Weber et al. 2015), become aggregated into higher densities by internal waves (Kingsford and Choat 1986, Shanks and Wright 1987, Greer et al. 2014), or be locally retained by eddies (Mullaney and Suthers 2013, Beldade et al. 2016). Therefore, these strong site-specific recruitment patterns may be driven by different hydrodynamic processes acting on each river (Maxwell 1956, Bowman et al. 1983). This has implications for studies of G. maculatus 
recruitment, as it may prove difficult to make generalisations about recruitment patterns without careful review of geographic position and current influenced dispersal.

Spatial variation in phenotype patterns and larval retention can have strong ecological consequences. Sites that have low levels of retention may be considered demographically open, and become source populations for other areas in a metapopulation (Jones et al. 2009). This is a common pattern in amphidromous species due to their high dispersal capabilities (McDowall 2007, McDowall 2010), but may lead to externally regulated extinction balances. If a population does not self-recruit then it is susceptible to high rates of local extinction due to demographic stochasticity (Jones et al. 2009). However, other open populations can then balance this local extinction through demographic connectivity, and thus can show resilience over evolutionary time scales (Kritzer and Sale 2006, McDowall 2010). Conversely, having high levels of retention may lead to a population being demographically closed. Closed populations can be regulated by either density-independent or -dependent effects, which can have differing population consequences. Closed populations regulated by density-dependent processes show low susceptibility to local extinction and are able to persist through self recruitment, yet have no way to be re-established following extinction (Jones et al. 2009). Closed populations regulated by density-independent processes have no internal regulation (Hixon et al. 2002), and therefore are unlikely to recover following local extinction (Gonzalez et al. 1998, Hill et al. 2002). This metapopulation framework sets up an interesting dynamic with the closely situated harbour-coast system. Under the assumption that Wellington Harbour is a partially closed population, and Cook Strait is primarily an open population, then the persistence of the Wellington Harbour population may be dependent on how much input it has from other systems. If Wellington Harbour was to experience local extinction, then its recolonization may depend on closely situated open populations like the Wainuiomata River. 


\subsection{Effects of river mouth closure}

Migratory species can be classified as either obligate or facultative, depending on whether their migration is a necessary step in completing their life cycle (McDowall 1988, McDowall 1995). G. maculatus are generally considered to be obligate migrants (McDowall 1995), despite the presence of viable landlocked populations (Battini et al. 2000, Barriga et al. 2002, Barriga et al. 2007). These landlocked populations still undertake migrations, with newly hatched larvae moving from spawning locations in streams to the limnetic zone of lakes (Pollard 1971). This obligatory migration can make amphidromous populations of $G$. maculatus susceptible to the effects of river mouth closure. During November 2015 the Wainuiomata River mouth was closed by gravel build-up, and therefore juvenile G. maculatus were blocked from entering the river. It is unknown whether closure of the Wainuiomata River mouth is a common occurrence, but frequent closures may drive temporally variable patterns in recruitment. My results from Chapter 2 showed that growth rates decreased over the recruitment season, such that the Hutt River's slowest growing monthly cohort of fish came from November. In Chapter 4, I found that adult G. maculatus growth rates were overall very slow, and that they matched juvenile growth rates from October in the Wainuiomata River and November in the Hutt River. Chapter 4 also indicated that there may be an 'optimum' time to hatch, but this may not benefit freshwater survival if fish are unable to enter the river. This may lead to interesting metapopulation dynamics, where phenotypically 'superior' fish are unable to enter a freshwater habitat to settle. $G$. maculatus juveniles may be forced to undertake further dispersal to find a new river to enter. This may enhance demographic connectivity between rivers, but may also increase temporal fluctuations in recruitment, depending on the rivers susceptibility to closure (McDowall 1995). Therefore, no fish entering the Wainuiomata River in November may have affected patterns of adult recruitment, both in the Wainuiomata River and geographically proximate rivers 


\subsection{Future directions}

A central hypothesis I have proposed in this thesis is that Wellington Harbour promotes a higher retention of larval G. maculatus (that likely have hatched in the Hutt River) than would be expected in a coastally positioned system. Waters et al (2000) used the mitochondrial $\mathrm{CO} 1$ gene to conclude that there was no genetic population structure in New Zealand. However the small number of migrants required to overcome genetic differentiation may mask any evidence of short term isolation. Therefore, a result of no population structure may be an artefact of a small amount of mixing between harbour and coastal populations (Slatkin 1985). With this limitation, a more powerful approach may be to generate whole genome data in the form of SNPs (single nucleotide polymorphisms). Next generation techniques such as RAD sequencing (Baird et al. 2008) and Genotyping-by-Sequencing (Elshire et al. 2011) would provide the fine scale genetic data needed to detect whether harbour populations experience higher retention of larval G. maculatus than typical coast populations.

Results from Chapter 4 show that there was a correlation between juveniles that had experienced slow marine growth during early life stages, and the early life growth rate of adult fish. While there is support in the literature for slow growth rates enhancing fitness (Litvak and Leggett 1992), an experimental setup is required to elucidate that slower growth rates are indeed a dominant factor in the recruitment process for $G$. maculatus. Mesocosms have been successfully used to test selective mortality on phenotypic traits (Parker 1971, Hargreaves and LeBrasseur 1986, Caie 2016), and a similar approach may be appropriate here, where a mesocosm is constructed that contains juvenile G. maculatus and a natural predator (i.e., trout). A comparison of the otoliths of consumed fish (from predator guts) and unconsumed fish would facilitate conclusions about selective mortality on growth rates, and whether slow growth is an optimum strategy for post-settlement G. maculatus.

Chapters 2, 3, and 4 all made use of a dataset collected over a single year of sampling. Although I was able to describe both spatial and temporal patterns in my data, it is 
difficult to know whether these patterns are consistent over multiple years. Similar studies by McDowall (1994) and Barbee et al (2011) found results only weakly related to the age and growth data presented in this thesis, which suggests that these patterns might experience considerable annual fluctuations. Future studies should try to accommodate multi-year sampling of juvenile and adult G. maculatus in order to compare year-to-year phenotype distributions and shifts.

\subsection{Conclusions}

In summary, populations of fish are comprised of individuals with diverse early life histories and phenotypes. This diversity of life histories can have implications for survival in both pre- and post-settlement life stages, and is crucial for shaping the demographic rates of populations. This thesis contributes to the knowledge that early life history has carry over effects to future life stages, and recruitment is dependent on smaller spatial and temporal scales than previously thought. Therefore, context and life history should be understood when describing the ecology of any organism, especially those with stage structured life histories. 


\section{REFERENCES}

Agrawal, A. A. (2001). "Phenotypic plasticity in the interactions and evolution of species." Science 294(5541): 321-326.

Amara, R., Y. Desaunay and F. Lagardere (1994). "Seasonal variation in growth of larval sole Solea solea (L.) and consequences on the success of larval immigration." Netherlands Journal of Sea Research 32(3-4): 287-298.

Anderson, J. T. (1988). "A review of size dependent survival during pre-recruit stages of fishes in relation to recruitment." Journal of Northwest Atlantic Fishery Science 8: 55-66.

Anderson, T. W. and D. A. Darling (1954). "A test of goodness of fit." Journal of the American Statistical Association 49(268): 765-769.

Bagenal, T. (1971). "The interrelation of the size of fish eggs, the date of spawning and the production cycle." Journal of Fish Biology 3(2): 207-219.

Bailey, K. and E. Houde (1989). "Predation on eggs and larvae of marine fishes and the recruitment problem." Advances in marine biology 25: 1-83.

Bailey, K. M. (1994). "Predation on juvenile flatfish and recruitment variability." Netherlands Journal of Sea Research 32(2): 175-189. 
Baird, N. A., P. D. Etter, T. S. Atwood, M. C. Currey, A. L. Shiver, Z. A. Lewis, E. U. Selker, W. A. Cresko and E. A. Johnson (2008). "Rapid SNP discovery and genetic mapping using sequenced RAD markers." PLoS One 3(10): e3376.

Baker, M. B. and S. Rao (2004). "Incremental costs and benefits shape natal dispersal: theory and example with Hemilepistus reaumuri." Ecology 85(4): 1039-1051.

Baker, T. T. and L. S. Timmons (1991). "Precision of ages estimated from five bony structures of Arctic char (Salvelinus alpinus) from the Wood River System, Alaska." Canadian Journal of Fisheries and Aquatic Sciences 48(6): 1007-1014.

Barbee, N. C., R. Hale, J. R. Morrongiello, A. S. Hicks, D. Semmens, B. J. Downes and S. E. Swearer (2011). "Large-scale variation in life-history traits of the widespread diadromous fish, Galaxias maculatus, reflects geographic differences in local environmental conditions." Marine and Freshwater Research 62: 790-800.

Barker, J. R. and D. M. Lambert (1988). "A genetic analysis of populations of Galaxias maculatus from the Bay of Plenty: Implications for natal river return." New Zealand Journal of Marine and Freshwater Research 22(3): 321-326.

Barriga, J. P., M. A. Battini and V. E. Cussac (2007). "Annual dynamics variation of a landlocked Galaxias maculatus (Jenyns 1842) population in a Northern Patagonian river: occurrence of juvenile upstream migration." Journal of Applied Ichthyology 23(2): 128-135.

Barriga, J. P., M. A. Battini, M. García-Asorey, C. Carrea, P. J. Macchi and V. E. Cussac (2012). "Intraspecific variation in diet, growth, and morphology of landlocked Galaxias maculatus during its larval period: the role of food availability and predation risk." Hydrobiologia 679(1): 27-41.

Barriga, J. P., M. A. Battini, P. J. Macchi, D. Milano and V. E. Cussac (2002). "Spatial and temporal distribution of landlocked Galaxias maculatus and Galaxias platei (Pisces : Galaxiidae) in a lake in the South American Andes." New Zealand Journal of Marine and Freshwater Research 36(2): 345-359.

Bastrikin, D. K., A. Gallego, C. P. Millar, I. G. Priede and E. G. Jones (2014). "Settlement length and temporal settlement patterns of juvenile cod (Gadus morhua), haddock (Melanogrammus aeglefinus), and whiting (Merlangius merlangus) in a northern North Sea coastal nursery area." ICES Journal of Marine Science: Journal du Conseil 71(8): 2101-2113. 
Battini, M., V. Rocco, M. Lozada, B. Tartarotti and H. Zagarese (2000). "Effects of ultraviolet radiation on the eggs of landlocked Galaxias maculatus (Galaxiidae, Pisces) in northwestern Patagonia." Freshwater Biology 44(3): 547-552.

Baumann, H. and M. Gagliano (2011). "Changing otolith/fish size ratios during settlement in two tropical damselfishes." Helgoland Marine Research 65(3): 425.

Baumann, H., M. A. Peck and J.-P. Herrmann (2005). "Short-term decoupling of otolith and somatic growth induced by food level changes in postlarval Baltic sprat, Sprattus sprattus." Marine and Freshwater Research 56(5): 539-547.

Beldade, R., S. J. Holbrook, R. J. Schmitt, S. Planes and G. Bernardi (2016). "Spatial patterns of self - recruitment of a coral reef fish in relation to island - scale retention mechanisms." Molecular Ecology 25(20): 5203-5211.

Benzie, V. (1968a). "Some ecological aspects of the spawning behaviour and early development of the common whitebait, Galaxias maculatus attenuatus (Jenyns)." Proceedings (New Zealand Ecological Society) 15: 31-39.

Bergenius, M. A., M. I. McCormick, M. G. Meekan and D. R. Robertson (2005). "Environmental influences on larval duration, growth and magnitude of settlement of a coral reef fish." Marine Biology 147(2): 291-300.

Berra, T. M., L. Crowley, W. Ivantsoff and P. A. Fuerst (1996). "Galaxias maculatus: an explanation of its biogeography." Marine and Freshwater Research 47(6): 845-849.

Bertram, D. and W. Leggett (1994). "Predation risk during the early life history periods of fishes: separating the effects of size and age." Marine Ecology Progress Series 109: 105-105.

Berven, K. A. (1990). "Factors affecting population fluctuations in larval and adult stages of the wood frog (Rana sylvatica)." Ecology 71(4): 1599-1608.

Biro, P. A., M. V. Abrahams, J. R. Post and E. A. Parkinson (2004). "Predators select against high growth rates and risk-taking behaviour in domestic trout populations." Proceedings of the Royal Society of London B: Biological Sciences 271(1554): 22332237. 
Biro, P. A., M. V. Abrahams, J. R. Post and E. A. Parkinson (2006). "Behavioural trade - offs between growth and mortality explain evolution of submaximal growth rates." Journal of Animal Ecology 75(5): 1165-1171.

Bjørnstad, O. N., J.-M. Fromentin, N. C. Stenseth and J. Gjøsæter (1999). "Cycles and trends in cod populations." Proceedings of the National Academy of Sciences 96(9): 5066-5071.

Bogner, D. M., M. A. Kaemingk and M. R. Wuellner (2016). "Consequences of Hatch Phenology on Stages of Fish Recruitment." PLoS One 11(10): e0164980.

Bolger, T. and P. Connolly (1989). "The selection of suitable indices for the measurement and analysis of fish condition." Journal of Fish Biology 34(2): 171-182.

Bonnett, M. L. and A. R. McIntosh (2004). "The influence of juvenile brown trout (Salmo trutta) on habitat use of inanga (Galaxias maculatus) in a stream simulator." Journal of the Royal Society of New Zealand 34(4): 357-367.

Bowman, M., A. Kibblewhite, R. Murtagh, S. Chiswell and B. Sanderson (1983). "Circulation and mixing in greater Cook Strait, New Zealand." Oceanologica acta 6(4): 383-391.

Brown, C. A. and S. H. Gruber (1988). "Age assessment of the lemon shark, Negaprion brevirostris, using tetracycline validated vertebral centra." Copeia: 747-753.

Buijse, A. D. and R. P. Houthuijzen (1992). "Piscivory, growth, and size-selective mortality of age 0 pikeperch (Stizostedion lucioperca)." Canadian Journal of Fisheries and Aquatic Sciences 49(5): 894-902.

Bunt, J. S. (1975). Primary productivity of marine ecosystems. Primary productivity of the biosphere, Springer: 169-183.

Burgess, S. C. and D. J. Marshall (2011). "Are numbers enough? Colonizer phenotype and abundance interact to affect population dynamics." Journal of Animal Ecology 80(3): 681-687.

Burgess, S. C., E. A. Treml and D. J. Marshall (2012). "How do dispersal costs and habitat selection influence realized population connectivity?" Ecology 93(6): 13781387. 
Buston, P. M. and J. Elith (2011). "Determinants of reproductive success in dominant pairs of clownfish: a boosted regression tree analysis." Journal of Animal Ecology 80(3): 528-538.

Caie, P. (2016). Selective mortality on early life-history traits of a temperate reef fish (unpublished MSc thesis). Wellington, New Zealand, Victoria University of Wellington.

Caley, M., M. Carr, M. Hixon, T. Hughes, G. Jones and B. Menge (1996). "Recruitment and the local dynamics of open marine populations." Annual Review of Ecology and Systematics: 477-500.

Campana, S. E. and J. D. Neilson (1985). "Microstructure of fish otoliths." Canadian Journal of Fisheries and Aquatic Sciences 42(5): 1014-1032.

Cappo, M., P. Eden, S. J. Newman and S. Robertson (2000). "A new approach to validation of periodicity and timing of opaque zone formation in the otoliths of eleven species of Lutjanus from the central Great Barrier Reef." Fishery Bulletin 98(3): 474474.

Caputi, N., W. Fletcher, A. Pearce and C. Chubb (1996). "Effect of the Leeuwin Current on the recruitment of fish and invertebrates along the Western Australian coast." Marine and Freshwater Research 47(2): 147-155.

Cargnelli, L. M. and M. R. Gross (1996). "The temporal dimension in fish recruitment: birth date, body size, and size-dependent survival in a sunfish (bluegill: Lepomis macrochirus)." Canadian Journal of Fisheries and Aquatic Sciences 53(2): 360-367.

Carrera, C., J. P. Barriga, V. E. Cussac and D. E. Ruzzante (2012). "Genetic and phenotypic differentitation among Galaxias maculatus populations in a Patagonian postglacial lake system." Biological Journal of the Linnean Society 107: 368-382.

Cass, A. J. and R. J. Beamish (1983). "First evidence of validity of the fin-ray method of age determination for marine fishes." North American Journal of Fisheries Management 3(2): 182-188.

Casselman, J. (1987). Determination of age and growth. The biology of fish growth. S. Gill. London, Academic Press: 209-242. 
Chambers, R. C. (1993). "Phenotypic variability in fish populations and its representation in individual-based models." Transactions of the American Fisheries Society 122(3): 404-414.

Chambers, R. C. and W. C. Leggett (1987). "Size and age at metamorphosis in marine fishes: an analysis of laboratory-reared Winter Flounder (Pseudopleutonectes americanus) with a review of variation in other species." Canadian Journal of Fisheries and Aquatic Sciences 44(11): 1936-1947.

Chambers, R. C. and E. Trippel (2012). Early life history and recruitment in fish populations, Springer Science \& Business Media.

Chapman, B. B., K. Hulthén, C. Brönmark, P. A. Nilsson, C. Skov, L. A. Hansson and J. Brodersen (2015). "Shape up or ship out: migratory behaviour predicts morphology across spatial scale in a freshwater fish." Journal of Animal Ecology 84: 1187-1193.

Chapman, D. and D. Robson (1960). "The analysis of a catch curve." Biometrics: 354368.

Chiswell, S. M. and G. J. Rickard (2011). "Larval connectivity of harbours via ocean currents: a New Zealand study." Continental Shelf Research 31(10): 1057-1074.

Condie, S., J. Mansbridge and M. Cahill (2011). "Contrasting local retention and crossshore transports of the East Australian Current and the Leeuwin Current and their relative influences on the life histories of small pelagic fishes." Deep Sea Research Part II: Topical Studies in Oceanography 58(5): 606-615.

Confer, J. and J. Cooley (1977). "Copepod instar survival and predation by zooplankton." Journal of the Fisheries Board of Canada 34(5): 703-706.

Connell, S. (1996). "Variations in mortality of a coral-reef fish: links with predator abundance." Marine Biology 126(2): 347-352.

Conover, D. O. and E. T. Schultz (1997). "Natural selection and the evolution of growth rate in the early life history: what are the trade-offs?" Fish and Fisheries Series 21: 305332. 
Cowan, J. H., E. D. Houde and K. A. Rose (1996). "Size-dependent vulnerability of marine fish larvae to predation: an individual-based numerical experiment." ICES Journal of Marine Science: Journal du Conseil 53(1): 23-37.

Cowen, R. K. (2002). Larval dispersal and retention and consequences for population connectivity. Coral reef fishes: New insights into their ecology. P. F. Sale. London, Academic Press: 149-170.

Cowen, R. K. and L. R. Castro (1994). "Relation of coral reef fish larval distributions to island scale circulation around Barbados, West Indies." Bulletin of Marine Science 54(1): 228-244.

Cowen, R. K. and S. Sponaugle (2009). "Larval dispersal and marine population connectivity." Annual Review Marine Science 1: 443-446.

Crean, A. J., K. Monro and D. J. Marshall (2011). "Fitness consequences of larval traits persist across the metamorphic boundary." Evolution 65(11): 3079-3089.

Crecco, V. A. and T. F. Savoy (1985). "Effects of biotic and abiotic factors on growth and relative survival of young American shad, Alosa sapidissima, in the Connecticut River." Canadian Journal of Fisheries and Aquatic Sciences 42(10): 1640-1648.

Crowl, T. A., C. R. Townsend and A. R. McIntosh (1992). "The impact of introduced brown and rainbow trout on native fish: the case of Australasia." Reviews in Fish Biology and Fisheries 2(3): 217-241.

Cushing, D. (1969). "The regularity of the spawning season of some fishes." Journal du Conseil 33(1): 81-92.

Cushing, D. (1990). "Plankton production and year-class strength in fish populations: an update of the match/mismatch hypothesis." Advances in marine biology 26: 249-293.

Cushing, D. H. (1975). Marine ecology and fisheries, CUP Archive.

Cussac, V., S. Ortubay, G. Iglesias, D. Milano, M. E. Lattuca, J. P. Barriga, M. Battini and M. Gross (2004). "The distribution of South American galaxiid fishes: the role of biological traits and post-glacial history." Journal of Biogeography 31(1): 103-121. 
Cussac, V. E., P. M. Cervellini and M. Á. Battini (1992). "Intralacustrine movements of Galaxias maculatus (Galaxiidae) and Ondontesthes microlepidotus (Atherinidae) during their early life history." Environmental Biology of Fishes 35: 141-148.

Dahlberg, M. D. (1979). "A review of survival rates of fish eggs and larvae in relation to impact assessments." Marine Fisheries Review 41(3): 1-12.

Danylchuk, A. J. and W. M. Tonn (2001). "Effects of social structure on reproductive activity in male fathead minnows (Pimephales promelas)." Behavioral Ecology 12(4): 482-489.

Divino, J. and W. Tonn (2007). "Effects of reproductive timing and hatch date on fathead minnow recruitment." Ecology of Freshwater Fish 16(2): 165-176.

Dunn, A., R. Francis and I. Doonan (2002). "Comparison of the Chapman-Robson and regression estimators of $Z$ from catch-curve data when non-sampling stochastic error is present." Fisheries Research 59(1): 149-159.

Edeline, E. (2007). "Adaptive phenotypic plasticity of eel diadromy." Marine Ecology Progress Series 341: 229-232.

Einum, S. (2003). "Atlantic salmon growth in strongly food-limited environments: Effects of egg size and paternal phenotype?" Environmental Biology of Fishes 67(3): 263-268.

Elshire, R. J., J. C. Glaubitz, Q. Sun, J. A. Poland, K. Kawamoto, E. S. Buckler and S. E. Mitchell (2011). "A robust, simple genotyping-by-sequencing (GBS) approach for high diversity species." PLoS One 6(5): e19379.

Essig, R. J. and C. F. Cole (1986). "Methods of estimating larval fish mortality from daily increments in otoliths." Transactions of the American Fisheries Society 115(1): 34-40.

Fiksen, Ø., C. Jørgensen, T. Kristiansen, F. Vikebø and G. Huse (2007). "Linking behavioural ecology and oceanography: larval behaviour determines growth, mortality and dispersal." Marine Ecology Progress Series 347: 195-205. 
Fitzsimons, J. M., R. M. Zink and R. T. Nishimoto (1990). "Genetic variation in the Hawaiian stream goby, Lentipes concolor." Biochemical Systematics and Ecology 18(1): 81-83.

Fogarty, M. J., M. P. Sissenwine and E. B. Cohen (1991). "Recruitment variability and the dynamics of exploited marine populations." Trends in Ecology \& Evolution 6(8): 241-246.

Fouzai, N., A. F. Opdal, C. Jørgensen and Ø. Fiksen (2015). "Effects of temperature and food availability on larval cod survival: a model for behaviour in vertical gradients." Marine Ecology Progress Series 529: 199-212.

Fowler, A. and P. Doherty (1992). "Validation of annual growth increments in the otoliths of two species of damselfish from the southern Great Barrier Reef." Marine and Freshwater Research 43(5): 1057-1068.

Francis, M. P., M. W. Williams, A. C. Pryce, S. Pollard and S. G. Scott (1993). "Uncoupling of otolith and somatic growth in Pagrus auratus (Sparidae)." Fishery Bulletin - National Oceanic and Atmospheric Administration 91: 159-164.

Fuiman, L. A. (1989). "Vulnerability of Atlantic herring larvae to predation by yearling herring." Marine Ecology Progress Series 51(3): 291-299.

Gagliano, M., M. I. McCormick and M. G. Meekan (2007). "Survival against the odds: ontogenetic changes in selective pressure mediate growth-mortality trade-offs in a marine fish." Proceedings of the Royal Society of London B: Biological Sciences 274(1618): 1575-1582.

Gaillard, J.-M., M. Festa-Bianchet, N. Yoccoz, A. Loison and C. Toigo (2000). "Temporal variation in fitness components and population dynamics of large herbivores." Annual Review of Ecology and Systematics 31: 367-393.

Gaines, S., S. Brown and J. Roughgarden (1985). "Spatial variation in larval concentrations as a cause of spatial variation in settlement for the barnacle, Balanus glandula." Oecologia 67(2): 267-272.

Gaines, S. D. and J. Roughgarden (1987). "Fish in offshore kelp forests affect recruitment to intertidal barnacle populations." Science 235(4787): 479-480. 
Garvey, J. E., T. P. Herra and W. C. Leggett (2002). "Protracted reproduction in sunfish: the temporal dimesion in fish recruitment revisited." Ecological Applications 12(1): 194-205.

GIMP Team (2016). GNU Image Manipulation Program.

Gleason, T. R. and D. A. Bengtson (1996). "Size-selective mortality of inland silversides: Evidence from otolith microstructure." Transactions of the American Fisheries Society 125(6): 860-873.

Glova, G. (2003). "A test for interaction between brown trout (Salmo trutta) and inanga (Galaxias maculatus) in an artificial stream." Ecology of Freshwater Fish 12(4): 247253.

Gonzalez, A., J. Lawton, F. Gilbert, T. Blackburn and I. Evans-Freke (1998).

"Metapopulation dynamics, abundance, and distribution in a microecosystem." Science 281(5385): 2045-2047.

Good, S., J. Dodson, M. Meekan and D. A. Ryan (2001). "Annual variation in sizeselective mortality of Atlantic salmon (Salmo salar) fry." Canadian Journal of Fisheries and Aquatic Sciences 58(6): 1187-1195.

Goodgame, L. S. and L. E. Miranda (1993). "Early growth and survival of age-0 largemouth bass in relation to parental size and swim-up time." Transactions of the American Fisheries Society 122(1): 131-138.

Gosselin, L. A. and P.-Y. Qian (1997). "Juvenile mortality in benthic marine invertebrates." Marine Ecology Progress Series 146: 265-282.

Graham, W. M. and J. L. Largier (1997). "Upwelling shadows as nearshore retention sites: the example of northern Monterey Bay." Continental Shelf Research 17(5): 509532.

Green, B. S. and R. Fisher (2004). "Temperature influences swimming speed, growth and larval duration in coral reef fish larvae." Journal of Experimental Marine Biology and Ecology 299(1): 115-132. 
Green, S. J. and I. M. Côté (2014). "Trait - based diet selection: prey behaviour and morphology predict vulnerability to predation in reef fish communities." Journal of Animal Ecology 83(6): 1451-1460.

Greer, A. T., R. K. Cowen, C. M. Guigand, J. A. Hare and D. Tang (2014). "The role of internal waves in larval fish interactions with potential predators and prey." Progress in Oceanography 127: 47-61.

Grether, G. F. (2005). "Environmental change, phenotypic plasticity, and genetic compensation." The American Naturalist 166(4): E115-E123.

Grorud-Colvert, K. and S. Sponaugle (2006). "Influence of condition on behavior and survival potential of a newly settled coral reef fish, the bluehead wrasse Thalassoma bifasciatum." Marine Ecology Progress Series 327: 279-288.

Grorud-Colvert, K. and S. Sponaugle (2011). "Variability in water temperature affects trait-mediated survival of a newly settled coral reef fish." Oecologia 165(3): 675-686.

Gross, M. R., R. M. Coleman and R. M. McDowall (1988). "Aquatic productivity and the evolution of diadromous fish migration." Science 239(4845): 1291-1293.

Günther, C. C., J.-P. Herrmann and A. Temming (2015). "Laboratory calibration of optimal growth to deduce in situ feeding conditions of early juvenile sprat Sprattus sprattus from otoliths." Marine Ecology Progress Series 525: 199-215.

Hadfield, M. and M. Strathmann (1996). "Variability, flexibility and plasticity in life histories of marine invertebrates." Oceanologica Acta 19(3-4): 323-334.

Hambright, K. D. (1991). "Experimental analysis of prey selection by largemouth bass: role of predator mouth width and prey body depth." Transactions of the American Fisheries Society 120(4): 500-508.

Hamilton, S. L. (2008). "Larval history influences post-metamorphic condition in a coral-reef fish." Oecologia 158(3): 449-461.

Hamilton, S. L., J. Regetz and R. R. Warner (2008). "Postsettlement survival linked to larval life in a marine fish." Proceedings of the National Academy of Sciences 105(5): 1561-1566. 
Handelsman, C. A., E. D. Broder, C. M. Dalton, E. W. Ruell, C. A. Myrick, D. N. Reznick and C. K. Ghalambor (2013). "Predator-induced phenotypic plasticity in metabolism and rate of growth: rapid adaptation to a novel environment." Integrative and Comparative Biology 53(6): 975-988.

Hargreaves, N. B. and R. J. LeBrasseur (1986). "Size selectivity of coho (Oncorhynchus kisutch) preying on juvenile chum salmon (O. keta)." Canadian Journal of Fisheries and Aquatic Sciences 43(3): 581-586.

Harrod, C., J. Mallela and K. K. Kahilainen (2010). "Phenotype - environment correlations in a putative whitefish adaptive radiation." Journal of Animal Ecology 79(5): 1057-1068.

Hartl, D. L. (1988). A primer of population genetics, Sinauer Associates, Inc.

Helson, J. G., S. Pledger and J. P. Gardner (2007). "Does differential particulate food supply explain the presence of mussels in Wellington Harbour (New Zealand) and their absence on neighbouring Cook Strait shores?" Estuarine, Coastal and Shelf Science 72(1): 223-234.

Hickford, M. J. and D. R. Schiel (2016). "Otolith microchemistry of the amphidromous Galaxias maculatus shows recruitment to coastal rivers from unstructured larval pools." Marine Ecology Progress Series 548: 197-207.

Hickford, M. J. H., M. Cagnon and D. R. Schiel (2010). "Predation, vegetation and habitat-specific survival of terrestrial eggs of a diadromous fish, Galaxias maculatus (Jenyns, 1842)." Journal of Experimental Marine Biology and Ecology 385(1-2): 66-72.

Hickford, M. J. H. and D. R. Schiel (2013). "Artificial spawning habitats improve egg production of a declining diadromous fish, galaxias maculatus (Jenyns, 1842)." Restoration Ecology 21(6): 686-694.

Hill, M. F., A. Hastings and L. W. Botsford (2002). "The effects of small dispersal rates on extinction times in structured metapopulation models." The American Naturalist 160(3): 389-402.

Hixon, M. A. (1991). Predation as a process structuring coral reef fish communities. The Ecology of Fishes on Coral Reefs. P. F. Sale. San Diego, California, Academic Press: 475-508. 
Hixon, M. A., S. W. Pacala and S. A. Sandin (2002). "Population regulation: historical context and contemporary challenges of open vs. closed systems." Ecology 83(6): 14901508 .

Hjort, J. (1914). "Fluctuations in the great fisheries of northern Europe viewed in the light of biological research." Rapports et Procès-Verbaux des Réunions du Conseil Permanent International Pour L'Exploration de la Mer 20: 1-228.

Hoenig, J. M. (1983). "Empirical use of longevity data to estimate mortality rates." Fishery Bulletin 82(1): 898-903.

Hoey, A. S. and M. I. McCormick (2004). "Selective predation for low body condition at the larval-juvenile transition of a coral reef fish." Oecologia 139(1): 23-29.

Hoffnagle, T. L. and T. J. Timmons (1989). "Age, growth, and catch analysis of the commercially exploited paddlefish population in Kentucky Lake, Kentucky-Tennessee." North American Journal of Fisheries Management 9(3): 316-326.

Holmes, T. H. and M. I. McCormick (2006). "Location influences size-selective predation on newly settled reef fish." Marine Ecology Progress Series 317: 203-209.

Houde, E. (1989). "Subtleties and episodes in the early life of fishes." Journal of Fish Biology 35: 29-38.

Houde, E. and R. Hoyt (1987). Fish early life dynamics and recruitment variability. American Fisheries Science Symposium.

Houde, E. D. (1989). "Comparative growth, mortality, and energetics of marine fish larvae: Temperature and implied latitudinal effects." Fishery Bulletin 87(3): 471-495.

Houde, E. D. (1994). "Differences between marine and freshwater fish larvae implications for recruitment." ICES Journal of Marine Science 51(1): 91-97.

Houde, E. D. (1997). "Patterns and consequences of selective processes in teleost early life histories." Fish and Fisheries Series 21: 173-196. 
Houde, E. D. and C. E. Zastrow (1993). "Ecosystem-and taxon-specific dynamic and energetics properties of larval fish assemblages." Bulletin of Marine Science 53(2): 290335.

Hovenkamp, F. (1992). "Growth-dependent mortality of larval plaice Pleuronectes platessa in the North Sea." Marine Ecology Progress Series 82(1): 95-101.

Imre, I., R. McLaughlin and D. Noakes (2002). "Phenotypic plasticity in brook charr: changes in caudal fin induced by water flow." Journal of Fish Biology 61(5): 11711181 .

Irvine, R. L., D. C. Schmidt and L. R. Hildebrand (2007). "Population status of white sturgeon in the lower Columbia River within Canada." Transactions of the American Fisheries Society 136(6): 1472-1479.

Jackson, D. A., P. R. Peres-Neto and J. D. Olden (2001). "What controls who is where in freshwater fish communities the roles of biotic, abiotic, and spatial factors." Canadian Journal of Fisheries and Aquatic Sciences 58(1): 157-170.

Jacob, A., G. Evanno, E. Renai, R. Sermier and C. Wedekind (2009). "Male body size and breeding tubercles are both linked to intrasexual dominance and reproductive success in the minnow." Animal Behaviour 77(4): 823-829.

Jakob, E. M., S. D. Marshall and G. W. Uetz (1996). "Estimating fitness: a comparison of body condition indices." Oikos: 61-67.

Jellyman, P. G. and A. R. McIntosh (2008). "The influence of habitat availability and adult density on non-diadromous galaxiid fry settlement in New Zealand." Journal of Fish Biology 72(1): 143-156.

Jenkins, G. P. and D. King (2006). "Variation in larval growth can predict the recruitment of a temperate, seagrass-associated fish." Oecologia 147(4): 641-649.

Jessopp, M. J. and R. J. McAllen (2007). "Water retention and limited larval dispersal: implications for short and long distance dispersers in marine reserves." Marine Ecology Progress Series 333: 27-36.

Johnson, D. and M. Hixon (2010). "Ontogenetic and spatial variation in size - selective mortality of a marine fish." Journal of Evolutionary Biology 23(4): 724-737. 
Johnson, D. W., K. Grorud - Colvert, S. Sponaugle and B. X. Semmens (2014).

"Phenotypic variation and selective mortality as major drivers of recruitment variability in fishes." Ecology Letters 17(6): 743-755.

Johnston, I. A. (2006). "Environment and plasticity of myogenesis in teleost fish." Journal of Experimental Biology 209(12): 2249-2264.

Jones, G. (1986). "Food availability affects growth in a coral reef fish." Oecologia 70(1): 136-139.

Jones, G. P. (1990). "The importance of recruitment to the dynamics of a coral reef fish population." Ecology 71(5): 1691-1698.

Jones, G. P., G. R. Almany, G. Russ, P. Sale, R. Steneck, M. Van Oppen and B. Willis (2009). "Larval retention and connectivity among populations of corals and reef fishes: history, advances and challenges." Coral Reefs 28(2): 307-325.

Jones, G. P., S. Planes and S. R. Thorrold (2005). "Coral reef fish larvae settle close to home." Current Biology 15(14): 1314-1318.

Jonsson, B. (1985). "Life history patterns of freshwater resident and sea-run migrant brown trout in Norway." Transactions of the American Fisheries Society 114(2): 182194.

Kaemingk, M. A., K. J. Stahr, J. C. Jolley, R. S. Holland and D. W. Willis (2013). "Evidence for bluegill spawning plasticity obtained by disentangling complex factors related to recruitment." Canadian Journal of Fisheries and Aquatic Sciences 71(1): 93 105.

Kekalainen, J., J. Kahkonen, V. Kiviniemi and H. Huuskonen (2010). "Morphological variation of perch Perca fluviatilis in humic lakes: the effect of predator density, competition and prey abundance." Journal of Fish Biology 76(4): 787-799.

Kell, L., S. Bonhommeau and J.-M. Fromentin (2013). "A catch curve analysis for east Atlantic and Mediterranean bluefin tuna." Collective Volume of Scientific Papers 69(1): 199-203. 
Kerr, L. A. and D. H. Secor (2009). "Bioenergetic trajectories underlying partial migration in Patuxent River (Chesapeake Bay) white perch (Morone americana)." Canadian Journal of Fisheries and Aquatic Sciences 66(4): 602-612.

Kingsford, M. and J. Choat (1986). "Influence of surface slicks on the distribution and onshore movements of small fish." Marine Biology 91(2): 161-171.

Kohler, C. C., R. J. Sheehan and J. J. Sweatman (1993). "Largemouth bass hatching success and first-winter survival in two Illinois reservoirs." North American Journal of Fisheries Management 13(1): 125-133.

Koslow, J. A., K. R. Thompson and W. Silvert (1987). "Recruitment to northwest Atlantic cod (Gadus morhua) and haddock (Melanogrammus aeglefinus) stocks: influence of stock size and climate." Canadian Journal of Fisheries and Aquatic Sciences 44(1): 26-39.

Kramer, R. H. and L. L. Smith Jr (1962). "Formation of year classes in largemouth bass." Transactions of the American Fisheries Society 91(1): 29-41.

Kritzer, J. P. and P. F. Sale (2006). The metapopulation ecology of coral reef fishes. Marine metapopulations: 31-67.

Lande, R. and S. J. Arnold (1983). "The measurement of selection on correlated characters." Evolution 37(6): 1210-1226.

Langerhans, R. B., C. A. Layman, A. M. Shokrollahi and T. J. DeWitt (2004).

"Predator-driven phenotypic diversification in Gambusia affinis." Evolution 58(10): 2305-2318.

Largier, J. L. (2003). "Considerations in estimating larval dispersal distances from oceanographic data." Ecological Applications 13(1): S71-S89.

Leggett, W. and E. Deblois (1994). "Recruitment in marine fishes: is it regulated by starvation and predation in the egg and larval stages?" Netherlands Journal of Sea Research 32(2): 119-134.

Leis, J. M. (2006). "Are Larvae of Demersal Fishes Plankton or Nekton?" Advances in marine biology 51: 57-141. 
Lenth, R. V. (2016). "Least-Squares Means: The R Package lsmeans." Journal of Statistical Software 69(1): 1-33.

Levin, L. A. (2006). "Recent progress in understanding larval dispersal: new directions and digressions." Integrative and Comparative Biology 46(3): 282-297.

Li, H. W. and P. B. Moyle (1981). "Ecological analysis of species introductions into aquatic systems." Transactions of the American Fisheries Society 110(6): 772-782.

Litvak, M. K. and W. C. Leggett (1992). "Age and size-selective predation on larval fishes: the bigger-is-better hypothesis revisited." Marine Ecology Progress Series 81(1): $13-24$.

Losos, J. B., D. A. Creer, D. Glossip, R. Goellner, A. Hampton, G. Roberts, N. Haskell, P. Taylor and J. Ettling (2000). "Evolutionary implications of phenotypic plasticity in the hindlimb of the lizard Anolis sagrei." Evolution 54(1): 301-305.

MacDonald, B. and R. Thompson (1985). "Influence of temperature and food availability on the ecological energetics of the giant scallop Placopecten magellanicus.

I. Growth rates of shell and somatic tissue." Marine Ecology Progress Series 25(3): 279294.

Mackas, D. L. and P. J. Harrison (1997). "Nitrogenous nutrient sources and sinks in the Juan de Fuca Strait/Strait of Georgia/Puget Sound estuarine system: assessing the potential for eutrophication." Estuarine, Coastal and Shelf Science 44(1): 1-21.

Mann, K. (1993). "Physical oceanography, food chains, and fish stocks: a review." ICES Journal of Marine Science: Journal du Conseil 50(2): 105-119.

Maxwell, B. E. (1956). "Hydrobiological observations for Wellington Harbour." Transactions of the Royal Society of New Zealand 83(3): 493-503.

McCauley, E., W. G. Wilson and A. M. de Roos (1993). "Dynamics of age-structured and spatially structured predator-prey interactions: individual-based models and population-level formulations." American Naturalist 142(3): 412-442.

McCormick, M. I. (2006). "Mothers matter: crowding leads to stressed mothers and smaller offspring in marine fish." Ecology 87(5): 1104-1109. 
McDowall, R. M. (1968). "Galaxias maculatus (Jenyns) the New Zealand whitebait." Fisheries Research Bulletin New Zealand No. 2: 1-84.

McDowall, R. M. (1969). "Relationships of galaxioid fishes with a further discussion of salmoniform classification." Copeia: 796-824.

McDowall, R. M. (1972). "The species problem in freshwater fishes and the taxonomy of diadromous and lacustrine populations of Galaxias maculates (Jenyns)." Journal of the Royal Society of New Zealand 2(3): 325-367.

McDowall, R. M. (1978). New Zealand freshwater fishes. Auckland, Heinemann Educational.

McDowall, R. M. (1984). The New Zealand whitebait book. Wellington, Reed.

McDowall, R. M. (1988). Diadromy in fishes: migrations between freshwater and marine environments. London, Croom Helm.

McDowall, R. M. (1994). "On size and growth in freshwater fish." Ecology of Freshwater Fish 3(2): 67-79.

McDowall, R. M. (1995). "Seasonal pulses in migrations of New Zealand diadromous fish and the potential impacts of river mouth closure." New Zealand Journal of Marine and Freshwater Research 29(4): 517-526.

McDowall, R. M. (2002). "Accumulating evidence for a dispersal biogeography of southern cool temperate freshwater fishes." Journal of Biogeography 29(2): 207-219.

McDowall, R. M. (2003). "Hawaiian biogeography and the islands' freshwater fish fauna." Journal of Biogeography 30(5): 703-710.

McDowall, R. M. (2007). "On amphidromy, a distinct form of diadromy in aquatic organisms." Fish and Fisheries 8: 1-13.

McDowall, R. M. (2009). "Why be amphidromous: expatrial dispersal and the place of source and sink population dynamics?" Reviews in Fish Biology and Fisheries 20(1): 87-100. 
McDowall, R. M. (2010). "Why be amphidromous: expatrial dispersal and the place of source and sink population dynamics?" Reviews in Fish Biology and Fisheries 20(1): 87-100.

McDowall, R. M., D. Robertson and R. Saito (1975). "Occurrence of galaxiid larvae and juveniles in the sea." New Zealand Journal of Marine and Freshwater Research 9(1): 1-9.

McDowall, R. M. and G. A. Eldon (1980). "Ecology of whitebait migrations (Galaxiidae: Galaxias spp)." New Zealand Fisheries Research Division Fisheries Research Bulletin(20): 1-171.

McDowall, R. M., C. P. Mitchell and E. B. Brothers (1994). "Age at migration from the sea of juvenile Galaxias in New Zealand (Pisces, Galaxiidae)." Bulletin of Marine Science 54(2): 385-402.

McDowall, R. M. and S. Charteris (2006). "The possible adaptive advantages of terrestrial egg deposition in some fluvial diadromous galaxiid fishes (Teleostei: Galaxiidae)." Fish and Fisheries 7(3): 153-164.

McGurk, M. D. (1986). "Natural mortality of marine pelagic fish eggs and larvae: role of spatial patchiness." Marine Ecology Progress Series 34(3): 227-242.

Media Cybernetics (2016). Image-Pro Premier. Rockville, Maryland, USA.

Meekan, M. and L. Fortier (1996). "Selection for fast growth during the larval life of Atlantic cod Gadus morhua on the Scotian Shelf." Marine Ecology Progress Series 137: 25-37.

Meekan, M., J. Carleton, A. McKinnon, K. Flynn and M. Furnas (2003). "What determines the growth of tropical reef fish larvae in the plankton: food or temperature?" Marine Ecology Progress Series 256: 193-204.

Meekan, M., L. Vigliola, A. Hansen, P. Doherty, A. Halford and J. Carleton (2006). "Bigger is better: size-selective mortality throughout the life history of a fast-growing clupeid, Spratelloides gracilis." Marine Ecology Progress Series 317: 237-244. 
Meekan, M. G., C. von Kuerthy, M. I. McCormick and B. Radford (2010). "Behavioural mediation of the costs and benefits of fast growth in a marine fish." Animal Behaviour 79(4): 803-809.

Milano, D., D. E. Ruzzante, V. E. Cussac, P. J. Macchi, R. A. Ferriz, J. P. Barriga, J. C. Aigo, M. E. Lattuca and S. J. Walde (2006). "Latitudinal and ecological correlates of morphological variation in Galaxias platei (Pisces, Galaxiidae) in Patagonia."

Biological Journal of the Linnean Society 87: 69-82.

Milicich, M. M., M. M. Meekan and P. P. Doherty (1992). "Larval supply: a good predictor of recruitment of three species of reef fish (Pomacentridae)." Marine Ecology Progress Series 86: 153-166.

Miller, T. J., L. B. Crowder, J. A. Rice and E. A. Marschall (1988). "Larval size and recruitment mechanisms in fishes: toward a conceptual framework." Canadian Journal of Fisheries and Aquatic Sciences 45(9): 1657-1670.

Mitchell, C. P. (1989). "Laboratory culture ofGalaxias maculatusand potential applications." New Zealand Journal of Marine and Freshwater Research 23(3): 325-336.

Moody, K., S. Hunter, M. Childress, R. Blob, H. Schoenfuss, M. Blum and M. Ptacek (2015). "Local adaptation despite high gene flow in the waterfall - climbing Hawaiian goby, Sicyopterus stimpsoni." Molecular Ecology 24(3): 545-563.

Mooij, W., E. Lammens and W. V. Densen (1994). "Growth rate of 0+ fish in relation to temperature, body size, and food in shallow eutrophic Lake Tjeukemeer." Canadian Journal of Fisheries and Aquatic Sciences 51(3): 516-526.

Morgan, S. G., J. L. Fisher and J. L. Largier (2011). "Larval retention, entrainment, and accumulation in the lee of a small headland: Recruitment hotspots along windy coasts." Limnology and Oceanography 56(1): 161-178.

Mullaney, T. J. and I. M. Suthers (2013). "Entrainment and retention of the coastal larval fish assemblage by a short-lived, submesoscale, frontal eddy of the East Australian Current." Limnology and Oceanography 58(5): 1546-1556.

Munch, S. B., D. O. Conover and P. Wainwright (2003). "Rapid growth results in increased susceptibility to predation in Menidia menidia." Evolution 57(9): 2119-2127. 
Murdoch, W. W. (1994). "Population regulation in theory and practice." Ecology 75(2): 271-287.

Muylaert, K. and R. Raine (1999). "Import, mortality and accumulation of coastal phytoplankton in a partially mixed estuary (Kinsale harbour, Ireland)." Hydrobiologia 412: 53-65.

Myers, G. S. (1949). "Usage of anadromous, catadromous and allied terms for migratory fishes." Copeia: 89-97.

Myers, R., G. Mertz and J. Bridson (1997). "Spatial scales of interannual recruitment variations of marine, anadromous, and freshwater fish." Canadian Journal of Fisheries and Aquatic Sciences 54(6): 1400-1407.

Newman, S. J., D. Williams and G. R. Russ (1996). "Age validation, growth and mortality rates of the tropical snappers (Pisces: Lutjanidae) Lutjanus adetii (Castelnau, 1873) and L. quinquelineatus (Bloch, 1790) from the central Great Barrier Reef, Australia." Marine and Freshwater Research 47(4): 575-584.

Nicieza, A. G. and N. B. Metcalfe (1997). "Growth compensation in juvenile Atlantic salmon: responses to depressed temperature and food availability." Ecology 78(8): 2385-2400.

Norris, D. R. (2005). "Carry - over effects and habitat quality in migratory populations." Oikos 109(1): 178-186.

Ogle, D. H. (2016). FSA: Fisheries Stock Analysis.

Oliver, J. D., G. F. Holeton and K. E. Chua (1979). "Overwinter mortality of fingerling smallmouth bass in relation to size, relative energy stores, and environmental temperature." Transactions of the American Fisheries Society 108(2): 130-136.

Original S code by Richard A. Becker and Allan R. Wilks. R version by Ray Brownrigg (2016). mapdata: Extra Map Databases.

Original S code by Richard A. Becker and Allan R. Wilks. R version by Ray Brownrigg. Enhancements by Thomas P Minka and Alex Deckmyn (2016). maps: Draw Geographical Maps. 
Pannella, G. (1971). "Fish otoliths - Daily growth layers and periodical patterns." Science 173(4002): 1124-\&.

Parker, R. R. (1971). "Size selective predation among juvenile salmonid fishes in a British Columbia inlet." Journal of the Fisheries Board of Canada 28(10): 1503-1510.

Pauly, D. (1990). "Length-converted catch curves and the seasonal growth of fishes." Fishbyte 8(3): 33-38.

Peel, R., G. Taylor and O. Weyl (2016). "Validation of annulus formation in sagittal otoliths of three tropical cichlids Oreochromis andersonii (Castelnau, 1861), Oreochromis macrochir (Boulenger, 1912), and Coptodon rendalli (Boulenger, 1896)." Journal of Applied Ichthyology 32: 859-865.

Pepin, P. (1987). "Influence of alternative prey abundance on pelagic fish predation of larval fish: a model." Canadian Journal of Fisheries and Aquatic Sciences 44(1): 222227.

Pepin, P. (1991). "Effect of temperature and size on development, mortality, and survival rates of the pelagic early life history stages of marine fish." Canadian Journal of Fisheries and Aquatic Sciences 48(3): 503-518.

Pepin, P. (1992). "Significance of body size to the interaction between a larval fish (Mallotus villosus) and a vertebrate predator (Gasterosteus aculeatus)." Marine Ecology Progress Series 81: 1-12.

Perez, K. O. and S. B. Munch (2010). "Extreme selection on size in the early lives of fish." Evolution 64(8): 2450-2457.

Pfaff, M. C., G. M. Branch, J. L. Fisher, V. Hoffmann, A. G. Ellis and J. L. Largier (2015). "Delivery of marine larvae to shore requires multiple sequential transport mechanisms." Ecology 96(5): 1399-1410.

Phillips, N. E. (2005). "Growth of filter-feeding benthic invertebrates from a region with variable upwelling intensity." Marine Ecology Progress Series 295: 79-89.

Pineda, J., J. A. Hare and S. Sponaungle (2007). "Larval transport and dispersal in the coastal ocean and consequences for population connectivity." Oceanography 20(3): 2239. 
Pineda, J., N. B. Reyns and V. R. Starczak (2009). "Complexity and simplification in understanding recruitment in benthic populations." Population ecology 51(1): 17-32.

Pinheiro, J., D. Bates, S. DebRoy, D. Sarkar and R Core Team (2016). Linear and Nonlinear Mixed Effects Models.

Pollard, D. (1971). "The biology of a landlocked form of the normally catadromous salmoniform fish Galaxias maculatus (Jenyns). I. Life cycle and origin." Marine and Freshwater Research 22(2): 91-124.

Post, J. R. and A. B. Prankevicius (1987). "Size-selective mortality in young-of-the-year yellow perch (Perca flavescens): evidence from otolith microstructure." Canadian Journal of Fisheries and Aquatic Sciences 44(11): 1840-1847.

Radtke, R. L. and R. A. Kinzie (1996). "Evidence of a marine larval stage in endemic Hawaiian stream gobies from isolated high-elevation locations." Transactions of the American Fisheries Society 125(4): 613-621.

Rätz, H.-J. and J. Lloret (2003). "Variation in fish condition between Atlantic cod (Gadus morhua) stocks, the effect on their productivity and management implications." Fisheries Research 60(2): 369-380.

Raventós, N. and E. Macpherson (2005). "Effect of pelagic larval growth and size at hatching on the post-settlement survivorship in two temperate labrid fishes of the genus Symphodus." Marine Ecology Progress Series 285: 205-211.

Restrepo, V. R., J. Ortiz de Urbina, J.-M. Fromentin and H. Arrizabalaga (2007). "Estimates of selectivity for eastern Atlantic bluefin tuna from catch curves." Collective Volume of Scientific Papers 60(3): 937-948.

Reznick, D. N. and C. K. Ghalambor (2001). "The population ecology of contemporary adaptations: what empirical studies reveal about the conditions that promote adaptive evolution." Genetica 112(1): 183-198.

Richardson, J., J. A. Boubée and D. W. West (1994). "Thermal tolerance and preference of some native New Zealand freshwater fish." New Zealand Journal of Marine and Freshwater Research 28(4): 399-407. 
Ricker, W. E. (1975). Computation and interpretation of biological statistics of fish populations, Dept. of Fisheries and Oceans.

Robillard, S. R. and J. E. Marsden (1996). "Comparison of otolith and scale ages for yellow perch from Lake Michigan." Journal of Great Lakes Research 22(2): 429-435.

Robson, D. and D. Chapman (1961). "Catch curves and mortality rates." Transactions of the American Fisheries Society 90(2): 181-189.

Rosenberg, A. and A. Haugen (1982). "Individual growth and size-selective mortality of larval turbot (Scophthalmus maximus) reared in enclosures." Marine Biology 72(1): 7377.

Roughgarden, J., S. Gaines and H. Possingham (1988). "Recruitment dynamics in complex life cycles." Science 241: 1460-1466.

Rowe, D. K., B. L. Chisnall, T. L. Dean and J. Richardson (1999). "Effects of land use on native fish communities in east coast streams of the North Island of New Zealand." New Zealand Journal of Marine and Freshwater Research 33(1): 141-151.

RStudio Team (2015). RStudio: Integrated Development for R. Boston, MA, RStudio Inc.

Rumrill, S. S. (1990). "Natural mortality of marine invertebrate larvae." Ophelia 32(12): 163-198.

Saccheri, I. and I. Hanski (2006). "Natural selection and population dynamics." Trends in Ecology \& Evolution 21(6): 341-347.

Sandström, O. and G. Thoresson (1988). "Mortality in perch populations in a Baltic pulp mill effluent area." Marine pollution bulletin 19(11): 564-567.

Santucci Jr, V. J. and D. H. Wahl (2003). "The effects of growth, predation, and firstwinter mortality on recruitment of bluegill cohorts." Transactions of the American Fisheries Society 132(2): 346-360.

Savino, J. F. and R. A. Stein (1989). "Behavioural interactions between fish predators and their prey: effects of plant density." Animal Behaviour 37: 311-321. 
Schluter, D., T. D. Price and L. Rowe (1991). "Conflicting selection pressures and life history trade-offs." Proceedings of the Royal Society of London B: Biological Sciences 246(1315): 11-17.

Schneider, C. A., W. S. Rasband and K. W. Eliceiri (2012). "NIH Image to ImageJ: 25 years of image analysis." Nature methods 9(7): 671-675.

Schoener, T. W. (2011). "The newest synthesis: understanding the interplay of evolutionary and ecological dynamics." Science 331(6016): 426-429.

Scholz, F. W. and M. A. Stephens (1987). "K-sample Anderson-Darling tests." Journal of the American Statistical Association 82(399): 918-924.

Schupp, E. W. (1990). "Annual variation in seedfall, postdispersal predation, and recruitment of a neotropical tree." Ecology 71(2): 504-515.

Scott, D. E. (1994). "The effect of larval density on adult demographic traits in Ambystoma opacum." Ecology 75(5): 1383-1396.

Searcy, S. P. and S. Sponaugle (2000). "Variable larval growth in a coral reef fish." Marine Ecology Progress Series 206: 213-226.

Searcy, S. P. and S. Sponaugle (2001). "Selective mortality during the larval-juvenile transition in two coral reef fishes." Ecology 82(9): 2452-2470.

Shanks, A. L. and W. G. Wright (1987). "Internal-wave-mediated shoreward transport of cyprids, megalopae, and gammarids and correlated longshore differences in the settling rate of intertidal barnacles." Journal of Experimental Marine Biology and Ecology 114(1): 1-13.

Shapiro, M. D., M. E. Marks, C. L. Peichel, B. K. Blackman, K. S. Nereng, B. Jónsson, D. Schluter and D. M. Kingsley (2004). "Genetic and developmental basis of evolutionary pelvic reduction in threespine sticklebacks." Nature 428(6984): 717-723.

Shepherd, J. and D. Cushing (1980). "A mechanism for density-dependent survival of larval fish as the basis of a stock-recruitment relationship." Journal du Conseil 39(2): $160-167$. 
Shima, J. S. and A. M. Findlay (2002). "Pelagic larval growth rate impacts benthic settlement and survival of a temperate reef fish." Marine Ecology Progress Series 235: 303-309.

Shima, J. S. and S. E. Swearer (2009). "Larval quality is shaped by matrix effects: implications for connectivity in a marine matapopulation." Ecology 90(5): 1255-1267.

Shima, J. S. and S. E. Swearer (2010). "The legacy of dispersal: larval experience shapes persistence later in the life of a reef fish." Journal of Animal Ecology 79(6): 1308-1314.

Shulman, M. J. (1985). "Recruitment of coral reef fishes: effects of distribution of predators and shelter." Ecology 66(3): 1056-1066.

Shuter, B., J. MacLean, F. Fry and H. Regier (1980). "Stochastic simulation of temperature effects on first-year survival of smallmouth bass." Transactions of the American Fisheries Society 109(1): 1-34.

Siegel, D., B. Kinlan, B. Gaylord and S. Gaines (2003). "Lagrangian descriptions of marine larval dispersion." Marine Ecology Progress Series 260: 83-96.

Simpson, A. C. (1959). "The spawning of the plaice (Pleuronectes platessa) in the North Sea." MAFF Fishery Investigations Series 2 22(7): 111.

Sissenwine, M. P. (1984). Why do fish populations vary? Exploitation of marine communities. Berlin, Springer: 59-94.

Slatkin, M. (1985). "Gene flow in natural populations." Annual Review of Ecology and Systematics 16: 393-430.

Smith, D. C. (1987). "Adult recruitment in chorus frogs: effects of size and date at metamorphosis." Ecology 68(2): 344-350.

Smith, M. W., A. Y. Then, C. Wor, G. Ralph, K. H. Pollock and J. M. Hoenig (2012).

"Recommendations for catch-curve analysis." North American Journal of Fisheries Management 32(5): 956-967. 
Soetaert, K. and P. M. Herman (1994). "One foot in the grave: zooplankton drift into the Westerschelde estuary (The Netherlands)." Marine Ecology Progress Series 105(1-2): 19-29.

Sogard, S. M. (1997). "Size-selective mortality in the juvenile stage of teleost fishes: a review." Bulletin of Marine Science 60(3): 1129-1157.

Sorensen, M. C., J. M. Hipfner, T. K. Kyser and D. R. Norris (2009). "Carry - over effects in a Pacific seabird: stable isotope evidence that pre - breeding diet quality influences reproductive success." Journal of Animal Ecology 78(2): 460-467.

Sponaugle, S., K. Grorud-Colvert and D. Pinkard (2006). "Temperature-mediated variation in early life history traits and recruitment success of the coral reef fish Thalassoma bifasciatum in the Florida Keys." Marine Ecology Progress Series 308: 115.

Sponaugle, S., T. Lee, V. Kourafalou and D. Pinkard (2005). "Florida Current frontal eddies and the settlement of coral reef fishes." Limnology and Oceanography 50(4): 1033-1048.

Sponaugle, S. and D. Pinkard (2004). "Impact of variable pelagic environments on natural larval growth and recruitment of the reef fish Thalassoma bifasciatum." Journal of Fish Biology 64(1): 34-54.

Staudinger, M. D. and F. Juanes (2010). "Size-dependent susceptibility of longfin inshore squid (Loligo pealeii) to attack and capture by two predators." Journal of Experimental Marine Biology and Ecology 393(1): 106-113.

Stearns, S. C. (1992). The evolution of life histories, Oxford University Press Oxford.

Stewart, B., G. Fenton, D. Smith and S. Short (1995). "Validation of otolith-increment age estimates for a deepwater fish species, the warty oreo Allocyttus verrucosus, by radiometric analysis." Marine Biology 123(1): 29-38.

Sutherland, W. J., R. P. Freckleton, H. C. J. Godfray, S. R. Beissinger, T. Benton, D. D. Cameron, Y. Carmel, D. A. Coomes, T. Coulson, M. C. Emmerson, R. S. Hails, G. C. Hays, D. J. Hodgson, M. J. Hutchings, D. Johnson, J. P. G. Jones, M. J. Keeling, H. Kokko, W. E. Kunin, X. Lambin, O. T. Lewis, Y. Malhi, N. Mieszkowska, E. J. MilnerGulland, K. Norris, A. B. Phillimore, D. W. Purves, J. M. Reid, D. C. Reuman, K. Thompson, J. M. J. Travis, L. A. Turnbull, D. A. Wardle and T. Wiegand (2013). 
"Identification of 100 fundamental ecological questions." Journal of Ecology 101(1): 58-67.

Svanback, R. and P. Eklov (2002). "Effects of habitat and food resources on morphology and ontogenetic growth trajectories in perch." Oecologia 131(1): 61-70.

Swearer, S. E., J. E. Caselle, D. W. Lea and R. R. Warner (1999). "Larval retention and recruitment in an island population of a coral-reef fish." Nature 402(6763): 799-802.

Swearer, S. E. and J. S. Shima (2010). "Regional variation in larval retention and dispersal drives recruitment patterns in a temperate reef fish." Marine Ecology Progress Series 417: 229-236.

Swearer, S. E., J. S. Shima, M. E. Hellberg, S. R. Thorrold, G. P. Jones, D. R. Robertson, S. G. Morgan, K. A. Selkoe, G. M. Ruiz and R. R. Warner (2002). "Evidence of self-recruitment in demersal marine populations." Bulletin of Marine Science 70(1): 251-271.

Taubert, B. D. and D. W. Coble (1977). "Daily rings in otoliths of three species of Lepomis and Tilapia mossambica." Journal of the Fisheries Board of Canada 34(3): 332-340.

Taylor, B. W., C. R. Anderson and B. L. Peckarsky (1998). "Effects of size at metamorphosis on stonefly fecundity, longevity, and reproductive success." Oecologia 114(4): 494-502.

Taylor, G. C., R. A. Peel, C. J. Hay and O. L. Weyl (2016). "Validation of the periodicity of growth zone formation in the otoliths of four fish species from the Upper Zambezi ecoregion, southern Africa." African Zoology 51(3): 1-7.

Thorson, G. (1950). "Reproductive and larval ecology of marine bottom invertebrates." Biological reviews 25(1): 1-45.

Tonn, W. M. and C. A. Paszkowski (1986). "Size-limited predation, winterkill, and the organization of Umbra-Perca fish assemblages." Canadian Journal of Fisheries and Aquatic Sciences 43(1): 194-202.

Trussell, G. C. and L. D. Smith (2000). "Induced defenses in response to an invading crab predator: An explanation of historical and geographic phenotypic change." 
Proceedings of the National Academy of Sciences of the United States of America 97(5): 2123-2127.

Tsukamoto, K., H. Kuwada, J. Hirokawa, M. Oya, S. Sekiya and H. Fujimoto (1989). "Size - dependent mortality of red sea bream, Pagrus major, juveniles released with fluorescent otolith - tags in News Bay, Japan." Journal of Fish Biology 35(sA): 59-69.

Victor, B. (1982). "Daily otolith increments and recruitment in two coral-reef wrasses, Thalassoma bifasciatum and Halichoeres bivittatus." Marine Biology 71(2): 203-208.

Victor, B. C. (1986). "Larval settlement and juvenile mortality in a recruitment - limited coral reef fish population." Ecological Monographs 56(2): 145-160.

Vigliano, P. H., D. A. Beauchamp, D. Milano, P. J. Macchi, M. F. Alonso, M. I. G. Asorey, M. A. Denegri, J. E. Ciancio, G. Lippolt and M. Rechencq (2009). "Quantifying predation on galaxiids and other native organisms by introduced rainbow trout in an ultraoligotrophic lake in northern Patagonia, Argentina: a bioenergetics modeling approach." Transactions of the American Fisheries Society 138(6): 1405-1419.

Vigliola, L. (1997). "Validation of daily increment formation in otoliths for three Diplodus species in the Mediterranean sea." Journal of Fish Biology 51(2): 349-360.

Vigliola, L., P. J. Doherty, M. G. Meekan, D. M. Drown, M. E. Jones and P. H. Barber (2007). "Genetic identity determines risk of post-settlement mortality of a marine fish." Ecology 88(5): 1263-1277.

Vigliola, L. and M. G. Meekan (2002). "Size at hatching and planktonic growth determine post-settlement survivorship of a coral reef fish." Oecologia 131(1): 89-93.

Vilizzi, L. and G. H. Copp (2013). "Bias, precision and validation of ageing 0+ European barbel Barbus barbus (L.) from their otoliths." Central European Journal of Biology 8(7): 654-661.

Ward, B. and P. Slaney (1988). "Life history and smolt-to-adult survival of Keogh River steelhead trout (Salmo gairdneri) and the relationship to smolt size." Canadian Journal of Fisheries and Aquatic Sciences 45(7): 1110-1122.

Ware, D. (1975). "Relation between egg size, growth, and natural mortality of larval fish." Journal of the Fisheries Board of Canada 32(12): 2503-2512. 
Waters, J. M. and C. P. Burridge (1999). "Extreme Intraspecific Mitochondrial DNA Sequence Divergence inGalaxias maculatus (Osteichthys: Galaxiidae), One of the World's Most Widespread Freshwater Fish." Molecular Phylogenetics and Evolution 11(1): 1-12.

Waters, J. M., L. H. Dijkstra and G. P. Wallis (2000). "Biogeography of a southern hemisphere freshwater fish: how important is marine dispersal?" Molecular Ecology 9(11): 1815-1821.

Weber, E. D., Y. Chao, F. Chai and S. McClatchie (2015). "Transport patterns of Pacific sardine Sardinops sagax eggs and larvae in the California Current System." Deep Sea Research Part I: Oceanographic Research Papers 100: 127-139.

Webster, M. S. (2002). "Role of predators in the early post-settlement demography of coral-reef fishes." Oecologia 131(1): 52-60.

Werner, E. E. and D. J. Hall (1974). "Optimal foraging and the size selection of prey by the bluegill sunfish (Lepomis macrochirus)." Ecology 55(5): 1042-1052.

Werner, E. E., D. J. Hall, D. R. Laughlin, D. J. Wagner, L. A. Wilsmann and F. C. Funk (1977). "Habitat partitioning in a freshwater fish community." Journal of the Fisheries Board of Canada 34(3): 360-370.

White, J. W., S. G. Morgan and J. L. Fisher (2014). "Planktonic larval mortality rates are lower than widely expected." Ecology 95(12): 3344-3353.

Williams, D. M., E. Wolanski and J. Andrews (1984). "Transport mechanisms and the potential movement of planktonic larvae in the central region of the Great Barrier Reef." Coral Reefs 3(4): 229-236.

Wilson, D. T. and M. I. McCormick (1997). "Spatial and temporal validation of settlement-marks in the otoliths of tropical reef fishes." Marine Ecology Progress Series 153: $259-271$.

Windsland, K. (2014). "Total and natural mortality of red king crab (Paralithodes camtschaticus) in Norwegian waters: catch-curve analysis and indirect estimation methods." ICES Journal of Marine Science: Journal du Conseil fsu138: 1-19. 
Woodson, C. and M. McManus (2007). "Foraging behavior can influence dispersal of marine organisms." Limnology and Oceanography 52(6): 2701-2709. 
